\title{
Synthesis of HDAC Substrate Peptidomimetic Inhibitors (SPIs) using Fmoc Amino Acids Incorporating Zinc- Binding Groups
}

Amit Mahindra ${ }^{\dagger}$, Christopher J. Millard $\$$, Iona Black ${ }^{\dagger}$, Lewis J. Archibald ${ }^{\dagger}$, John W.R. Schwabe ${ }^{\ddagger}$ and Andrew G. Jamieson ${ }^{\dagger}$

†School of Chemistry, University of Glasgow, Joseph Black Building, University Avenue, Glasgow G12 8QQ, U.K.

Leicester Institute of Structural and Chemical Biology, Department of Molecular and Cell Biology, University of Leicester, Leicester, LE1 7RH, U.K.

\section{Contents}

I. General information 3

II. Experimental procedures and characterisation data: .5

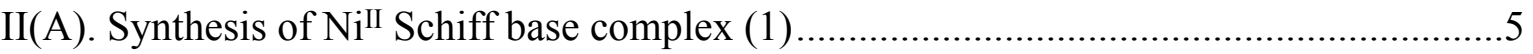

(S)- $N$-Boc-(2-Benzoylphenyl)pyrrolidine-2-carboxamide (II) ......................................

(S)- $N$-(2-Benzoylphenyl)pyrrolidine-2-carboxamide ·TFA (III) .................................6

(S)-N-(2-Benzoylphenyl)-1-(2-fluorobenzyl)pyrrolidine-2-carboxamide (IV) ................6

(S)-(\{2-[1-(2-Fluorobenzyl)-pyrrolidine-2-carboxamide]phenyl $\}$ phenylmethylene)-

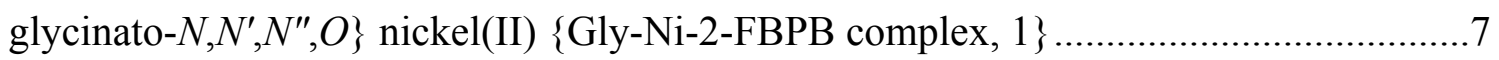

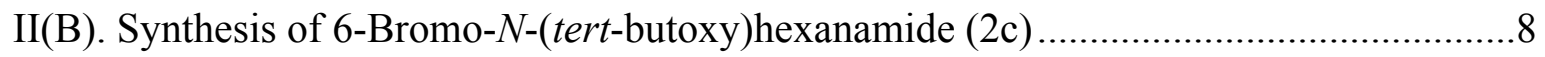

II(C). Synthesis of Fmoc-L-Asu(NHO'Bu)-OH (5) .....................................................

(S)-(\{2-[1-(2-Fluorobenzyl)benzyl)pyrrolidine-2-carboxamide]-

phenyl\} phenylmethylene)-(S)-( $N$-(tert-butoxy)hexanamide) glycinato- $N, N$, $N$,', O

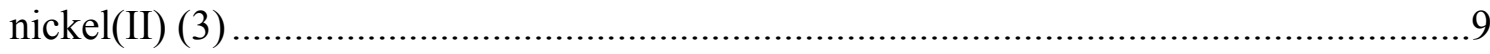

(L)-2-Amino-8-(tert-butoxyamino)-8-oxooctanoic acid [L-Asu(NHO ${ }^{\mathrm{t}} \mathrm{Bu}$ )-OH, 4] ........10

(L)-2-(\{[(9H-Fluoren-9-yl)methoxy)carbonyl $]$ amino $\}-8$-(tert-butoxyamino)-8oxooctanoic acid [Fmoc-L-Asu(NHO'Bu)-OH, 5]

(D)-2-(\{[(9H-Fluoren-9-yl)methoxy)carbonyl $]$ amino $\}-8$-(tert-butoxyamino)-8-

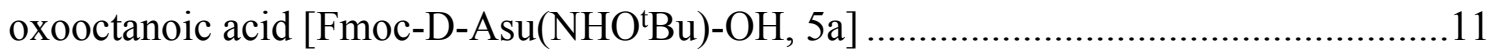

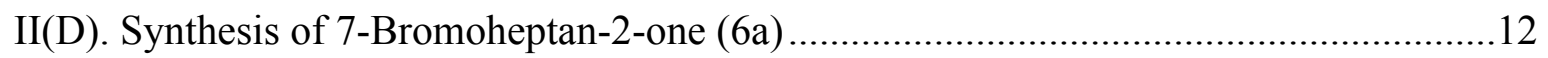

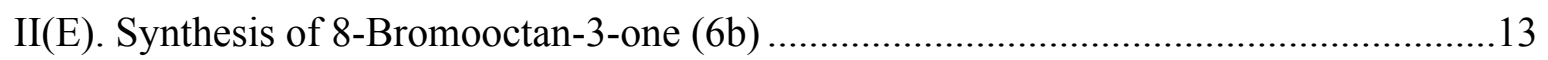

II(F). Synthesis of (L)-2-((((9H-Fluoren-9-yl)methoxy)carbonyl)amino)-8-oxononanoic acid (Fmoc-L-Aon-OH, 9)

(S)-(\{2-[1-(2-Fluorobenzyl)benzyl)pyrrolidine-2-carboxamide]-

phenyl\} phenylmethylene)-(S)-(heptan-2-one) glycinato- $\left.N, N^{\prime}, N^{\prime},, O\right\}$ nickel(II) (7a) ....14

(L)-2-Amino-8-oxononanoic acid [L-Aon-OH, 8a] .... 
(L)-2-((((9H-Fluoren-9-yl)methoxy)carbonyl)amino)-8-oxononanoic acid (Fmoc-LAon-OH, 9)

II(G). Synthesis of (L)-2((((9H-Fluoren-9-yl)methoxy)carbonyl)amino)-8-oxodecanoic acid (Fmoc-L-Aod-OH, 10)

(S)-(\{2-[1-(2-Fluorobenzyl)benzyl)pyrrolidine-2-carboxamide]-

phenyl phenylmethylene)-(S)-(octan-3-one) glycinato- $N, N$, $N$ '”, $O\}$ nickel(II) (7b) ......17

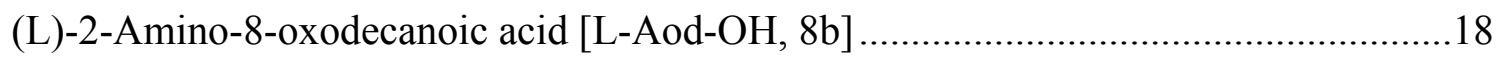

(L)-2((((9H-Fluoren-9-yl)methoxy)carbonyl)amino)-8-oxodecanoic acid (Fmoc-L-Aod-

$\mathrm{OH}, 10)$. .18

II(H). General Solid Phase Peptide Synthesis ...............................................................19

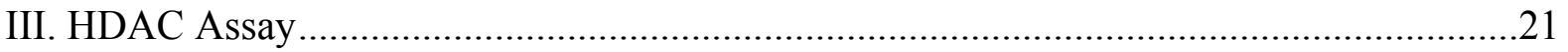

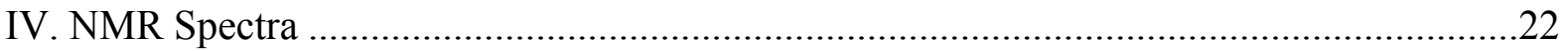

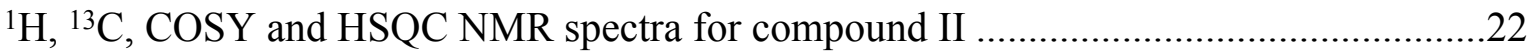

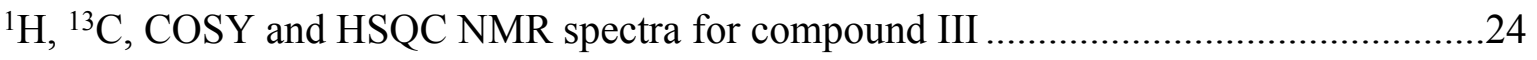

${ }^{1} \mathrm{H},{ }^{13} \mathrm{C}$, COSY, HSQC and ${ }^{19} \mathrm{~F}$ NMR spectra for compound IV .......................................26

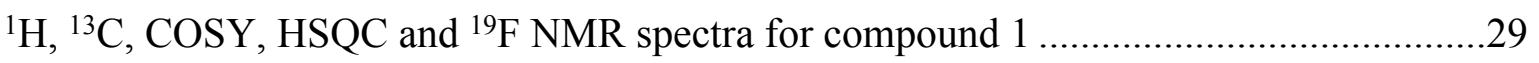

${ }^{1} \mathrm{H},{ }^{13} \mathrm{C}, \mathrm{COSY}$ and HSQC NMR spectra for compound 2c .............................................. 31

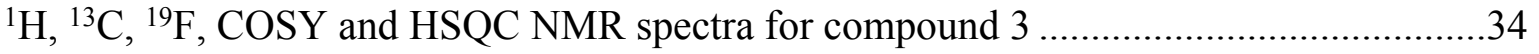

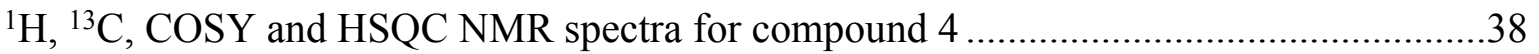

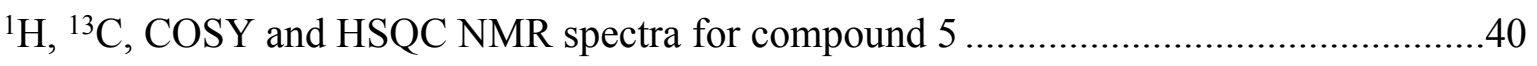

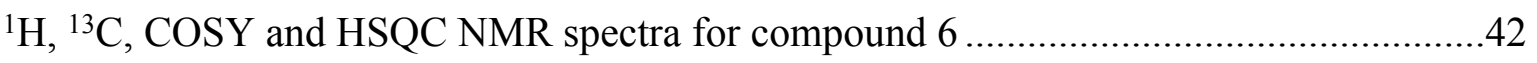

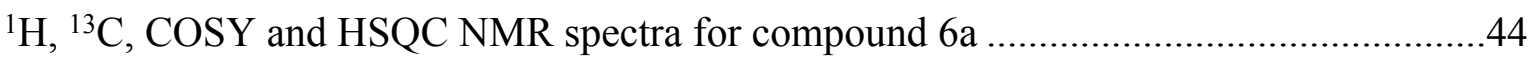

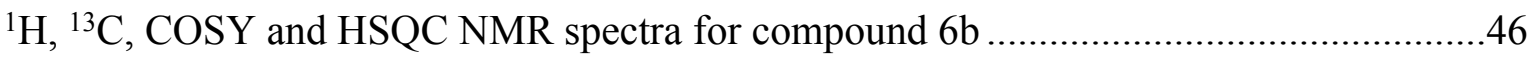

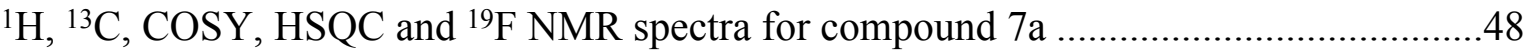

${ }^{1} \mathrm{H},{ }^{13} \mathrm{C}, \mathrm{COSY}$ and HSQC NMR spectra for compound 8a ................................................

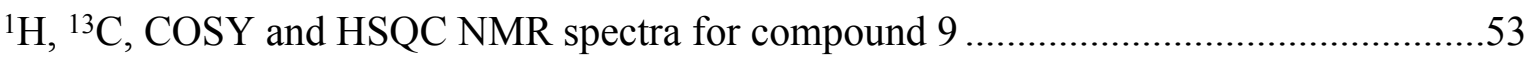

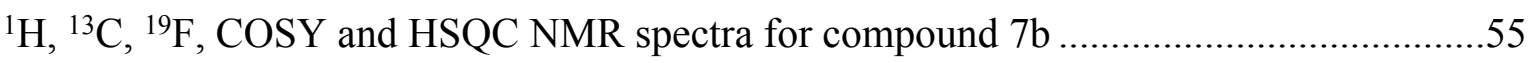

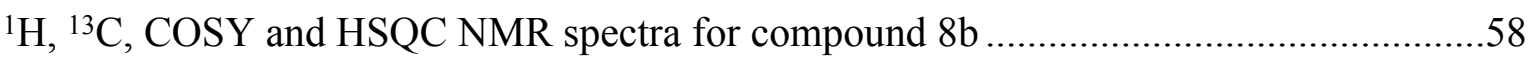

${ }^{1} \mathrm{H},{ }^{13} \mathrm{C}, \mathrm{COSY}$ and HSQC NMR spectra for compound 10 ............................................60

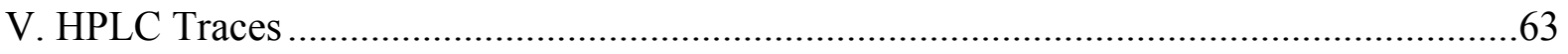

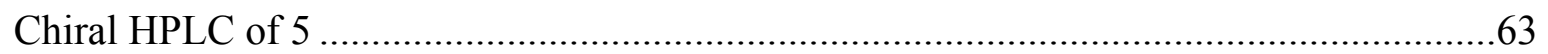

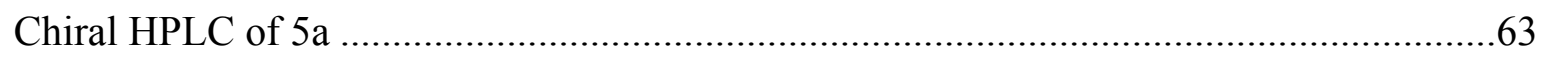

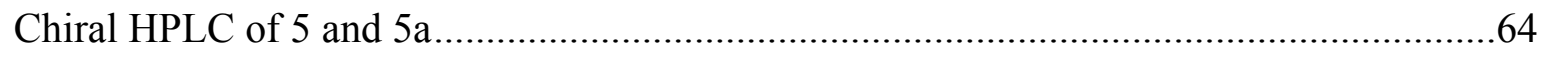

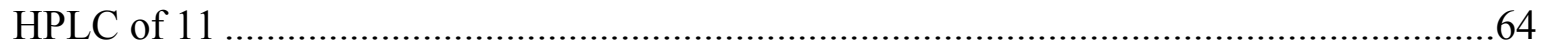


HPLC of 12

HPLC of 13

HPLC of 14 .68

\section{General information}

All starting materials were purchased from Sigma-Aldrich or Fluorochem and used further without any additional purification. All glassware was dried with a flame under flushing argon gas or stored in the oven and let cool under an inert atmosphere prior to use. Anhydrous solvents (THF, DCM and DMF) were obtained by passage through solvent filtration systems (Pure Solv) and solvents were transferred by syringe. All other solvents were reagent grade and used as received. Petroleum ether refers to the fraction that boils in the range $40-60{ }^{\circ} \mathrm{C}$. Analytical thin-layer chromatography (TLC) was performed using aluminium plates precoated with silica gel (0.25 mm, $60 \AA$ pore-size) impregnated with a fluorescent indicator (254 $\mathrm{nm})$.Visualization on TLC was achieved by the use of UV light $(254 \mathrm{~nm})$, treatment with $10 \%$ ninhydrin in ethanol or strained with lodine. Flash column chromatography was undertaken on silica gel (400-630 mesh). Proton nuclear magnetic resonance spectra ( ${ }^{1} \mathrm{H}$ NMR) were recorded on AVANCE III 400 Bruker (400 MHz). Proton chemical shifts are expressed in parts per million (ppm, $\delta$ scale) and are referenced to residual protium in the NMR solvent $\left(\mathrm{CDCl}_{3}, \delta 7.26 ; \mathrm{CD}_{3} \mathrm{OD}, \delta 3.31\right.$ and $\mathrm{D}_{2} \mathrm{O}, \delta$ 4.79). The following abbreviations were used to describe peak patterns when appropriate: $\mathrm{br}=$ broad, $\mathrm{s}=$ singlet, $\mathrm{d}=$ doublet, $\mathrm{t}=$ triplet, $\mathrm{q}=$ quadruplet, $\mathrm{m}=$ multiplet. Coupling constants, J, were reported in Hertz unit $(\mathrm{Hz})$. Carbon 13 nuclear magnetic resonance spectroscopy $\left({ }^{13} \mathrm{C} N M R\right)$ was recorded on AVANCE III 400 Bruker $(100 \mathrm{MHz})$ and was fully decoupled by broad band decoupling. Chemical shifts were reported in ppm referenced to the centre line of a triplet at 77.0 and 49.0 ppm of $\mathrm{CDCl}_{3}$ and $\mathrm{CD}_{3} \mathrm{OD}$. Infrared (IR) spectra were reported in frequency of the absorption $\left(\mathrm{cm}^{-1}\right)$ using Shimadzu IR Affinity-1S. Low-resolution mass spectrometry (LRMS) was performed on a Thermo Scientific LCQ Fleet quadrupole mass spectrometer using electrospray ionisation in positive mode $\left(\mathrm{ESI}^{+}\right)$. High-resolution mass spectrometry (HRMS) was performed on a Bruker microTOF-Q II $\left(\mathrm{ESI}^{+}\right)$. Melting points were obtained on an Electrothermal IA9200 series apparatus at a ramp rate of $1^{\circ} \mathrm{C} / \mathrm{min}$ and are uncorrected. Specific rotations, $[\alpha]^{\mathrm{D}}$ values, were 
calculated from optical rotations measured at $20^{\circ} \mathrm{C}$ in $\mathrm{CHCl}_{3}$ or $\mathrm{CH}_{3} \mathrm{OH}$ at the specified concentrations (c in g/100 mL) using a $0.5 \mathrm{dm}$ cell length (I) on a Ruldolph Research Analytical polarimeter at $589 \mathrm{~nm}$, using the general formula: $[\alpha]_{D}{ }^{20}=(100 \times$ $\alpha) /(I \times c)$.

All amino acids are of L-configuration unless otherwise stated. Standard Fmoc protected amino acids were purchased from CEM Corporation or Pepceuticals Ltd. and HCTU and peptide grade DMF were purchased from Pepceuticals Ltd. Peptides were synthesised on a Biotage Initiator+ Alstra microwave assisted peptide synthesiser. Peptides were purified on a reverse-phase Dionex HPLC system equipped with Dionex P680 pumps and a Dionex UVD170U UV-vis detector (monitoring at $214 \mathrm{~nm}$ and $280 \mathrm{~nm}$ ), using a Phenomenex, Gemini, C18, $5 \mu \mathrm{m}, 250 \mathrm{x}$ $21.2 \mathrm{~mm}$ column. Gradients were performed using solvents consisting of $\mathrm{A}\left(\mathrm{H}_{2} \mathrm{O}+\right.$ $0.1 \%$ TFA $)$ and $\mathrm{B}\left(\mathrm{CH}_{3} \mathrm{CN}+0.1 \% \mathrm{TFA}\right)$ and fractions were lyophilised on a Christ Alpha 2-4 LO plus freeze dryer. Pure peptides were analysed on a Shimadzu reverse-phase HPLC (RP-HPLC) system equipped with Shimadzu LC-20AT pumps, a SIL-20A autosampler and a SPD-20A UV-vis detector (monitoring at $214 \mathrm{~nm}$ ) using a Phenomenex, Aeris, $5 \mu \mathrm{m}$, peptide XB-C18, $150 \times 4.6 \mathrm{~mm}$ column at a flow rate of $1 \mathrm{~mL} / \mathrm{min}$. RP-HPLC gradients were run using a solvent system consisting of solution A $\left(5 \% \mathrm{CH}_{3} \mathrm{CN}\right.$ in $\mathrm{H}_{2} \mathrm{O}+0.1 \%$ TFA) and $\mathrm{B}\left(5 \% \mathrm{H}_{2} \mathrm{O}\right.$ in $\mathrm{CH}_{3} \mathrm{CN}+0.1 \%$ TFA). Two gradients were used to characterise each peptide; a gradient from $0 \%$ to $100 \%$ solution B over 20 min and a 50 min gradient from $0 \%-100 \%$ solution B. Analytical RP-HPLC data is reported as column retention time $\left(t_{R}\right)$ in minutes $(\mathrm{min})$. 


\section{Experimental procedures and characterisation data:}

\section{II(A). Synthesis of Nill Schiff base complex (1)}

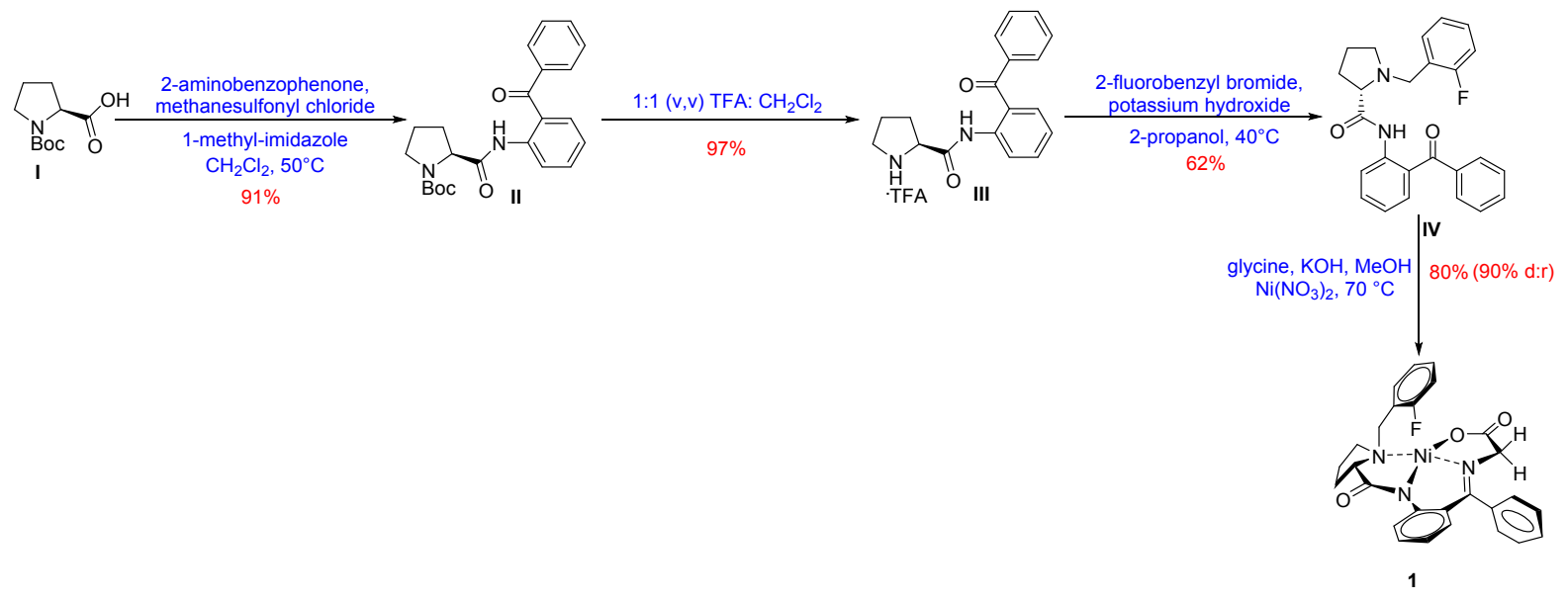

Figure S1. Synthesis of Nill Schiff base complex (1)

(S)-N-Boc-(2-Benzoylphenyl)pyrrolidine-2-carboxamide (II)

(S)-1-(tert-Butoxycarbonyl)pyrrolidine-2-carboxylic acid (Boc-L-proline) (I) (10.0 g, $46.5 \mathrm{mmol}, 1.0$ equiv.) was dissolved in $\mathrm{CH}_{2} \mathrm{Cl}_{2}(40.0 \mathrm{~mL})$ under stirring at $25^{\circ} \mathrm{C}$. To this, 1-methyl-imidazole (8.10 mL, $102.3 \mathrm{mmol}, 2.2$ equiv.) and methane sulfonylchloride (3.60 mL, $46.5 \mathrm{mmol}, 1.0$ equiv.) were added. After stirring for ten min, 2-aminobenzophenone (9.20 g, $46.5 \mathrm{mmol}, 1$ equiv.) was added. The reaction mixture was reflux and followed by TLC (20\% EtOAC in Pet. Ether). After total consumption of starting materials was observed by TLC $(36 \mathrm{~h})$, the reaction mixture was cooled to $25{ }^{\circ} \mathrm{C}$ and diluted with water $(40.0 \mathrm{~mL})$. The aqueous layer was extracted with $\mathrm{CH}_{2} \mathrm{Cl}_{2}(3 \times 40.0 \mathrm{~mL})$ and the combined organic layers washed with $\mathrm{HCl}\left(\mathrm{aq}, 1 \mathrm{M}, 3 \times 150 \mathrm{~mL}\right.$ ) and with $\mathrm{NaHCO}_{3}$ (sat. aq., $3 \times 150 \mathrm{~mL}$ ). The combined organic layers were then dried $\left(\mathrm{MgSO}_{4}\right)$, filtered and concentrated in vacuo to give (S)-N-Boc-(2-benzoylphenyl)pyrrolidine-2-carboxamide (II) (16.5 g, 91\%) as a pale yellow solid. ${ }^{1} \mathrm{H}$ NMR (400 MHz, $\left.\mathrm{CDCl}_{3}\right) \delta: 11.18(\mathrm{~s}, 1 \mathrm{H}, \mathrm{NH}), 8.68(\mathrm{~d}, J=8.4 \mathrm{~Hz}$, $1 \mathrm{H},-\mathrm{Ar}-\mathrm{CH}), 7.67$ (d, J=7.4 Hz, 2H, -Ar-CH), 7.60-7.49 (m, 3H, -Ar-CH), 7.45 (t, J = $7.4 \mathrm{~Hz}, 2 \mathrm{H},-\mathrm{Ar}-\mathrm{CH}), 7.07$ (t, J = $6.9 \mathrm{~Hz}, 1 \mathrm{H},-\mathrm{Ar}-\mathrm{CH}), 4.34$ (br s, 1H, -NC(O)CH), 3.81-3.75 (br s, 1H, -NC(O)CHH), 3.60-3.40 (br s, 1H, $-\mathrm{NC}(\mathrm{O}) \mathrm{CH}), 2.36-2.05(\mathrm{~m}$, $\left.2 \mathrm{H},-\mathrm{NC}(\mathrm{O}) \mathrm{CHCH}_{2}\right), 1.98-1.81\left(\mathrm{~m}, 2 \mathrm{H},-\mathrm{NC}(\mathrm{O}) \mathrm{CH}_{2} \mathrm{CH}_{2}\right), 1.35$ (s, 9H, $\left.-\mathrm{C}\left(\mathrm{CH}_{3}\right)_{3}\right)$ additional peaks arise from rotamers; ${ }^{13} \mathrm{C}$ NMR $\left(100 \mathrm{MHz}, \mathrm{CDCl}_{3}\right) \delta$ : 199.1 (ketone $\boldsymbol{C}=0$ ), 172.6 (carbamate $\boldsymbol{C}=0$ ), 154.2 (amide $\boldsymbol{C}=0$ ), 140.1 (-Ar- $\boldsymbol{C}$ ), 138.6 (-Ar- $\boldsymbol{C}$ ), $134.2(-\mathrm{Ar}-\mathrm{CH}), 133.6(-\mathrm{Ar}-\mathrm{CH}), 132.4$ (-Ar-CH), 129.9 (-Ar-CH), $128.2(-\mathrm{Ar}-\mathrm{CH})$, 
123.6 (-Ar- $\mathrm{CH}$ ), $122.3(-\mathrm{Ar}-\mathrm{CH}), 121.2(-\mathrm{Ar}-\mathrm{CH}), 80.3$ (carbamate $\mathrm{C}-\mathrm{O}), 62.6$ ($\mathrm{NC}(\mathrm{O}) \mathrm{CH}), 46.9\left(-\mathrm{NC}(\mathrm{O}) \mathrm{CH}_{2}\right), 31.5\left(-\mathrm{NC}(\mathrm{O}) \mathrm{CHCH}_{2}\right), 28.3\left(-\mathrm{C}\left(\mathrm{CH}_{3}\right)_{3}\right), 23.9$ $\mathrm{NC}(\mathrm{O}) \mathrm{CH}_{2} \mathrm{CH}_{2}$ ) additional peaks arise from rotamers; IR (vmax/ $/ \mathrm{cm}^{-1}$, neat) 3264, 2976, 1692, 1580, 1512, 1445, 1379, 1260, 1155, 1117, 920, 752, 698, 640; HRMS $\left(\mathrm{ESI}^{+}\right)$calcd for $\mathrm{C}_{23} \mathrm{H}_{26} \mathrm{~N}_{2} \mathrm{O}_{4} \mathrm{Na}[\mathrm{M}+\mathrm{Na}]^{+} 417.1785$, found 417.1780 ( $\Delta=1.2 \mathrm{ppm}$ ).

\section{(S)-N-(2-Benzoylphenyl)pyrrolidine-2-carboxamide-TFA (III)}

(S)-N-Boc-(2-Benzoylphenyl)pyrrolidine-2-carboxamide (II) (10.0 g, $25.4 \mathrm{mmol}, 1$ equiv.) was dissolved in $\mathrm{CH}_{2} \mathrm{CL}_{2}(20.0 \mathrm{~mL})$ under stirring at $25{ }^{\circ} \mathrm{C}$. To this, trifluoroacetic acid $(20.0 \mathrm{~mL})$ was added. The reaction was followed by TLC $(20 \%$ EtOAC in Pet. Ether). After complete consumption of starting material was observed by TLC (2 h), the reaction mixture was concentrated under vacuum to give ( $S)-\mathrm{N}-(2-$ benzoylphenyl)pyrrolidine-2-carboxamide·TFA (III) $(10.1 \mathrm{~g}, 97 \%)$ as a yellow/brown oil. ${ }^{1} \mathrm{H}$ NMR (400 MHz, $\mathrm{CDCl}_{3}$ ) $\delta: 11.09$ (s, $\left.1 \mathrm{H}, \mathrm{C}(\mathrm{O}) \mathrm{NH}\right), 10.28$ (s, $1 \mathrm{H}, \mathrm{CH}_{2} \mathrm{NHCH}$ ), $8.13(\mathrm{~d}, J=8.3 \mathrm{~Hz}, 1 \mathrm{H},-\mathrm{Ar}-\mathrm{CH}), 7.59$ (d, J = 7.2 Hz, 2H, -Ar-CH), 7.55-7.48 (m, 2H, Ar- $\mathrm{CH}$ ), 7.48-7.42 (m, 1H, -Ar-CH), $7.39(\mathrm{t}, J=7.6 \mathrm{~Hz}, 2 \mathrm{H},-\mathrm{Ar}-\mathrm{CH}), 7.10(\mathrm{t}, J=7.6$ $\mathrm{Hz}, 1 \mathrm{H},-\mathrm{Ar}-\mathrm{CH}$ ), 4.60 (br s, $1 \mathrm{H},-\mathrm{NC}(\mathrm{O}) \mathrm{CH}$ ), 3.37 (br s, 2H, - $\mathrm{NC}(\mathrm{O}) \mathrm{CH}_{2}$ ), 2.45-2.35 (m, $\left.1 \mathrm{H},-\mathrm{NC}(\mathrm{O}) \mathrm{CH}_{2} \mathrm{CHH}\right), 2.10-1.80\left(\mathrm{~m}, 3 \mathrm{H},-\mathrm{NC}(\mathrm{O}) \mathrm{CHCH}_{2}\right.$ and $\left.-\mathrm{NC}(\mathrm{O}) \mathrm{CH}_{2} \mathrm{CH} H\right)$; ${ }^{13} \mathrm{C}$ NMR $\left(100 \mathrm{MHz}, \mathrm{CDCl}_{3}\right.$ ) $\delta: 199.3$ (ketone $\boldsymbol{C}=\mathrm{O}$ ), 167.0 (amide $\boldsymbol{C}=\mathrm{O}$ ), 138.0 (-ArC), 137.7 (-Ar-C), 134.1 (-Ar-CH), 133.3 (CH, -Ar-CH), 133.0 (-Ar-CH), 129.9 (-Ar$\mathrm{CH}), 128.4$ (-Ar-CH), 125.2 (-Ar-CH), $124.2(-\mathrm{Ar}-\mathrm{CH}), 122.2(-\mathrm{Ar}-\mathrm{CH}), 60.8$ ($\mathrm{NC}(\mathrm{O}) \mathrm{CH}), 46.7\left(-\mathrm{NC}(\mathrm{O}) \mathrm{CH}_{2}\right), 29.6\left(-\mathrm{NC}(\mathrm{O}) \mathrm{CHCH}_{2}\right), 24.4\left(-\mathrm{NC}(\mathrm{O}) \mathrm{CH}_{2} \mathrm{CH}_{2}\right) ; \mathrm{IR}$ (vmax/cm ${ }^{-1}$, neat) 3090, 2338, 1674, 1531, 1449, 1265, 1146, 939, 795, 700; HRMS $\left(\mathrm{ESI}^{+}\right)$calcd for $\mathrm{C}_{18} \mathrm{H}_{18} \mathrm{~N}_{2} \mathrm{O}_{2} \mathrm{Na}[\mathrm{M}+\mathrm{Na}]^{+} 317.1260$, found 317.1250 ( $\left.\Delta=3.3 \mathrm{ppm}\right)$.

\section{(S)-N-(2-Benzoylphenyl)-1-(2-fluorobenzyl)pyrrolidine-2-carboxamide (IV)}

Potassium hydroxide ( $4.10 \mathrm{~g}, 74.0 \mathrm{mmol}, 3$ equiv.) was dissolved in 2-propanol (30.0 $\mathrm{mL}$ ) at $40{ }^{\circ} \mathrm{C}$. (S)- $\mathrm{N}$-(2-Benzoylphenyl)pyrrolidine-2-carboxamide-TFA (III) (10.0 g, $24.5 \mathrm{mmol}, 1$ equiv.) dissolved in 2-propanol $(10.0 \mathrm{~mL})$ was added dropwise. After ten min, 2-fluorobenzyl bromide ( $3.00 \mathrm{~mL}, 24.5 \mathrm{mmol}, 1$ equiv.) was added dropwise, forming a white precipitate on addition. The reaction was followed by TLC $(20 \%$ EtOAC in Pet. Ether). After complete consumption of starting material was observed by TLC (24 h), the reaction mixture was cooled to $25{ }^{\circ} \mathrm{C}$ and was concentrated in vacuo. The residue was re-dissolved in $\mathrm{CH}_{2} \mathrm{Cl}_{2}$ and washed with water $(3 \times 30.0$ 
$\mathrm{mL})$. The combined aqueous layers were then extracted with $\mathrm{CH}_{2} \mathrm{Cl}_{2}(3 \times 30.0 \mathrm{~mL})$. The combined organic layers were then dried $\left(\mathrm{MgSO}_{4}\right)$, filtered and concentrated under vacuum. The orange/yellow solid obtained was re-dissolved in minimum amount of $\mathrm{CH}_{2} \mathrm{Cl}_{2}$ in a round bottom flask. Hexane was added dropwise until the solution turned cloudy. At this point, the flask was covered in aluminium foil and left open to the atmosphere for $48 \mathrm{~h}$ at which point large, pale-yellow, quartz-like crystals had formed. The crystals were washed with hexane and dried to yield $(S)-N-(2-$ benzoylphenyl)-1-(2-fluorobenzyl)pyrrolidine-2-carboxamide (IV) $(6.10 \mathrm{~g}, 62 \%)$; 88$90{ }^{\circ} \mathrm{C}$, lit. 88-90 ${ }^{\circ} \mathrm{C} ;{ }^{1} \mathrm{H}$ NMR $\left(400 \mathrm{MHz}, \mathrm{CDCl}_{3}\right)$ ס: 11.33 (s, $\left.1 \mathrm{H}, \mathrm{C}(\mathrm{O}) \mathrm{NH}\right), 8.47$ (d, J $=8.3 \mathrm{~Hz}, 1 \mathrm{H},-\mathrm{Ar}-\mathrm{CH}), 7.68(\mathrm{~d}, J=7.6 \mathrm{~Hz}, 2 \mathrm{H},-\mathrm{Ar}-\mathrm{CH}), 7.52(\mathrm{t}, J=7.4 \mathrm{~Hz}, 1 \mathrm{H},-\mathrm{Ar}-$ $\mathrm{CH}), 7.49-7.35(\mathrm{~m}, 5 \mathrm{H},-\mathrm{Ar}-\mathrm{CH}), 7.08-6.98(\mathrm{~m}, 2 \mathrm{H},-\mathrm{Ar}-\mathrm{CH}), 6.84$ (t, $J=7.5 \mathrm{~Hz}, 1 \mathrm{H},-$ $\operatorname{Ar}-\mathrm{CH}), 6.71(\mathrm{t}, J=9.2 \mathrm{~Hz}, 1 \mathrm{H},-\mathrm{Ar}-\mathrm{CH}), 3.82(\mathrm{~d}, J=13.2 \mathrm{~Hz}, 1 \mathrm{H},-\mathrm{NC}(\mathrm{O}) \mathrm{CHH}), 3.66$ (d, $J=13.2 \mathrm{~Hz}, 1 \mathrm{H},-\mathrm{NC}(\mathrm{O}) \mathrm{CH} H$ ), $3.27(\mathrm{dd}, J=10.3,4.6 \mathrm{~Hz}, 1 \mathrm{H},-\mathrm{NC}(\mathrm{O}) \mathrm{CH}$ ), 3.20$3.10(\mathrm{~m}, 1 \mathrm{H}, \mathrm{N}-\mathrm{CHHAr}), 2.45-2.35(\mathrm{~m}, 1 \mathrm{H}, \mathrm{N}-\mathrm{CHHAr}), 2.25-2.10(\mathrm{~m}, 1 \mathrm{H},-$ $\mathrm{NC}(\mathrm{O}) \mathrm{CHCHH}), \quad 1.92-1.82(\mathrm{~m}, \quad 1 \mathrm{H}, \quad-\mathrm{NC}(\mathrm{O}) \mathrm{CHCHH}), \quad 1.78-1.65(\mathrm{~m}, \quad 2 \mathrm{H}, \quad-$ $\mathrm{NC}(\mathrm{O}) \mathrm{CH}_{2} \mathrm{CH}_{2}$ ); ${ }^{13} \mathrm{C} \mathrm{NMR}\left(100 \mathrm{MHz}, \mathrm{CDCl}_{3}\right.$ ) $\delta: 197.9$ (ketone $\mathbf{C}=\mathrm{O}$ ), 174.4 (amide $\boldsymbol{C}=\mathrm{O}$ ), 162.3 (-Ar-CF), 159.8 (-Ar-C-CH ), 139.0 (-Ar-C), 138.6 (-Ar-C), 133.3 (-Ar$\mathrm{CH}), 132.5$ (-Ar-CH), 131.7 (-Ar-CH), 130.1 (-Ar-CH), 128.9 (-Ar-CH), 128.8 (-Ar$\mathrm{CH}$ ), 128.3 (-Ar-CH), 125.6 (-Ar-CH), 124.8 (-Ar-C), 123.9 (-Ar-CH), 122.3 (-Ar-CH), 121.5 (-Ar- $\mathrm{CH}), 115.2$ (-Ar-CH), $115.0(-\mathrm{Ar}-\mathrm{CH}), 67.9(-\mathrm{NC}(\mathrm{O}) \mathrm{CH}), 53.8\left(-\mathrm{NCH}_{2} \mathrm{Ar}\right)$, $52.1\left(-\mathrm{NC}(\mathrm{O}) \mathrm{CH}_{2}\right), 31.1\left(-\mathrm{NC}(\mathrm{O}) \mathrm{CHCH}_{2}\right), \quad 24.3\left(-\mathrm{NC}(\mathrm{O}) \mathrm{CH}_{2} \mathrm{CH}_{2}\right) ;{ }^{19} \mathrm{~F} \mathrm{NMR}(376$ $\mathrm{MHz}, \mathrm{CDCl}_{3}$ ) $\delta$ : 117.6; IR (vmax/cm${ }^{-1}$, neat) 3275, 2965, 2841, 1680, 1645, 1576, 1510, 1487, 1443, 1265, 1101, 923, 878, 768, 696, 635; HRMS (ESI+) calcd for $\mathrm{C}_{25} \mathrm{H}_{23} \mathrm{FN}_{2} \mathrm{O}_{2} \mathrm{Na}[\mathrm{M}+\mathrm{Na}]^{+}:$425.1636, found 425.1620 ( $\Delta=3.6 \mathrm{ppm}$ ).

\section{(S)-(\{2-[1-(2-Fluorobenzyl)-pyrrolidine-2-}

carboxamide]phenyl\}phenylmethylene)-glycinato- $N, N, N ", O\}$ nickel(II) $\{G l y-N i-$ 2-FBPB complex, 1\}

(S)-N-(2-Benzoylphenyl)-1-(2-fluorobenzyl)pyrrolidine-2-carboxamide (2-FBPB) (IV) (2.0 g, $4.9 \mathrm{mmol}, 1.0$ equiv.), $\mathrm{Ni}\left(\mathrm{NO}_{3}\right)_{2} \cdot 6 \mathrm{H}_{2} \mathrm{O}(2.8 \mathrm{~g}, 9.9 \mathrm{mmol}, 2.0$ equiv.) and glycine $(0.9 \mathrm{~g}, 9.9 \mathrm{mmol}, 2.0$ equiv.) were dissolved in methanol $(50.0 \mathrm{~mL}, 0.1 \mathrm{M})$ at $50{ }^{\circ} \mathrm{C}$. Potassium hydroxide $(1.9 \mathrm{~g}, 34.8 \mathrm{mmol}, 7.0$ equiv.) was added and the mixture was heated to $70{ }^{\circ} \mathrm{C}$ for 1 hour. The reaction mixture was cooled and then concentrated. The resulting residue was taken up in water $(40.0 \mathrm{~mL})$ and extracted 
with EtOAc $(3 \times 40.0 \mathrm{~mL})$. The combined organic layers were washed with saturated brine solution $(3 \times 30.0 \mathrm{~mL})$, dried $\left(\mathrm{MgSO}_{4}\right)$ and concentrated in vacuo to give the title compound (1) as a red crystalline solid (1.7 g, 70\%); m.p: $125-127^{\circ} \mathrm{C}$; ${ }^{1} \mathrm{H}$ NMR (400 MHz, $\left.\mathrm{CDCl}_{3}\right)$ ס: 8.29-8.22 (m, 2H, -Ar-CH), 7.49-7.42 (m, 3H, -Ar-CH), 7.25 (tdd, $J=7.2,6.3,1.9 \mathrm{~Hz}, 1 \mathrm{H},-\mathrm{Ar}-\mathrm{CH}), 7.19-7.14(\mathrm{~m}, 2 \mathrm{H},-\mathrm{Ar}-\mathrm{CH}), 7.07-7.02(\mathrm{~m}, 2 \mathrm{H},-$ Ar- $\mathrm{CH}$ ), $6.91(\mathrm{dt}, J=6.0,1.9 \mathrm{~Hz}, 1 \mathrm{H},-\mathrm{Ar}-\mathrm{CH}), 6.75(\mathrm{dd}, J=8.2,1.7 \mathrm{~Hz}, 1 \mathrm{H},-\mathrm{Ar}-\mathrm{CH})$, 6.65 (ddd, $J=8.2,6.9,1.2 \mathrm{~Hz}, 1 \mathrm{H},-\mathrm{Ar}-\mathrm{CH}$ ), 4.41 (dd, $J=13.0,1.4 \mathrm{~Hz}, 1 \mathrm{H},-\mathrm{N}-\mathrm{CHH}$ ), $3.87(\mathrm{dd}, J=12.9,1.2 \mathrm{~Hz}, 1 \mathrm{H},-\mathrm{N}-\mathrm{CH} H), 3.73-3.63\left(\mathrm{~m}, 2 \mathrm{H},-\mathrm{NC}(\mathrm{O}) \mathrm{CH}_{2}\right), 3.60-3.56$ $(\mathrm{m}, 1 \mathrm{H},-\mathrm{NC}(\mathrm{O}) \mathrm{CH}), 3.39(\mathrm{dd}, J=10.8,5.7 \mathrm{~Hz}, 1 \mathrm{H},-\mathrm{C}(\mathrm{O}) \mathrm{CHH}), 3.34-3.23(\mathrm{~m}, 1 \mathrm{H},-$ $\mathrm{C}(\mathrm{O}) \mathrm{CH} H)$, 2.63-2.55 (m, 1H, - $\mathrm{NC}(\mathrm{O}) \mathrm{CHCHH}), 2.45-2.35(\mathrm{~m}, 1 \mathrm{H},-\mathrm{NC}(\mathrm{O}) \mathrm{CHCHH})$, 2.04 (tdd, $\left.J=12.0,9.5,6.2 \mathrm{~Hz}, 2 \mathrm{H},-\mathrm{NC}(\mathrm{O}) \mathrm{CH}_{2} \mathrm{CH}_{2}\right) ;{ }^{13} \mathrm{C} \mathrm{NMR}\left(100 \mathrm{MHz}, \mathrm{CDCl}_{3}\right) \delta$ : 180.9 (ketone $\boldsymbol{C}=0$ ), 177.3 (amide $\boldsymbol{C}=0$ ), 171.7 (-Ar-CF), 142.5 (-Ar- $\boldsymbol{C}$ ), 134.6 (-Ar$\mathrm{CH}$ ), 134.3 (-Ar-CH), 134.2 (-Ar-CH), 133.3 (-Ar-CH), 132.3 (-Ar-CH), 131.4 (-Ar$\mathrm{CH}), 131.4$ (-Ar- $\mathrm{CH}), 129.8$ (-Ar-CH), 129.6 (-Ar-CH), 129.3 (-Ar- $\mathrm{CH}), 126.3$ (-Ar$\mathrm{CH}), 125.7$ (-Ar-CH), 125.3 (-Ar-CH), 124.6 (-Ar-CH), 124.6 (-Ar-CH), 124.4 (-Ar$\mathrm{CH}), 120.9$ (-Ar- $\mathrm{CH}$ ), 120.5 (-Ar- $\mathrm{CH}$ ), 116.3 (-Ar-C), 116.1 (-Ar- $\mathrm{CH}$ ), 70.1 (carbamate C-O), $61.3(-\mathrm{NC}(\mathrm{O}) \mathrm{CH}), 57.3\left(-\mathrm{NCH}_{2} \mathrm{Ar}\right), 55.7\left(-\mathrm{NC}(\mathrm{O}) \mathrm{CH}_{2}\right), 30.6\left(-\mathrm{NC}(\mathrm{O}) \mathrm{CHCH}_{2}\right)$,

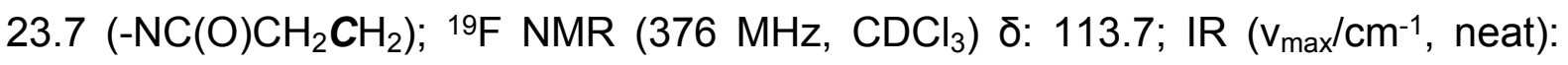
2931, 2362, 1671, 1628, 1576, 1491, 1445, 1356, 1243, 1162, 1109, 1068, 968, 726; HRMS $(\mathrm{m} / \mathrm{z})[\mathrm{M}+\mathrm{H}]^{+}$calcd for $\mathrm{C}_{27} \mathrm{H}_{25} \mathrm{FN}_{3} \mathrm{NiO}_{3}[\mathrm{M}+\mathrm{H}]^{+} 516.1233$, found $516.1235(\Delta=$ $0.4 \mathrm{ppm})$.

\section{II(B). Synthesis of 6-Bromo-N-(tert-butoxy)hexanamide (2c)}

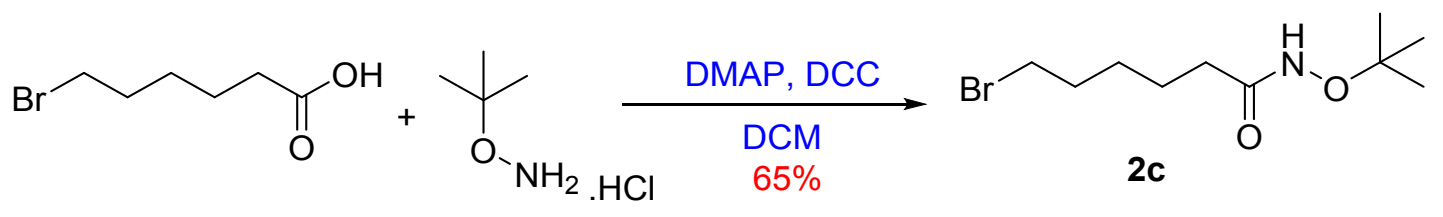

Figure S2. Synthesis of 6-Bromo- $N$-(tert-butoxy)hexanamide (2c)

6-Bromohexanoic acid (600 mg, $3.1 \mathrm{mmol}, 1$ equiv.) was dissolved in dry dichloromethane $(10 \mathrm{~mL})$ at $0{ }^{\circ} \mathrm{C}$ under a nitrogen atmosphere. O-(tert-butyl) hydroxyl amine hydrochloride (582.7 $\mathrm{mg}, 4.6 \mathrm{mmol}, 1.5$ equiv.) was added to the solution followed by DMAP (75.6 $\mathrm{mg}, 0.62 \mathrm{mmol}, 0.2$ equiv.) were added and allowed to stir for 5 mins at $0{ }^{\circ} \mathrm{C}$. N,N'-Dicyclohexylcarbodiimide, DCC (951 mg, 4.6 mmol, 1.5 equiv.) was added and the mixture warmed to room temperature, then stirred for a further $20 \mathrm{~h}$ at room temperature. The mixture was filtered and the filtrate 
washed with water $(10 \mathrm{~mL})$. The two layers were separated and the organic layer was dried $\left(\mathrm{MgSO}_{4}\right)$, then the solvent removed in vacuo. Purification was carried out by flash column chromatography ( $40 \%$ ethyl acetate-petroleum ether). Fractions containing the product were combined and the solvent removed in vacuo to give 6bromo- $\mathrm{N}$-(tert-butoxy)hexanamide (2c) $(534 \mathrm{mg}, 65 \%)$ as a colourless oil. ${ }^{1} \mathrm{H}$ NMR $\left(400 \mathrm{MHz}, \mathrm{CDCl}_{3}\right.$ ) ס: 3.34 (t, $J=6.7 \mathrm{~Hz}, 2 \mathrm{H},-\mathrm{CH}_{2} \mathrm{Br}$ ), 2.42-2.35 (m, $1 \mathrm{H},-\mathrm{CH}_{2} \mathrm{CH}_{2} \mathrm{Br}$ ), 2.11-2.06 (m, $\left.1 \mathrm{H},-\mathrm{CH}_{2} \mathrm{CH}_{2} \mathrm{Br}\right), 1.81\left(\mathrm{p}, J=6.9 \mathrm{~Hz}, 2 \mathrm{H},-\mathrm{CH}_{2} \mathrm{CH}_{2} \mathrm{CH}_{2} \mathrm{Br}\right), 1.61$ (q, $J=$ $\left.7.4 \mathrm{~Hz}, 2 \mathrm{H},-\mathrm{CH}_{2} \mathrm{CH}_{2} \mathrm{CH}_{2} \mathrm{CH}_{2} \mathrm{Br}\right)$, 1.46-1.38 (m, $\left.2 \mathrm{H},-\mathrm{CH}_{2} \mathrm{CH}_{2} \mathrm{CH}_{2} \mathrm{CH}_{2} \mathrm{CH}_{2} \mathrm{Br}\right), 1.20$ (s, 9H, $\left.-\left\{\mathrm{CH}_{3}\right\}_{3}\right) ;{ }^{13} \mathrm{C} \mathrm{NMR}\left(100 \mathrm{MHz}, \mathrm{CDCl}_{3}\right)$ ס: $172.0(\mathrm{C}=\mathrm{O}), 81.9\left(-\mathrm{NHC}_{-}\left\{\mathrm{CH}_{3}\right\}_{3}\right)$, $44.8\left(-\mathrm{CH}_{2} \mathrm{Br}\right), 33.6\left(-\mathrm{CH}_{2} \mathrm{CH}_{2} \mathrm{Br}\right), 32.4\left(-\mathrm{CH}_{2} \mathrm{CH}_{2} \mathrm{CH}_{2} \mathrm{Br}\right), 27.7\left(-\mathrm{CH}_{2} \mathrm{CH}_{2} \mathrm{CH}_{2} \mathrm{CH}_{2} \mathrm{Br}\right)$, $26.3\left(-\left\{\mathrm{CH}_{3}\right\}_{3}\right) ; 24.7\left(-\mathrm{CH}_{2} \mathrm{CH}_{2} \mathrm{CH}_{2} \mathrm{CH}_{2} \mathrm{CH}_{2} \mathrm{Br}\right) ; \mathrm{IR}\left(\mathrm{v}_{\max } / \mathrm{cm}^{-1}\right.$, neat): 3326, 3104, 1680, 1412, 784; HRMS $\left(E S I^{+}\right)$calcd for $\mathrm{C}_{10} \mathrm{H}_{20} \mathrm{BrNO}_{2} \mathrm{Na}[\mathrm{M}+\mathrm{Na}]^{+} 288.0575$, found $288.0580(\Delta=1.2 \mathrm{ppm})$.

\section{II(C). Synthesis of Fmoc-L-Asu(NHO'Bu)-OH (5)}

\section{(S)-(\{2-[1-(2-Fluorobenzyl)benzyl)pyrrolidine-2-carboxamide]-}

phenyl\}phenylmethylene)-(S)-(N-(tert-butoxy)hexanamide) glycinato-N,N',N",O\} nickel(II) (3)

Freshly ground sodium hydroxide ( $232.9 \mathrm{mg}, 5.8 \mathrm{mmol}, 5.0$ equiv.) was taken up in DMF $(5.0 \mathrm{~mL})$ with stirring at $0{ }^{\circ} \mathrm{C}$ under an atmosphere of nitrogen. (S)-(\{2-[1-(2Fluorobenzyl)-pyrrolidine-2-carboxamide]phenyl\}phenylmethylene)-glycinato$\left.N, N^{\prime}, N^{\prime \prime}, O\right\}$ nickel(II) (1) (600 mg, $1.2 \mathrm{mmol}, 1.0$ equiv.) was added and stirred for 2 minutes; the solution darkened in colour and the ice bath was removed. A solution of 6-bromo- $N$-(tert-butoxy)hexanamide (2c) $(954.3 \mathrm{mg}, 3.6 \mathrm{mmol} 3.0$ equiv.) was added to reaction mixture. The solution was left to stir for 30 minutes at room temperature, then quenched with the addition of water. The mixture was concentrated in vacuo, taken up in water $(10.0 \mathrm{~mL})$ and extracted with dichloromethane $(3 \times 15.0 \mathrm{~mL})$. The combined organic extracts were washed with aqueous lithium chloride solution $(5 \%$ $\mathrm{v} / \mathrm{v})(3 \times 20.0 \mathrm{~mL})$, brine $(3 \times 20.0 \mathrm{~mL})$, dried $\left(\mathrm{MgSO}_{4}\right)$ and concentrated in vacuo. Purification by flash column chromatography $\left(10 \% \mathrm{CH}_{3} \mathrm{OH}-\mathrm{CH}_{2} \mathrm{Cl}_{2}\right)$ gave the title compound (3) as a deep red-orange solid (655.4 mg, 78\%); m.p: $182-184{ }^{\circ} \mathrm{C} ;{ }^{1} \mathrm{H}$ NMR (400 MHz, $\mathrm{CD}_{3} \mathrm{OD}$ ) ס: 8.36 (td, $J=7.3,3.3 \mathrm{~Hz}, 1 \mathrm{H},-\mathrm{Ar}-\mathrm{CH}$ ), 7.97 (dd, $J=8.6$, $0.7 \mathrm{~Hz}, 1 \mathrm{H},-\mathrm{Ar}-\mathrm{CH}), 7.65-7.57(\mathrm{~m}, 2 \mathrm{H},-\mathrm{Ar}-\mathrm{CH}), 7.53(\mathrm{td}, J=7.4,1.3 \mathrm{~Hz}, 1 \mathrm{H},-\mathrm{Ar}-$ $\mathrm{CH}$ ), 7.39-7.37 (m, 1H, -Ar-CH), 7.27-7.22 (m, 2H, -Ar-CH), 7.15 (ddd, $J=8.7,6.9$, 
$1.8 \mathrm{~Hz}, 1 \mathrm{H},-\mathrm{Ar}-\mathrm{CH}), 7.11-7.03(\mathrm{~m}, 2 \mathrm{H},-\mathrm{Ar}-\mathrm{CH}), 6.76-6.72(\mathrm{~m}, 1 \mathrm{H},-\mathrm{Ar}-\mathrm{CH}), 6.69$ (dd, $J=8.2,1.7 \mathrm{~Hz}, 1 \mathrm{H},-\mathrm{Ar}-\mathrm{CH}), 4.87$ (s, 2H, $\left.-\mathrm{CH}_{2}\right), 4.20$ (d, J=12.9 Hz, 1H, $\left.-\mathrm{N}-\mathrm{CHH}\right)$, 3.90 (dd, $J=8.0,3.3 \mathrm{~Hz}, 1 \mathrm{H},-\mathrm{CH}), 3.75$ (t, $J=13.2 \mathrm{~Hz}, 1 \mathrm{H},-\mathrm{N}-\mathrm{CH} \boldsymbol{H}), 3.60$ (tq, $J=$ 9.7, $4.9 \mathrm{~Hz}, 2 \mathrm{H},-\mathrm{CH}_{2}$ ), $3.32(\mathrm{dd}, J=3.3,1.7 \mathrm{~Hz}, 1 \mathrm{H},-\mathrm{NC}(\mathrm{O}) \mathrm{CH}), 2.72$ (pd, $J=11.1$, $7.7 \mathrm{~Hz}, 2 \mathrm{H},-\mathrm{CH}_{2}$ ), 2.31-2.20 (m, 2H, $-\mathrm{CH}_{2}$ ), 2.06 (ddd, J = 13.5, 11.8, 6.4 Hz, 4H, $\left.\mathrm{CH}_{2}\right), 1.67-1.56\left(\mathrm{~m}, 4 \mathrm{H},-\mathrm{CH}_{2}\right), 1.24\left(\mathrm{~s}, 9 \mathrm{H},-\left\{\mathrm{CH}_{3}\right\}_{3}\right) ;{ }^{13} \mathrm{C}$ NMR (100 MHz, CD $\left.\mathrm{CD}_{3} \mathrm{O}\right) \delta:$ 180.9 (ketone $\boldsymbol{C}=\mathrm{O}$ ), 172.6 (amide $\boldsymbol{C}=\mathrm{O}$ ), 171.3 (amide $\boldsymbol{C}=\mathrm{O}$ ), 163.0 (-Ar- $\boldsymbol{C}$ ), 160.6 (Ar-CF), 141.6 (-Ar-C), 133.8 (-Ar-CH), 133.7 (-Ar-CH), 133.1 (-Ar-CH), 131.7 (-Ar$\mathrm{CH}), 131.2(-\mathrm{Ar}-\mathrm{CH}), 131.1$ (-Ar-CH), 129.8 (-Ar- $\mathrm{CH}), 128.9$ (-Ar- $\mathrm{CH}), 128.8$ (-Ar$\mathrm{CH}), 127.7$ (-Ar-CH), 127.0 (-Ar-C), 126.7 (-Ar-C), 124.6 (-Ar-CH), 124.5 (-Ar-CH), 123.6 (-Ar-CH), 121.9 (-Ar-C), 121.7 (-Ar-C), 121.0 (-Ar-CH), 115.8 (-Ar-CH), 115.5 (Ar- $\mathrm{CH}), 81.4\left(-\mathrm{CH}_{2}\right), 71.4(-\mathrm{CH}), 70.1,57.4(-\mathrm{NC}(\mathrm{O}) \mathrm{CH}), 56.4\left(-\mathrm{CH}_{2}\right), 53.5,34.5(-$ $\left.\mathrm{CH}_{2}\right), 32.2\left(-\mathrm{CH}_{2}\right), 30.4\left(-\mathrm{CH}_{2}\right), 28.2\left(-\mathrm{CH}_{2}\right), 25.3\left(-\mathrm{CH}_{2}\right), 25.1\left(-\mathrm{CH}_{2}\right), 24.7\left(-\mathrm{CH}_{2}\right)$, $23.4-\left\{\mathrm{CH}_{3}\right\}_{3} ;{ }^{19} \mathrm{~F}$ NMR (376 MHz, CD $\left.\mathrm{CD}_{3} \mathrm{OD}\right) \delta:-114.9$; IR $\left(\mathrm{v}_{\max } / \mathrm{cm}^{-1}\right.$, neat): 3287, 3091, 2966, 2356, 1670, 1625, 1571, 1487, 1442, 1351, 1237, 1160, 1076, 963, 722; HRMS $\left(\mathrm{ESI}^{+}\right)$calcd for $\mathrm{C}_{37} \mathrm{H}_{44} \mathrm{FN}_{4} \mathrm{NiO}_{5}[\mathrm{M}+\mathrm{H}]^{+} 701.2649$, found $701.2643(\Delta=1.4$ ppm).

\section{(L)-2-Amino-8-(tert-butoxyamino)-8-oxooctanoic acid [L-Asu(NHOtBu)-OH, 4]}

(S)-(\{2-[1-(2-Fluorobenzyl)benzyl)pyrrolidine-2-carboxamide]-

phenyl\}phenylmethylene)-(S)-( $N$-(tert-butoxy)hexanamide) glycinato- $N, N^{\prime}, N$ ",O\} nickel(II) (3) (500 mg, $0.71 \mathrm{mmol}, 1$ equiv.) and 8-hydroxyquinoline (259.2 mg, 1.78 mmol, 2.5 equiv.) were taken up in acetonitrile $(10 \mathrm{~mL})$. Water $(1.5 \mathrm{~mL})$ was added and the mixture heated to $30{ }^{\circ} \mathrm{C}$ for $18 \mathrm{~h}$. The mixture was filtered and the precipitate washed with water. The filtrate was extracted with $\mathrm{CH}_{2} \mathrm{Cl}_{2}(3 \times 20 \mathrm{~mL})$. The aqueous layer was lyophilised to give (L)-2-amino-8-(tert-butoxy)-8-oxooctanoic acid (4) as a white fluffy powder (174 mg, 94\%); m.p: $208-210{ }^{\circ} \mathrm{C}$; ${ }^{1} \mathrm{H}$ NMR (400 $\left.\mathrm{MHz}, \mathrm{D}_{2} \mathrm{O}\right) \delta: 3.65\left(\mathrm{t}, J=6.1 \mathrm{~Hz}, 1 \mathrm{H},-\mathrm{CHNH}_{2}\right), 2.14\left(\mathrm{t}, J=7.3 \mathrm{~Hz}, 2 \mathrm{H},-\mathrm{C}(\mathrm{O}) \mathrm{CH}_{2}\right)$, 1.81-1.75 (m, 2H, $\left.-\mathrm{CH}_{2} \mathrm{CHNH}_{2}\right), 1.56\left(\mathrm{p}, J=7.6 \mathrm{~Hz}, 2 \mathrm{H},-\mathrm{C}(\mathrm{O}) \mathrm{CH}_{2} \mathrm{CH}_{2}\right), 1.31(\mathrm{~h}, J=$ 7.3, $\left.5.7 \mathrm{~Hz}, 4 \mathrm{H}-\mathrm{C}(\mathrm{O}) \mathrm{CH}_{2} \mathrm{CH}_{2} \mathrm{CH}_{2} \mathrm{CH}_{2}\right), 1.18$ (s, 9H, $\left.-\left\{\mathrm{CH}_{3}\right\}_{3}\right) ;{ }^{13} \mathrm{C} \mathrm{NMR}(100 \mathrm{MHz}$, $\left.\mathrm{D}_{2} \mathrm{O}\right)$ ठ: $174.8(-\boldsymbol{C}=\mathrm{OOH}), 174.2(-\boldsymbol{C}=\mathrm{O}), 83.7\left(-\mathrm{NHC}-\left\{\mathrm{CH}_{3}\right\}_{3}\right), 54.7(-\mathrm{NHCH}), 32.3(-$ $\left.\mathrm{CH}_{2}\right), 30.1\left(-\mathrm{CH}_{2}\right), 27.7\left(-\mathrm{CH}_{2}\right), 25.3\left(-\mathrm{CH}_{3}\right), 24.6\left(-\mathrm{CH}_{2}\right), 23.8\left(-\mathrm{CH}_{2}\right)$; IR $\left(\mathrm{V}_{\text {max }} / \mathrm{cm}^{-1}\right.$, neat): 3432, 3261, 2953, 1680, 1156; HRMS $\left(E S I^{+}\right)$calcd for $\mathrm{C}_{12} \mathrm{H}_{25} \mathrm{~N}_{2} \mathrm{O}_{4}[\mathrm{M}+\mathrm{H}]^{+}$ 261.1814, found $261.1823(\Delta=1.6 \mathrm{ppm})$. 


\section{(L)-2-(\{[(9H-Fluoren-9-yl)methoxy)carbonyl]amino\}-8-(tert-butoxyamino)-8- oxooctanoic acid [Fmoc-L-Asu(NHOtBu)-OH, 5]}

(L)-2-Amino-8-(tert-butoxy)-8-oxooctanoic acid (4) (400 mg, $1.54 \mathrm{mmol}, 1$ equiv.) and potassium carbonate $(425.1 \mathrm{mg}, 3.08 \mathrm{mmol}, 2$ equiv.) were taken up in water ( 1.5 $\mathrm{mL}$ ) and cooled to $0{ }^{\circ} \mathrm{C}$. Fmoc succinimide $(519.5 \mathrm{mg}, 1.54 \mathrm{mmol}, 1.0$ equiv.) was dissolved in dioxane $(10 \mathrm{~mL})$ and added dropwise to the aqueous solution over 20 mins. The reaction was warmed to room temperature and left to stir for $24 \mathrm{~h}$. Excess water was added to the mixture then extracted with $\mathrm{CH}_{2} \mathrm{Cl}_{2}(3 \times 25 \mathrm{~mL})$. The combined organic layers were back extracted with sodium bicarbonate $(3 \times 20 \mathrm{~mL})$ then the aqueous acidified to $\mathrm{pH} 1$ with $3 \mathrm{M}$ hydrochloric acid. The aqueous fractions were then extracted with $\mathrm{CH}_{2} \mathrm{Cl}_{2}(3 \times 30 \mathrm{~mL})$. The combined organic layers were washed with brine $(3 \times 30 \mathrm{~mL})$, dried $\left(\mathrm{MgSO}_{4}\right)$ and concentrated in vacuo. Purification was carried out by flash column chromatography $\left(10 \% \mathrm{CH}_{3} \mathrm{OH}-\mathrm{CH}_{2} \mathrm{Cl}_{2}\right)$. Fractions containing the product were combined and the solvent removed in vacuo to give (L)-2-(\{[(9H-Fluoren-9-yl)methoxy)carbonyl]amino\}-8-(tert-butoxyamino)-8oxooctanoic acid (5) as an off white powder (728 mg, 98\%); m.p: $112-114{ }^{\circ} \mathrm{C} ;{ }^{1} \mathrm{H}$ NMR (400 MHz, $\mathrm{CD}_{3} \mathrm{OD}$ ) ס: 7.68 (dt, $J=7.6,0.9 \mathrm{~Hz}, 2 \mathrm{H},-\mathrm{Ar}-\mathrm{CH}$ ), 7.56 (dd, $J=7.5$, $3.9 \mathrm{~Hz}, 2 \mathrm{H},-\mathrm{Ar}-\mathrm{CH}), 7.30-7.26$ (m, 2H, -Ar-CH), 7.20 (tt, $J=7.4,1.0 \mathrm{~Hz}, 2 \mathrm{H},-\mathrm{Ar}-\mathrm{CH}$ ), 4.28 (dd, $J=10.5,7.1 \mathrm{~Hz}, 1 \mathrm{H},-\mathrm{CH}_{2} \mathrm{OC}(\mathrm{O}) \mathrm{NH}$ ), $4.21(\mathrm{dd}, J=10.5,6.7 \mathrm{~Hz}, 1 \mathrm{H}$, $\mathrm{CH}_{2} \mathrm{OC}(\mathrm{O}) \mathrm{NH}$ ), 4.10 (t, $\left.J=6.7 \mathrm{~Hz}, 1 \mathrm{H},-\mathrm{CHCH}_{2} \mathrm{OC}(\mathrm{O}) \mathrm{NH}\right), 3.94(\mathrm{dd}, J=8.6,4.7 \mathrm{~Hz}$, $1 \mathrm{H},-\mathrm{OC}(\mathrm{O}) \mathrm{NHCH}$ ), $2.02\left(\mathrm{t}, J=7.4 \mathrm{~Hz}, 2 \mathrm{H},-\mathrm{C}(\mathrm{O}) \mathrm{CH}_{2} \mathrm{CH}_{2}\right), 1.72(\mathrm{p}, J=7.5,6.9 \mathrm{~Hz}$, $\left.1 \mathrm{H},-\mathrm{C}(\mathrm{O}) \mathrm{CH}_{2} \mathrm{CH}_{2} \mathrm{CH}_{2}\right), 1.53\left(\mathrm{~h}, \mathrm{~J}=7.1 \mathrm{~Hz}, 3 \mathrm{H},-\mathrm{C}(\mathrm{O}) \mathrm{CH}_{2} \mathrm{CH}_{2} \mathrm{CH}_{2} \mathrm{CH}_{2}\right), 1.33-1.23$ (m, 4H, C(O) $\mathrm{CH}_{2} \mathrm{CH}_{2} \mathrm{CH}_{2} \mathrm{CH}_{2}$ ), 1.13 (s, 9H, $\left.-\left\{\mathrm{CH}_{3}\right\}_{3}\right) ;{ }^{13} \mathrm{C} \mathrm{NMR}\left(100 \mathrm{MHz}, \mathrm{CD}_{3} \mathrm{OD}\right.$ ) $\delta:$ $172.9(-\mathrm{C}=\mathrm{OOH}), 157.1(-\mathrm{NHC}=\mathrm{O}), 144.0(-\mathrm{C}(\mathrm{O}) \mathrm{C}=\mathrm{O}), 143.8$ (-Ar-C), 141.2 (-Ar-C), 127.4 (-Ar- $\mathrm{CH}), 126.8$ (-Ar-CH), 124.8 (-Ar-CH), 124.7 (-Ar-CH), 119.5 (-Ar-CH), 81.5 $\left(-\mathrm{NHC}-\left\{\mathrm{CH}_{3}\right\}_{3}\right), 66.4\left(-\mathrm{CH}_{2} \mathrm{OC}(\mathrm{O}) \mathrm{NH}\right), 55.4(-\mathrm{OC}(\mathrm{O}) \mathrm{NHCH}), 32.5\left(-\mathrm{CH}_{2}\right), 31.9\left(-\mathrm{CH}_{2}\right)$, $28.5\left(-\mathrm{CH}_{2}\right), 25.3\left(-\mathrm{CH}_{3}\right), 24.8\left(-\mathrm{CH}_{2}\right)$; IR $\left(\mathrm{v}_{\max } / \mathrm{cm}^{-1}\right.$, neat): 3331, 2932, 2858, 1715, 1526, 1449, 1211, 1151; HRMS (ESI+) calcd for $\mathrm{C}_{27} \mathrm{H}_{35} \mathrm{~N}_{2} \mathrm{O}_{6}[\mathrm{M}+\mathrm{H}]^{+} 483.2495$, found $483.2497(\Delta=0.4 \mathrm{ppm}) ;[\alpha]_{D}{ }^{20}=10.3\left(\mathrm{c}=0.5, \mathrm{CHCl}_{3}\right)$; Chiral HPLC (isocratic $30 \% 2$ propanol in hexane, $30 \mathrm{~min}$ gradient, $1 \mathrm{~mL} / \mathrm{min}$, Chiralpak-ODH column) retention time $=8.4 \mathrm{~min}$, calcd. ee $=>99 \%$.

(D)-2-(\{[(9H-Fluoren-9-yl)methoxy)carbonyl]amino\}-8-(tert-butoxyamino)-8oxooctanoic acid [Fmoc-D-Asu(NHOtBu)-OH, 5a] 
Synthesised analogously to (L)-2-(\{[(9H-Fluoren-9-yl)methoxy)carbonyl]amino\}-8(tert-butoxyamino)-8-oxooctanoic acid [Fmoc-L-Asu(NHO'Bu)-OH] (5) starting from Boc-D-proline. Chiral HPLC (isocratic 30\% 2-propanol in hexane, 30 min gradient, 1 $\mathrm{mL} / \mathrm{min}$, Chiralpak-ODH column) retention time $=6.3 \mathrm{~min}$, calcd. ee $=>99 \% ;[\alpha]_{D}{ }^{20}=$ $-10.8\left(c \quad 0.5, \mathrm{CHCl}_{3}\right)$.

\section{II(D). Synthesis of 7-Bromoheptan-2-one (6a)}

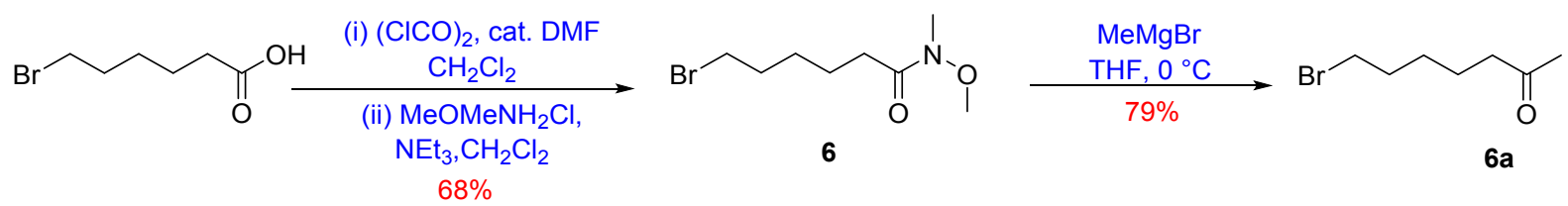

Figure S3. Synthesis of 7-Bromoheptan-2-one (6a)

To a solution of 6-Bromohexanoic acid ( $2.50 \mathrm{~g}, 12.8 \mathrm{mmol}, 1.0$ equiv.) in $\operatorname{dry} \mathrm{CH}_{2} \mathrm{Cl}_{2}$ $(25 \mathrm{~mL})$ at $25{ }^{\circ} \mathrm{C}$ under nitrogen was added dropwise a solution of $2.0 \mathrm{M}$ oxalyl chloride in dry $\mathrm{CH}_{2} \mathrm{Cl}_{2}$ (1.63 $\mathrm{mL}$ in $9.6 \mathrm{~mL}, 19.2 \mathrm{mmol}, 1.5$ equiv.). After dropwise addition of $1.4 \mathrm{~mL}$, dry DMF was added $(6.25 \mu \mathrm{L})$ and gas evolution was initiated. Addition of the remaining oxalyl chloride solution was added. The reaction was stirred at $25{ }^{\circ} \mathrm{C}$ for $3 \mathrm{~h}$, then concentrated in vacuo. The residue was dissolved in dry $\mathrm{CH}_{2} \mathrm{Cl}_{2}(6.25 \mathrm{~mL})$ and added dropwise over $5 \mathrm{~min}$ to a solution of $\mathrm{N}, \mathrm{O}$-dimethyl hydroxylamine hydrochloride (1.53 g, $15.7 \mathrm{mmol}, 1.23$ equiv.) and $\mathrm{Et}_{3} \mathrm{~N}(5.35 \mathrm{~mL})$ in $\mathrm{CH}_{2} \mathrm{Cl}_{2}(50 \mathrm{~mL})$, and the reaction was stirred for $22 \mathrm{~h}$. The reaction mixture was then washed with water $(30 \mathrm{~mL}), 1.0 \mathrm{M}$ aqueous $\mathrm{HCl}(30 \mathrm{~mL}), 1.0 \mathrm{M}$ aqueous $\mathrm{NaOH}(30$ $\mathrm{mL})$ and brine $(30 \mathrm{~mL})$, dried with $\mathrm{MgSO}_{4}$ and concentrated in vacuo to afford 6Bromo- $\mathrm{N}$-methoxy- $\mathrm{N}$-methylhexanamide $6(2.07 \mathrm{~g}, 68 \%)$ as a yellow oil. ${ }^{1} \mathrm{H}$ NMR

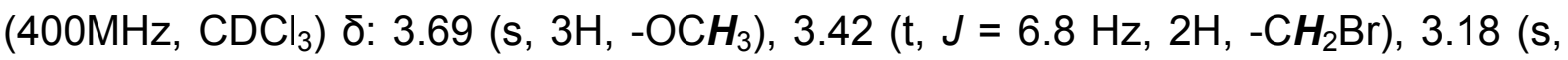
$3 \mathrm{H},-\mathrm{NCH}_{3}$ ), 2.44 (t, $\left.J=7.4 \mathrm{~Hz}, 2 \mathrm{H},-\mathrm{C}(\mathrm{O}) \mathrm{CH}_{2}\right), 1.91-1.86\left(\mathrm{~m}, 2 \mathrm{H},-\mathrm{CH}_{2} \mathrm{CH}_{2} \mathrm{Br}\right), 1.69-$ $1.63\left(\mathrm{~m}, 2 \mathrm{H},-\mathrm{C}(\mathrm{O}) \mathrm{CH}_{2} \mathrm{CH}_{2}\right), 1.53-1.46\left(\mathrm{~m}, 2 \mathrm{H},-\mathrm{CH}_{2} \mathrm{CH}_{2} \mathrm{CH}_{2} \mathrm{Br}\right) ;{ }^{33} \mathrm{C} \mathrm{NMR}(100 \mathrm{MHz}$, $\left.\mathrm{CDCl}_{3}\right)$ ס: $174.3(-\mathrm{C}=\mathrm{O}), 61.2\left(-\mathrm{OCH}_{3}\right), 33.7\left(-\mathrm{CH}_{2} \mathrm{Br}\right), 32.3\left(-\mathrm{NCH}_{3}\right), 31.6 \quad(-$ $\left.\mathrm{C}(\mathrm{O}) \mathrm{CH}_{2}\right), 28.0\left(-\mathrm{CH}_{2} \mathrm{CH}_{2} \mathrm{CH}_{2} \mathrm{Br}\right), 23.7\left(-\mathrm{C}(\mathrm{O}) \mathrm{CH}_{2} \mathrm{CH}_{2}\right)$; IR ( $\mathrm{V}_{\text {max }} / \mathrm{cm}^{-1}$, neat): 2932, 2014, 1659, 1412, 1381, 1319, 1265, 1173, 1111, 995, 640, 563; HRMS (ESI+) calcd for $\mathrm{C}_{8} \mathrm{H}_{16} \mathrm{BrNO}_{2} \mathrm{Na}[\mathrm{M}+\mathrm{Na}]^{+} 260.0257$, found $260.0270(\Delta=3.3 \mathrm{ppm})$.

7-Bromoheptan-2-one (6a) 
To a solution of 6-Bromo- $N$-methoxy- $N$-methylhexanamide (6) (1.0 g, 4.22 mmol, 1.0 equiv.) in dry THF $(12.5 \mathrm{ml})$ at $0{ }^{\circ} \mathrm{C}$ under nitrogen was added a solution of $3.0 \mathrm{M}$ methyl magnesium bromide in $\mathrm{Et}_{2} \mathrm{O}(2.25 \mathrm{~mL}, 6.32 \mathrm{mmol}, 1.5$ equiv.). The reaction mixture was stirred at $0{ }^{\circ} \mathrm{C}$ for $4.5 \mathrm{~h}$ and a white precipitate formed. The reaction mixture was cooled to $0{ }^{\circ} \mathrm{C}$ and $1.0 \mathrm{M}$ aqueous $\mathrm{HCl}(12.5 \mathrm{~mL})$ was added slowly to the reaction mixture, which was then stirred for a further $0.5 \mathrm{~h}$. THF was removed in vacuo and the aqueous phase was extracted with EtOAc $(3 \times 25 \mathrm{~mL})$. The combined organic phases were then washed with brine $(25 \mathrm{~mL})$, dried with $\mathrm{MgSO}_{4}$ and concentrated in vacuo. Purification was carried out by flash column chromatography (30\% ethyl acetate-petroleum ether). Fractions containing the product were combined and the solvent removed in vacuo to give 7-Bromoheptan-2-one (6a) (640 mg, 79\%) as a yellow oil. ${ }^{1} \mathrm{H}$ NMR $\left(400 \mathrm{MHz} \mathrm{CDCl}_{3}\right) \delta: 3.34(\mathrm{t}, J=6.7 \mathrm{~Hz}, 2 \mathrm{H}$, $\mathrm{CH}_{2} \mathrm{Br}$ ), $2.38\left(\mathrm{t}, \mathrm{J}=7.3 \mathrm{~Hz}, 2 \mathrm{H}, \mathrm{CH}_{2} \mathrm{CH}_{2} \mathrm{Br}\right), 2.07$ (s, 3H, $\left.-\mathrm{CH}_{3}\right), 1.84-1.76(\mathrm{~m}, 2 \mathrm{H}$, $\left.\mathrm{CH}_{2} \mathrm{CH}_{2} \mathrm{CH}_{2} \mathrm{Br}\right), \quad 1.57-1.50\left(\mathrm{~m}, 2 \mathrm{H},-\mathrm{CH}_{2} \mathrm{CH}_{2} \mathrm{CH}_{2} \mathrm{CH}_{2} \mathrm{Br}\right), 1.41-1.33(\mathrm{~m}, 2 \mathrm{H}$, -

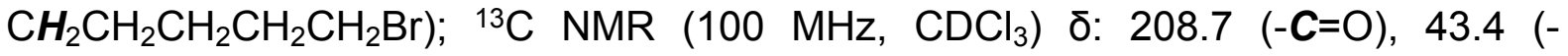
$\left.\mathrm{C}(\mathrm{O}) \mathrm{CH}_{2}\right), 33.6\left(-\mathrm{CH}_{2} \mathrm{Br}\right), 32.5\left(-\mathrm{CH}_{2} \mathrm{CH}_{2} \mathrm{Br}\right), 29.9\left(-\mathrm{CH}_{3}\right), 27.7\left(-\mathrm{CH}_{2} \mathrm{CH}_{2} \mathrm{CH}_{2} \mathrm{Br}\right)$, $22.8\left(-\mathrm{CH}_{2} \mathrm{CH}_{2} \mathrm{CH}_{2} \mathrm{CH}_{2} \mathrm{Br}\right)$; IR ( $\mathrm{V}_{\text {max }} / \mathrm{cm}^{-1}$, neat): 2932, 2014, 1659, 1412, 1381, 1319, 1265, 1173, 1111, 995, 640, 563; HRMS $\left(\mathrm{ESI}^{+}\right)$calcd for $\mathrm{C}_{8} \mathrm{H}_{16} \mathrm{BrNO}_{2} \mathrm{Na}[\mathrm{M}+\mathrm{Na}]^{+}$ 260.0257, found $260.0262(\Delta=1.2 \mathrm{ppm})$.

\section{II(E). Synthesis of 8-Bromooctan-3-one (6b)}

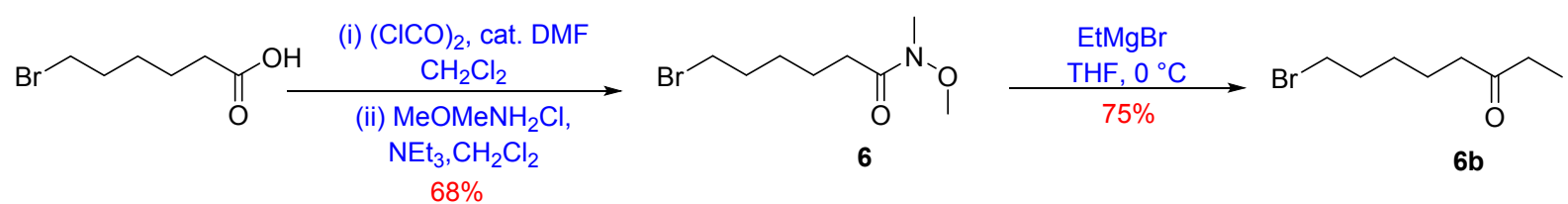

Figure S4. Synthesis of 8-Bromooctan-3-one (6b)

To a solution of 6-Bromo- $N$-methoxy- $N$-methylhexanamide (6) $(1.10 \mathrm{~g}, 4.62 \mathrm{mmol}$, 1.0 equiv. $)$ in dry $\operatorname{THF}(12.5 \mathrm{ml})$ at $0{ }^{\circ} \mathrm{C}$ under nitrogen was added a solution of $3.0 \mathrm{M}$ ethyl magnesium bromide in $\mathrm{Et}_{2} \mathrm{O}$ (2.31 mL, $6.93 \mathrm{mmol}, 1.5$ equiv.). The reaction mixture was stirred at $0{ }^{\circ} \mathrm{C}$ for $4.5 \mathrm{~h}$ and a white precipitate formed. The reaction mixture was cooled to $0{ }^{\circ} \mathrm{C}$ and $1.0 \mathrm{M}$ aqueous $\mathrm{HCl}(12.5 \mathrm{~mL})$ was added slowly to the reaction mixture, which was then stirred for a further $0.5 \mathrm{~h}$. THF was removed in vacuo and the aqueous phase was extracted with EtOAc $(3 \times 25 \mathrm{~mL})$. The combined organic phases were then washed with brine $(25 \mathrm{~mL})$, dried with $\mathrm{MgSO}_{4}$ and 
concentrated in vacuo. Purification was carried out by flash column chromatography (35\% ethyl acetate-petroleum ether). Fractions containing the product were combined and the solvent removed in vacuo to give 8-Bromooctan-3-one (6b) (905 mg, $75 \%)$ as a yellow oil. ${ }^{1} \mathrm{H} \mathrm{NMR}\left(400 \mathrm{MHz}, \mathrm{CDCl}_{3}\right) \delta: 3.40(\mathrm{t}, \mathrm{J}=6.8 \mathrm{~Hz}, 2 \mathrm{H}$, $\mathrm{CH}_{2} \mathrm{Br}$ ), 2.44 (q, $\left.J=7.3 \mathrm{~Hz}, 2 \mathrm{H},-\mathrm{C}(\mathrm{O}) \mathrm{CH}_{2} \mathrm{CH}_{2}\right), 2.40$ (q, $J=7.3 \mathrm{~Hz}, 2 \mathrm{H}$, $\left.\mathrm{C}(\mathrm{O}) \mathrm{CH}_{2} \mathrm{CH}_{3}\right), 1.90-1.83\left(\mathrm{~m}, 2 \mathrm{H},-\mathrm{CH}_{2} \mathrm{CH}_{2} \mathrm{Br}\right), 1.64-1.56\left(\mathrm{~m}, 2 \mathrm{H},-\mathrm{C}(\mathrm{O}) \mathrm{CH}_{2} \mathrm{CH}_{2}\right)$, 1.47-1.39 (t, $J=7.4 \mathrm{~Hz}, 2 \mathrm{H},-\mathrm{CH}_{2} \mathrm{CH}_{2} \mathrm{CH}_{2} \mathrm{Br}$ ), 1.05 (t, $J=7.4 \mathrm{~Hz}, 3 \mathrm{H},-\mathrm{CH}_{3}$ ); ${ }^{13} \mathrm{C}$ NMR (100 MHz, CDCl 3 ) ס: $211.4(-\mathrm{C}=\mathrm{O}), 42.1\left(-\mathrm{C}(\mathrm{O}) \mathrm{CH}_{2}\right), 36.1\left(-\mathrm{C}(\mathrm{O}) \mathrm{CH}_{2}\right), 33.7(-$ $\left.\mathrm{CH}_{2} \mathrm{Br}\right), 32.7\left(-\mathrm{CH}_{2} \mathrm{CH}_{2} \mathrm{Br}\right), 27.9\left(-\mathrm{CH}_{2} \mathrm{CH}_{2} \mathrm{CH}_{2} \mathrm{Br}\right), 23.0\left(-\mathrm{C}(\mathrm{O}) \mathrm{CH}_{2} \mathrm{CH}_{2}\right), 7.94\left(-\mathrm{CH}_{3}\right)$; IR ( $\mathrm{V}_{\max } / \mathrm{cm}^{-1}$, neat): 2932, 1713, 1451, 1412, 1366, 1250, 1111, 1018, 980, 733, 640, 563; HRMS $\left(\mathrm{ESI}^{+}\right)$calcd for $\mathrm{C}_{8} \mathrm{H}_{15} \mathrm{BrONa}[\mathrm{M}+\mathrm{Na}]^{+} 229.0198$, found $229.0192(\Delta=$ $1.4 \mathrm{ppm})$.

\section{II(F). Synthesis of (L)-2-((((9H-Fluoren-9-yl)methoxy)carbonyl)amino)-8- oxononanoic acid (Fmoc-L-Aon-OH, 9)}

(S)-(\{2-[1-(2-Fluorobenzyl)benzyl)pyrrolidine-2-carboxamide]phenyl\}phenylmethylene)-(S)-(heptan-2-one) glycinato- $\left.N, N^{\prime}, N^{\prime \prime}, O\right\}$ nickel(II) (7a)

Freshly ground sodium hydroxide ( $232.9 \mathrm{mg}, 5.8 \mathrm{mmol}, 5.0$ equiv.) was taken up in DMF $(5.0 \mathrm{~mL})$ with stirring at $0{ }^{\circ} \mathrm{C}$ under an atmosphere of nitrogen. (S)-(\{2-[1-(2Fluorobenzyl)-pyrrolidine-2-carboxamide]phenyl\}phenylmethylene)-glycinato$\left.N, N^{\prime}, N ", O\right\}$ nickel(II) (4) (600 mg, $1.2 \mathrm{mmol}, 1.0$ equiv.) was added and stirred for 2 minutes; the solution darkened in colour and the ice bath was removed. A solution of 7-Bromoheptan-2-one (6a) $(691.3 \mathrm{mg}, 3.6 \mathrm{mmol} 3.0$ equiv.) was added to reaction mixture. The solution was left to stir for 30 minutes at room temperature, then quenched with the addition of water. The mixture was concentrated in vacuo, taken up in water $(10.0 \mathrm{~mL})$ and extracted with dichloromethane $(3 \times 15.0 \mathrm{~mL})$. The combined organic extracts were washed with aqueous lithium chloride solution $(5 \%$ $\mathrm{v} / \mathrm{v})(3 \times 20.0 \mathrm{~mL})$, brine $(3 \times 20.0 \mathrm{~mL})$, dried $\left(\mathrm{MgSO}_{4}\right)$ and concentrated in vacuo. Purification by flash column chromatography $\left(7 \% \mathrm{CH}_{3} \mathrm{OH}-\mathrm{CH}_{2} \mathrm{Cl}_{2}\right)$ gave the title compound (7a) as a deep red-orange solid (669 mg, 89\%); m.p: $174-176{ }^{\circ} \mathrm{C} ;{ }^{1} \mathrm{H}$ NMR (400 MHz, $\mathrm{CD}_{3} \mathrm{OD}$ ) $\delta: 8.26$ (td, $J=7.2,2.9 \mathrm{~Hz}, 1 \mathrm{H},-\mathrm{Ar}-\mathrm{CH}$ ), 7.84 (ddd, $J=8.7$, 3.9, $1.1 \mathrm{~Hz}, 1 \mathrm{H},-\mathrm{Ar}-\mathrm{CH}), 7.54-7.45(\mathrm{~m}, 2 \mathrm{H},-\mathrm{Ar}-\mathrm{CH}), 7.42(\mathrm{tt}, J=7.6,6.9,2.0 \mathrm{~Hz}, 1 \mathrm{H}$, -Ar-CH), 7.28 (dt, J = 7.1, 1.9 Hz, 1H, -Ar-CH), 7.16-7.10 (m, 2H, -Ar-CH), 7.03 (ddd, $J=8.7,6.9,1.8 \mathrm{~Hz}, 1 \mathrm{H},-\mathrm{Ar}-\mathrm{CH}), 6.99-6.94(\mathrm{~m}, 2 \mathrm{H},-\mathrm{Ar}-\mathrm{CH}), 6.63$ (ddd, $J=8.1,6.9$, 
$1.1 \mathrm{~Hz}, 1 \mathrm{H},-\mathrm{Ar}-\mathrm{CH}), 6.57$ (dt, $J=8.2,1.6 \mathrm{~Hz}, 1 \mathrm{H},-\operatorname{Ar}-\mathrm{CH}), 4.10(\mathrm{~d}, J=12.7 \mathrm{~Hz}, 1 \mathrm{H},-$ $\mathrm{N}-\mathrm{CHH}$ ), 3.79 (dt, J = 8.1, 4.1 Hz, 1H, $-\mathrm{CH}), 3.64$ (dt, J = 12.9, $1.4 \mathrm{~Hz}, 1 \mathrm{H},-\mathrm{N}-\mathrm{CH} \boldsymbol{H})$, 3.49 (ddd, $J=15.4,10.2,6.8 \mathrm{~Hz}, 2 \mathrm{H},-\mathrm{CH}_{2}$ ), 3.25-3.23 (m, 1H, -NC(O)CH), 2.66-2.53 $\left(\mathrm{m}, 2 \mathrm{H},-\mathrm{CH}_{2}\right), 2.33(\mathrm{t}, \mathrm{J}=7.3 \mathrm{~Hz}, 1 \mathrm{H},-\mathrm{CH}), 2.20-2.09\left(\mathrm{~m}, 2 \mathrm{H},-\mathrm{CH}_{2}\right), 2.00(\mathrm{~s}, 3 \mathrm{H},-$ $\left.\mathrm{CH}_{3}\right), 1.95-1.89\left(\mathrm{~m}, 1 \mathrm{H},-\mathrm{CH}_{2}\right), 1.56-1.45\left(\mathrm{~m}, 2 \mathrm{H},-\mathrm{CH}_{2}\right), 1.44-1.37\left(\mathrm{~m}, 2 \mathrm{H},-\mathrm{CH}_{2}\right)$, $1.21\left(\mathrm{dt}, J=15.4,7.3 \mathrm{~Hz}, 1 \mathrm{H},-\mathrm{CH}_{2}\right), 1.12\left(\mathrm{~s}, 1 \mathrm{H},-\mathrm{CH}_{2}\right), 1.10-1.02\left(\mathrm{~m}, 2 \mathrm{H},-\mathrm{CH}_{2}\right) ;{ }^{13} \mathrm{C}$

NMR (100 MHz, CD $\left.{ }_{3} \mathrm{OD}\right)$ ס: 210.3 (-C=O), $180.9(-\mathrm{O}-\boldsymbol{C}=\mathrm{O}), 171.4(-\mathrm{NH}-\boldsymbol{C}=\mathrm{O}), 163.0$ (-Ar-C), 160.6 (-Ar-CF), 141.6 (-Ar-C), 133.7 (-Ar-CH), 133.1 (-Ar-CH), 131.0 (-Ar$\mathrm{CH}), 129.7$ (-Ar-CH), 128.9 (-Ar-CH), 128.8 (-Ar- $\mathrm{CH}), 127.7$ (-Ar- $\mathrm{CH}), 127.0$ (-Ar$\mathrm{CH}), 126.8$ (-Ar-CH), 124.5 (-Ar-C), 123.5 (-Ar-CH), 121.9 (-Ar-C), 121.7 (-Ar-C), 120.9 (-Ar-CH), 115.7 (-Ar-C), $115.5(-\mathrm{Ar}-\mathrm{CH}), 101.5(-\mathrm{Ar}-\mathrm{CH}), 71.5\left(-\mathrm{CH}_{2}\right), 70.1$ ($\mathrm{CH}), 57.4(-\mathrm{NC}(\mathrm{O}) \mathrm{CH}), 56.4\left(-\mathrm{CH}_{2}\right), 42.6\left(-\mathrm{CH}_{2}\right), 36.0\left(-\mathrm{CH}_{2}\right), 34.5\left(-\mathrm{CH}_{2}\right), 30.4(-$ $\left.\mathrm{CH}_{2}\right), 28.9\left(-\mathrm{CH}_{2}\right), 28.4\left(-\mathrm{CH}_{2}\right), 28.1\left(-\mathrm{CH}_{2}\right), 24.8\left(-\mathrm{CH}_{2}\right), 23.6\left(-\mathrm{CH}_{2}\right), 23.4\left(-\mathrm{CH}_{2}\right)$, $23.0\left(-\mathrm{CH}_{2}\right), 19.9\left(-\mathrm{CH}_{3}\right)$; ${ }^{19} \mathrm{~F}$ NMR (376 MHz; $\left.\mathrm{CD}_{3} \mathrm{OD}\right) \delta:-115.0$; IR ( $\mathrm{v}_{\text {max }} / \mathrm{cm}^{-1}$, neat): 2930, 2369, 1705, 1660, 1625, 1569, 1543, 1409, 1258, 1155, 1110, 1068, 1026 , 970, 840, 750, 710, 650; HRMS $\left(\mathrm{ESI}^{+}\right)$calcd for $\mathrm{C}_{34} \mathrm{H}_{36} \mathrm{FN}_{3} \mathrm{NiO}{ }_{4} \mathrm{Na}[\mathrm{M}+\mathrm{Na}]^{+}$ 650.1941 , found $650.1943(\Delta=0.4 \mathrm{ppm})$.

\section{(L)-2-Amino-8-oxononanoic acid [L-Aon-OH, 8a]}

(S)-(\{2-[1-(2-Fluorobenzyl)benzyl)pyrrolidine-2-carboxamide]-

phenyl\}phenylmethylene)-(S)-(heptan-2-one) glycinato- $N, N^{\prime}, N^{\prime \prime}$, O\} nickel(II) (7a) (500 mg, 0.80 mmol, 1 equiv.) and 8-hydroxyquinoline (289.3 mg, 1.99 mmol, 2.5 equiv.) were taken up in acetonitrile $(10 \mathrm{~mL})$. Water $(1.5 \mathrm{~mL})$ was added and the mixture heated to $30{ }^{\circ} \mathrm{C}$ for $18 \mathrm{~h}$. The mixture was filtered and the precipitate washed with water. The filtrate was extracted with $\mathrm{CH}_{2} \mathrm{Cl}_{2}(3 \times 20 \mathrm{~mL})$. The aqueous layer was lyophilised to give (L)-2-amino-8-oxononanoic acid (8a) as a white fluffy powder (141 mg, 94\%); m.p: 190-192 ${ }^{\circ} \mathrm{C} ;{ }^{1} \mathrm{H}$ NMR (400 MHz, D 2 ) $\delta: 3.68$ (t, J = $6.1 \mathrm{~Hz}, 1 \mathrm{H},-$ $\left.\mathrm{CHNH}_{2}\right), 2.49\left(\mathrm{t}, J=7.4 \mathrm{~Hz}, 2 \mathrm{H},-\mathrm{C}(\mathrm{O}) \mathrm{CH}_{2}\right), 2.13\left(\mathrm{~s}, 3 \mathrm{H},-\mathrm{C}(\mathrm{O}) \mathrm{CH}_{3}\right), 1.80-1.76(\mathrm{~m}$, $\left.2 \mathrm{H},-\mathrm{CH}_{2} \mathrm{CHNH}_{2}\right), 1.48\left(\mathrm{q}, J=7.4 \mathrm{~Hz}, 2 \mathrm{H},-\mathrm{C}(\mathrm{O}) \mathrm{CH}_{2} \mathrm{CH}_{2}\right), 1.33-1.23(\mathrm{~m}, 4 \mathrm{H}$, $\mathrm{CH}_{2} \mathrm{CH}_{2} \mathrm{CHNH}_{2}$ and $\left.-\mathrm{C}(\mathrm{O}) \mathrm{CH}_{2} \mathrm{CH}_{2} \mathrm{CH}_{2}\right) ;{ }^{13} \mathrm{C}$ NMR (100 MHz, D $\left.{ }_{2} \mathrm{O}\right) \delta: 217.5(-\mathrm{C}=\mathrm{O})$, $174.7(-\mathrm{C}=\mathrm{OOH}), 54.6\left(-\mathrm{CHNH}_{2}\right), 43.1\left(-\mathrm{C}(\mathrm{O}) \mathrm{CH}_{2}\right), 30.1\left(-\mathrm{CH}_{2} \mathrm{CHNH}_{2}\right), 29.3\left(-\mathrm{CH}_{3}\right)$, $27.8\left(-\mathrm{CH}_{2}\right), 24.0\left(-\mathrm{CH}_{2}\right), 22.9\left(-\mathrm{C}(\mathrm{O}) \mathrm{CH}_{2} \mathrm{CH}_{2}\right) ; \quad$ IR $\left(\mathrm{v}_{\max } / \mathrm{cm}^{-1}\right.$, neat): 2971, 2934, $2865,1705,1579,1510,1462,1441,1414,1184,1117,1076,972,855,810,660$, 
552; HRMS $\left(\mathrm{ESI}^{+}\right)$calcd for $\mathrm{C}_{9} \mathrm{H}_{17} \mathrm{NO}_{3} \mathrm{Na}[\mathrm{M}+\mathrm{Na}]^{+} 210.1106$, found $210.1113(\Delta=$ $1.4 \mathrm{ppm})$.

\section{(L)-2-((((9H-Fluoren-9-yl)methoxy)carbonyl)amino)-8-oxononanoic acid (Fmoc-} L-Aon-OH, 9)

(L)-2-Amino-8-oxononanoic acid (8a) (300 mg, $1.60 \mathrm{mmol}, 1$ equiv.) and potassium carbonate $(443.1 \mathrm{mg}, 3.21 \mathrm{mmol}, 2$ equiv.) were taken up in water $(2.0 \mathrm{~mL})$ and cooled to $0{ }^{\circ} \mathrm{C}$. Fmoc-succinimide (539.7 mg, $1.60 \mathrm{mmol}, 1.0$ equiv.) was dissolved in dioxane $(5 \mathrm{~mL})$ and added dropwise to the aqueous solution over 20 mins. The reaction was warmed to room temperature and left to stir for $24 \mathrm{~h}$. Excess water was added to the mixture then extracted with $\mathrm{CH}_{2} \mathrm{Cl}_{2}(3 \times 15 \mathrm{~mL})$. The combined organic layers were back extracted with sodium bicarbonate $(3 \times 20 \mathrm{~mL})$ then the aqueous acidified to $\mathrm{pH} 1$ with $3 \mathrm{M}$ hydrochloric acid. The aqueous fractions were then extracted with $\mathrm{CH}_{2} \mathrm{Cl}_{2}(3 \times 25 \mathrm{~mL})$. The combined organic layers were washed with brine $(3 \times 30 \mathrm{~mL})$, dried $\left(\mathrm{MgSO}_{4}\right)$ and concentrated in vacuo. Purification was carried out by flash column chromatography $\left(10 \% \mathrm{CH}_{3} \mathrm{OH}-\mathrm{CH}_{2} \mathrm{Cl}_{2}\right)$. Fractions containing the product were combined and the solvent removed in vacuo to give $(S)-2-(((9 H-$ fluoren-9-yl)methoxy)carbonyl)amino)-8-oxononanoic acid (9) as an off white powder

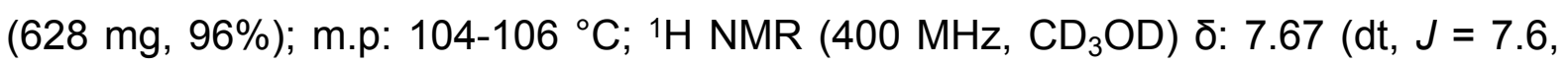
$0.9 \mathrm{~Hz}, 2 \mathrm{H},-\mathrm{Ar}-\mathrm{CH}$ ), 7.58-7.54 (m, 2H, -Ar-CH), 7.27 (td, $J=7.3,1.0 \mathrm{~Hz}, 2 \mathrm{H},-$ Ar$\mathrm{CH}), 7.19$ (td, $J=7.5,1.2 \mathrm{~Hz}, 2 \mathrm{H},-\mathrm{Ar}-\mathrm{CH}), 4.24\left(\mathrm{~d}, J=7.0 \mathrm{~Hz}, 2 \mathrm{H},-\mathrm{CH}_{2} \mathrm{OC}(\mathrm{O}) \mathrm{NH}\right.$ ), $4.10\left(\mathrm{t}, J=7.0 \mathrm{~Hz}, 1 \mathrm{H},-\mathrm{CHCH}_{2} \mathrm{OC}(\mathrm{O}) \mathrm{NH}\right), 4.02(\mathrm{dd}, J=9.2,4.8 \mathrm{~Hz}, 1 \mathrm{H},-$ $\mathrm{OC}(\mathrm{O}) \mathrm{NHCH}$ ), 2.34 (t, $J=7.3 \mathrm{~Hz}, 2 \mathrm{H},-\mathrm{C}(\mathrm{O}) \mathrm{CH}_{2}$ ), 1.99 (s, 3H, $\left.-\mathrm{C}(\mathrm{O}) \mathrm{CH}_{3}\right), 1.77-1.68$ $\left(\mathrm{m}, 1 \mathrm{H},-\mathrm{NHCHCH}_{2}\right), 1.56$ (ddt, $\left.J=14.3,9.1,4.2 \mathrm{~Hz}, 1 \mathrm{H},-\mathrm{NHCHCH}_{2}\right), 1.46-1.42(\mathrm{~m}$, $2 \mathrm{H},-\mathrm{C}(\mathrm{O}) \mathrm{CH}_{2} \mathrm{CH}_{2}$ ), 1.31-1.26 (m, 2H, $-\mathrm{CH}_{2} \mathrm{CH}_{2} \mathrm{CHNH}$ ), 1.20 (tdd, $J=10.3,5.9,3.1$ $\left.\mathrm{Hz}, 2 \mathrm{H},-\mathrm{C}(\mathrm{O}) \mathrm{CH}_{2} \mathrm{CH}_{2} \mathrm{CH}_{2}\right) ;{ }^{13} \mathrm{C}$ NMR (100 MHz, $\left.\mathrm{CD}_{3} \mathrm{OD}\right)$ ס: 210.7(-C=O), 175.0 ($\mathrm{C}=\mathrm{OOH}$ ), 157.3 (-NHC=O), 144.0 (-Ar-C), 141.2 (-Ar-C), 127.4 (-Ar-CH), 126.8 (-Ar$\mathrm{CH}), 126.8$ (-Ar-CH), 124.9 (-Ar-CH), 124.9 (-Ar-CH), 119.5 (-Ar-CH), 66.5 ($\left.\mathrm{CH}_{2} \mathrm{OC}(\mathrm{O}) \mathrm{NH}\right), 54.0(-\mathrm{OC}(\mathrm{O}) \mathrm{NHCH}), 42.7\left(-\mathrm{C}(\mathrm{O}) \mathrm{CH}_{2} \mathrm{CH}_{2}\right), 31.2\left(-\mathrm{C}(\mathrm{O}) \mathrm{CH}_{2}\right), 28.4$ ($\left.\mathrm{CH}_{2}\right), 28.3\left(-\mathrm{CH}_{2}\right)$, 25.3(-C(O) $\left.\mathrm{CH}_{2} \mathrm{CH}_{2}\right), 23.2\left(-\mathrm{CH}_{3}\right)$; IR ( $\mathrm{v}_{\text {max }} / \mathrm{cm}^{-1}$, neat): 3331, 2932, 2858, 1715, 1526, 1449, 1211, 1151; HRMS $\left(\mathrm{ESI}^{+}\right)$calcd for $\mathrm{C}_{24} \mathrm{H}_{28} \mathrm{NO}_{5}[\mathrm{M}+\mathrm{H}]^{+}$ 410.1967; found $410.1966(\Delta=0.2 \mathrm{ppm}) ;[\alpha]_{D}^{20}=17.3\left(\mathrm{c}=0.5, \mathrm{CHCl}_{3}\right)$. 


\section{II(G). Synthesis of (L)-2((((9H-Fluoren-9-yl)methoxy)carbonyl)amino)-8-}

oxodecanoic acid (Fmoc-L-Aod-OH, 10)

(S)-(\{2-[1-(2-Fluorobenzyl)benzyl)pyrrolidine-2-carboxamide]phenyl\}phenylmethylene)-(S)-(octan-3-one) glycinato-N,N',N", O\} nickel(II) (7b)

Freshly ground sodium hydroxide ( $389 \mathrm{mg}, 9.7 \mathrm{mmol}, 5.0$ equiv.) was taken up in DMF $(8.0 \mathrm{~mL})$ with stirring at $0{ }^{\circ} \mathrm{C}$ under an atmosphere of nitrogen. (S)-(\{2-[1-(2Fluorobenzyl)-pyrrolidine-2-carboxamide]phenyl\}phenylmethylene)-glycinato$N, N^{\prime}, N^{\prime \prime}, O$ \} nickel(II) (1) (1.0 g, $1.9 \mathrm{mmol}, 1.0$ equiv.) was added and stirred for $2 \mathrm{~min}$, the solution darkened in colour and the ice bath was removed. A solution of 8bromooctan-3-one (6b) (1.2 g, $5.7 \mathrm{mmol}, 3.0$ equiv.) in dry DMF (10 mL) was added to reaction mixture. The solution was stirred for $30 \mathrm{~min}$. at room temperature, then quenched with the addition of water. The mixture was concentrated in vacuo, taken up in water $(10.0 \mathrm{~mL})$ and extracted with dichloromethane $(3 \times 25.0 \mathrm{~mL})$. The combined organic extracts were washed with aqueous lithium chloride solution (5\% $\mathrm{v} / \mathrm{v})(3 \times 30.0 \mathrm{~mL})$, brine $(3 \times 30.0 \mathrm{~mL})$, dried $\left(\mathrm{MgSO}_{4}\right)$ and concentrated in vacuo. Purification by flash column chromatography $\left(8 \% \mathrm{CH}_{3} \mathrm{OH}-\mathrm{CH}_{2} \mathrm{Cl}_{2}\right)$ gave the title compound (7b) as a deep red solid (1.1 g, 88\%); m.p: 183-185 ${ }^{\circ} \mathrm{C}$; ${ }^{1} \mathrm{H}$ NMR (400 $\mathrm{MHz}, \mathrm{CD}_{3} \mathrm{OD}$ ) $\delta: ~ 8.38-8.33(\mathrm{~m}, 1 \mathrm{H},-\mathrm{Ar}-\mathrm{CH}), 7.93(\mathrm{dd}, J=8.7,1.1 \mathrm{~Hz}, 1 \mathrm{H},-\mathrm{Ar}-\mathrm{CH}$ ), 7.64-7.50 (m, 3H, -Ar-CH), 7.38 (dt, $J=7.3,1.8 \mathrm{~Hz}, 1 \mathrm{H},-\mathrm{Ar}-\mathrm{CH}$ ), 7.24 (ddd, $J=7.2$, 3.9, $2.0 \mathrm{~Hz}, 2 \mathrm{H},-\mathrm{Ar}-\mathrm{CH}$ ), 7.14 (ddd, $J=8.7,6.9,1.8 \mathrm{~Hz}, 1 \mathrm{H},-\mathrm{Ar}-\mathrm{CH}$ ), 7.07 (ddt, $J=$ 8.9, 7.2, 2.0 Hz, 2H, -Ar-CH), 6.74 (ddd, $J=8.1,6.9,1.2 \mathrm{~Hz}, 1 \mathrm{H},-\mathrm{Ar}-\mathrm{CH}$ ), 6.67 (dd, $J$ $=8.2,1.8 \mathrm{~Hz}, 1 \mathrm{H},-\mathrm{Ar}-\mathrm{CH}), 4.20(\mathrm{dd}, J=12.9,1.1 \mathrm{~Hz}, 1 \mathrm{H},-\mathrm{N}-\mathrm{CHH}), 3.89$ (dd, $J=$ 8.0, 3.5 Hz, $1 \mathrm{H},-\mathrm{CH}), 3.75(\mathrm{dd}, J=12.8,1.0 \mathrm{~Hz}, 1 \mathrm{H},-\mathrm{N}-\mathrm{CH} H), 3.63-3.57(\mathrm{~m}, 2 \mathrm{H},-$ $\left.\mathrm{CH}_{2}\right), 3.34(\mathrm{~d}, \mathrm{~J}=6.1 \mathrm{~Hz}, 1 \mathrm{H},-\mathrm{NC}(\mathrm{O}) \mathrm{CH}), 2.75-2.69\left(\mathrm{~m}, 2 \mathrm{H},-\mathrm{CH}_{2}\right), 2.46-2.38(\mathrm{~m}$, $\left.4 \mathrm{H},-\mathrm{C}(\mathrm{O}) \mathrm{CH}_{2} \mathrm{CH}_{2}\right), 2.29-2.21\left(\mathrm{~m}, 2 \mathrm{H},-\mathrm{CH}_{2}\right), 2.17-1.94\left(\mathrm{~m}, 2 \mathrm{H},-\mathrm{CH}_{2}\right), 1.65-1.47(\mathrm{~m}$, $\left.4 \mathrm{H},-\mathrm{CH}_{2}\right), 1.18-1.12\left(\mathrm{~m}, 2 \mathrm{H},-\mathrm{CH}_{2}\right), 0.99$ (t, $\left.J=7.3 \mathrm{~Hz}, 3 \mathrm{H},-\mathrm{CH}_{3}\right) ;{ }^{13} \mathrm{C}$ NMR $(100$

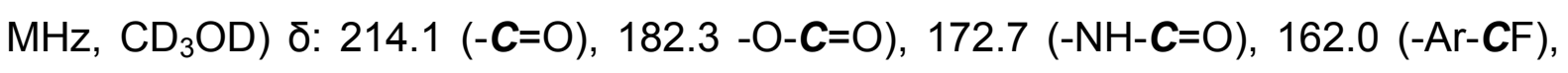
143.0 (-Ar-C), 135.1 (-Ar-CH), 134.5 (-Ar-CH), 133.1 (-Ar-CH), 132.5 (-Ar-CH), 132.5 (-Ar-CH), 131.1 (-Ar-CH), 130.3 (-Ar-CH), 130.2 (-Ar-CH), 129.2 (-Ar- $\mathrm{CH}), 128.4$ (-Ar$\mathrm{CH}), 128.2$ (-Ar-C), 126.0 (-Ar-C), 124.9 (-Ar-CH), 123.2 (-Ar-C), 122.4 (-Ar-C), 117.1 (-Ar-C), $116.9(-\mathrm{Ar}-\mathrm{CH}), 72.9\left(-\mathrm{CH}_{2}\right), 71.5(-\mathrm{CH}), 58.8(-\mathrm{NC}(\mathrm{O}) \mathrm{CH}), 57.8\left(-\mathrm{CH}_{2}\right), 42.7$ $\left(-\mathrm{CH}_{2}\right), 36.6\left(-\mathrm{CH}_{2}\right), 35.9\left(-\mathrm{CH}_{2}\right), 31.8\left(-\mathrm{CH}_{2}\right), 29.6\left(-\mathrm{CH}_{2}\right), 26.2\left(-\mathrm{CH}_{2}\right), 24.8\left(-\mathrm{CH}_{2}\right)$, $24.5\left(-\mathrm{CH}_{2}\right), 8.1\left(-\mathrm{CH}_{3}\right)$; ${ }^{19} \mathrm{~F}$ NMR $\left(376 \mathrm{MHz}, \mathrm{CD}_{3} \mathrm{OD}\right) \delta:-115.0$; IR $\left(\mathrm{V}_{\mathrm{max}} / \mathrm{cm}^{-1}\right.$, neat): 
2932, 2361, 1705, 1666, 1636, 1589, 1543, 1489, 1443, 1335, 1258, 1165, 1111, 1065, 1026, 972, 849, 756, 710, 625, 563, 532, 501, 417; HRMS (ESI ${ }^{+}$) calcd for $\mathrm{C}_{35} \mathrm{H}_{38} \mathrm{FN}_{3} \mathrm{NiO}_{4} \mathrm{Na}[\mathrm{M}+\mathrm{Na}]^{+} 664.2092$, found 664.2084 ( $\left.\Delta=1.7 \mathrm{ppm}\right)$.

\section{(L)-2-Amino-8-oxodecanoic acid [L-Aod-OH, 8b]}

(S)-(\{2-[1-(2-Fluorobenzyl)benzyl)pyrrolidine-2carboxamide]phenyl\}phenylmethylene)-(S)-8-oxooctylglycinato- $N, N^{\prime}, N^{\prime \prime}$, O\}nickel(II) (7b) $(1.0 \mathrm{~g}, 1.56 \mathrm{mmol}, 1.0$ equiv.) and 8-hydroxyquinoline (566.3 mg, $3.9 \mathrm{mmol}, 2.5$ equiv.) were taken up in acetonitrile $(25 \mathrm{~mL})$. Water $(3.5 \mathrm{~mL})$ was added and the mixture heated to $30^{\circ} \mathrm{C}$ for $18 \mathrm{~h}$. The mixture was filtered and the precipitate washed with water. The filtrate was extracted with $\mathrm{CH}_{2} \mathrm{Cl}_{2}(3 \times 40 \mathrm{~mL})$. The aqueous layer was lyophilised to give (L)-2-amino-8-oxodecanoic acid (8b) as a white powder (288 mg, 92\%); m.p: 201-203 ${ }^{\circ} \mathrm{C}$; ${ }^{1} \mathrm{H}$ NMR $\left(400 \mathrm{MHz}, \mathrm{D}_{2} \mathrm{O}\right)$ ס: 3.64 (t, $J=6.1 \mathrm{~Hz}, 1 \mathrm{H}$, $\left.-\mathrm{CHNH}_{2}\right), 2.50-2.45\left(\mathrm{~m}, 4 \mathrm{H},-\mathrm{C}(\mathrm{O}) \mathrm{CH}_{2} \mathrm{CH}_{2}\right.$ and $\left.-\mathrm{C}(\mathrm{O}) \mathrm{CH}_{2} \mathrm{CH}_{3}\right), 1.78-1.73(\mathrm{~m}, 2 \mathrm{H}$, $\left.\mathrm{CH}_{2} \mathrm{CHNH}_{2}\right)$, 1.52-1.44 (m, $\left.2 \mathrm{H},-\mathrm{C}(\mathrm{O}) \mathrm{CH}_{2} \mathrm{CH}_{2}\right), 1.32-1.25\left(\mathrm{~m}, 4 \mathrm{H},-\mathrm{CH}_{2} \mathrm{CH}_{2} \mathrm{CHNH}_{2}\right.$ and $\left.-\mathrm{C}(\mathrm{O}) \mathrm{CH}_{2} \mathrm{CH}_{2} \mathrm{CH}_{2}\right), 0.91$ (t, $\left.J=7.3 \mathrm{~Hz}, 3 \mathrm{H},-\mathrm{C}(\mathrm{O}) \mathrm{CH}_{2} \mathrm{CH}_{3}\right) ;{ }^{13} \mathrm{C} \mathrm{NMR}(100 \mathrm{MHz}$, $\left.\mathrm{D}_{2} \mathrm{O}\right)$ ठ: $220.1(-\mathrm{C}=\mathrm{O}), 174.9(-\mathrm{C}=\mathrm{OOH}), 54.8\left(-\mathrm{CHNH}_{2}\right), 41.7\left(-\mathrm{C}(\mathrm{O}) \mathrm{CH}_{2}\right), 35.7$ ($\left.\mathrm{C}(\mathrm{O}) \mathrm{CH}_{2}\right), 30.2\left(-\mathrm{CH}_{2} \mathrm{CHNH}_{2}\right), 27.9\left(-\mathrm{CH}_{2}\right), 24.0\left(-\mathrm{CH}_{2}\right), 23.1\left(-\mathrm{C}(\mathrm{O}) \mathrm{CH}_{2} \mathrm{CH}_{2}\right), 7.2(-$ $\mathrm{CH}_{3}$ ); IR ( $\mathrm{V}_{\text {max }} / \mathrm{cm}^{-1}$, neat): 2972, 2936, 2860, 1707, 1578, 1512, 1462, 1441, 1414, $1375,1348,1317,1184,1117,1076,972,852,804,660$; HRMS $\left(E S I^{+}\right)$calcd for $\left.\mathrm{C}_{10} \mathrm{H}_{19} \mathrm{NO}_{3} \mathrm{Na}[\mathrm{M}+\mathrm{Na}]^{+}\right)$224.1257, found $224.1261(\Delta=0.8 \mathrm{ppm})$.

\section{(L)-2((((9H-Fluoren-9-yl)methoxy)carbonyl)amino)-8-oxodecanoic acid (Fmoc-L-} Aod-OH, 10)

(L)-2-Amino-8-oxodecanoic acid (8b) (197 $\mathrm{mg}, 0.98 \mathrm{mmol}, 1.0$ equiv.) and potassium carbonate $(271 \mathrm{mg}, 2.0 \mathrm{mmol}, 2.0$ equiv.) were dissolved in water $(4.5 \mathrm{~mL})$ and the solution was cooled to $0{ }^{\circ} \mathrm{C}$. Fmoc succinimide (330.5 mg, $0.98 \mathrm{mmol}, 1.0$ equiv.) was dissolved in dioxane $(9 \mathrm{~mL})$ and added dropwise to the aqueous solution over $20 \mathrm{~min}$. The reaction was warmed to room temperature and stirred for $24 \mathrm{~h}$. Excess water was added to the mixture then extracted with $\mathrm{CH}_{2} \mathrm{Cl}_{2}(3 \times 10 \mathrm{~mL})$. The combined organic phases were back extracted with sodium bicarbonate $(3 \times 20 \mathrm{~mL})$ and the aqueous phases were acidified to $\mathrm{pH} 1$ with $3.0 \mathrm{M}$ aqueous $\mathrm{HCl}$. The aqueous fractions were then extracted with $\mathrm{CH}_{2} \mathrm{Cl}_{2}(3 \times 30 \mathrm{~mL})$. The combined organic layers were washed with brine $(3 \times 30 \mathrm{~mL})$, dried (MgSO4) and concentrated 
in vacuo. Purification was carried out by flash column chromatography $\left(12 \% \mathrm{CH}_{3} \mathrm{OH}\right.$ $\mathrm{CH}_{2} \mathrm{Cl}_{2}$ ). Fractions containing the product were combined and the solvent removed in vacuo to give afford (L)-2((((9H-fluoren-9-yl)methoxy)carbonyl)amino)-8-oxodecanoic acid (10) as an off-white powder (406 mg, 98\%); m.p: 109-111 ${ }^{\circ} \mathrm{C}$; ${ }^{1} \mathrm{H}$ NMR $(400$ $\mathrm{MHz}, \mathrm{CD}_{3} \mathrm{OD}$ ) ס: 7.69 (d, J = 7.5 Hz, 2H, -Ar-CH), 7.58-7.52 (m, 2H, -Ar-CH), 7.307.26 (m, 2H, -Ar-CH), 7.20 (tt, $J=7.5,1.1 \mathrm{~Hz}, 2 \mathrm{H},-\mathrm{Ar}-\mathrm{CH}$ ), 4.29 (dd, $J=10.5,7.2$ $\mathrm{Hz}, 1 \mathrm{H},-\mathrm{CH}_{2} \mathrm{OC}(\mathrm{O}) \mathrm{NH}$ ), 4.21 (dd, $\left.J=10.5,6.7 \mathrm{~Hz}, 1 \mathrm{H},-\mathrm{CH}_{2} \mathrm{OC}(\mathrm{O}) \mathrm{NH}\right), 4.11$ (t, $J=$ $6.8 \mathrm{~Hz}, 1 \mathrm{H},-\mathrm{CHCH}_{2} \mathrm{OC}(\mathrm{O}) \mathrm{NH}$ ), $3.94(\mathrm{dd}, J=8.9,4.7 \mathrm{~Hz}, 1 \mathrm{H},-\mathrm{OC}(\mathrm{O}) \mathrm{NHCH}$ ), 2.33 (q, $J=7.1 \mathrm{~Hz}, 4 \mathrm{H},-\mathrm{C}(\mathrm{O}) \mathrm{CH}_{2} \mathrm{CH}_{3}$ and $\left.\mathrm{C}(\mathrm{O}) \mathrm{CH}_{2} \mathrm{CH}_{2}\right), 1.71(\mathrm{dd}, \mathrm{J}=12.7,7.3 \mathrm{~Hz}, 1 \mathrm{H},-$ $\mathrm{NHCHCH}_{2}$ ), $1.54\left(\mathrm{dt}, J=13.8,7.5 \mathrm{~Hz}, 1 \mathrm{H},-\mathrm{NHCHCH}_{2}\right), 1.45(\mathrm{p}, J=7.5 \mathrm{~Hz}, 2 \mathrm{H}$, $\left.\mathrm{C}(\mathrm{O}) \mathrm{CH}_{2} \mathrm{CH}_{2}\right), 1.30-1.17\left(\mathrm{~m}, 4 \mathrm{H},-\mathrm{CH}_{2} \mathrm{CH}_{2} \mathrm{CHNH}\right.$ and $\left.-\mathrm{C}(\mathrm{O}) \mathrm{CH}_{2} \mathrm{CH}_{2} \mathrm{CH}_{2}\right), 0.89(\mathrm{t}, \mathrm{J}=$ $\left.7.3 \mathrm{~Hz}, 3 \mathrm{H},-\mathrm{C}(\mathrm{O}) \mathrm{CH}_{2} \mathrm{CH}_{3}\right) ;{ }^{13} \mathrm{C} \mathrm{NMR}\left(100 \mathrm{MHz}, \mathrm{CD}_{3} \mathrm{OD}\right)$ ס: $213.1(-\mathrm{C}=\mathrm{O}), 144.0$ ($\mathrm{Ar}-\mathrm{C}), 141.2$ (-Ar-C), 127.4 (-Ar-CH), 126.7 (-Ar-CH), 124.8 (-Ar- $\mathrm{CH}), 119.5$ (-Ar-CH), $66.4\left(-\mathrm{CH}_{2} \mathrm{OC}(\mathrm{O}) \mathrm{NH}\right), 48.2\left(-\mathrm{CHCH}_{2} \mathrm{OC}(\mathrm{O}) \mathrm{NH}\right), 41.5\left(-\mathrm{C}(\mathrm{O}) \mathrm{CH}_{2} \mathrm{CH}_{2}\right), 35.1 \quad(-$ $\left.\mathrm{C}(\mathrm{O}) \mathrm{CH}_{2} \mathrm{CH}_{3}\right), 28.5\left(-\mathrm{CH}_{2}\right), 25.3\left(-\mathrm{CH}_{2}\right), 23.4\left(-\mathrm{C}(\mathrm{O}) \mathrm{CH}_{2} \mathrm{CH}_{2}\right), \quad 6.7\left(-\mathrm{CH}_{3}\right) ; \mathrm{IR}$ $\left(\mathrm{V}_{\max } / \mathrm{cm}^{-1}\right.$, neat): $3341,3063,2986,2947,2862,1744,1690,1520,1450,1404$, 1335, 1281, 1227, 1196, 1173, 1088, 1042, 841, 733, 617, 540, 424; HRMS (ESI $\left.{ }^{+}\right)$ calcd for $\left.\mathrm{C}_{25} \mathrm{H}_{29} \mathrm{NO}_{5} \mathrm{Na}[\mathrm{M}+\mathrm{Na}]^{+}\right) 446.1938$, found $446.1935(\Delta=0.6 \mathrm{ppm}) ;[\alpha]_{D}{ }^{20}=$ $1.6\left(\mathrm{c}=0.5, \mathrm{CH}_{3} \mathrm{OH}\right)$.

\section{II(H). General Solid Phase Peptide Synthesis}

Peptides were synthesized on an automated microwave-assisted solid-phase peptide synthesizer (Biotage Initiator+ Alstra machine) using a $15 \mathrm{~mL}$ Teflon reactor vessel at $100 \mu \mathrm{mol}$ scale using Rink Amide Chemmatrix resin (substitution: 0.47 $\mathrm{mmol} / \mathrm{g})$. The resin was swollen for $20 \mathrm{~min}$ at ambient temperature in DMF (9 mL) prior to synthesis.

$\mathrm{N}$ - $\alpha$-Fmoc protected amino acids (0.2 M in DMF, 4.0 equiv for natural or 2.0 equiv for non-natural relative to resin loading) were coupled to resin bound peptide amines using HCTU (0.5 M / DMF, 4.0 eq.) and DIPEA (2.0 M / NMP, 8 eq.) at $75^{\circ} \mathrm{C}$ for 5 min natural or $10 \mathrm{~min}$ for non-natural amino acids. Fmoc-L-Arg(Pbf)-OH was coupled for $45 \mathrm{~min}$ at ambient temperature, followed by coupling at $75{ }^{\circ} \mathrm{C}$ for $5 \mathrm{~min}$. Fresh reagents were added and arginine was double coupled at $75^{\circ} \mathrm{C}$ for 5 min. Once the coupling reagents had been drained, the peptide resin was then washed four times with DMF $(4 \times 9 \mathrm{~mL})$ for $45 \mathrm{~s}$ at ambient temperature. $N$ - $\alpha$-Fmoc resin bound 
peptides were deprotected using two aliquots of $20 \%$ piperidine / DMF (v:v) and 0.1 M Oxyma pure $(9 \mathrm{~mL})$ for $3 \mathrm{~min}$, followed by $10 \mathrm{~min}$ at ambient temperature. The peptide resin was then washed four times with DMF $(4 \times 9 \mathrm{~mL})$ for $45 \mathrm{~s}$ at ambient temperature. $N$-Terminal acetyl capping was achieved using a mixture of DIPEA (2.0 $\mathrm{M} / \mathrm{NMP}, 50$ eq.) and acetic anhydride $\left(\mathrm{Ac}_{2} \mathrm{O}, 5.0 \mathrm{M} / \mathrm{DMF}, 50\right.$ eq. $)$ at ambient temperature for $10 \mathrm{~min}$. Once capping reagents had been drained, the peptide resin was then washed four times with DMF $(4 \times 9 \mathrm{~mL})$ for $45 \mathrm{~s}$ at ambient temperature. Resin bound peptide was washed with DCM $(4 \times 9 \mathrm{~mL})$ for $45 \mathrm{~s}$ at ambient temperature.

SPI 11, were cleaved from the resin using a cleavage cocktail of TFA/TIPS/DCM (98:1:1) for 24 hours before being drained and the TFA blown off with a stream of nitrogen. SPI 12-13, were cleaved from the resin using a cleavage cocktail of TFA/DCM (95:5) for 3 hours before being drained and the TFA blown off with a stream of nitrogen. The peptide was precipitated and washed three times in cold diethyl ether and spun down to a pellet before the diethyl ether removed and the peptide dried under a steady stream of nitrogen. Peptides were then purified by reverse phase high pressure liquid chromatography (RP-HPLC).

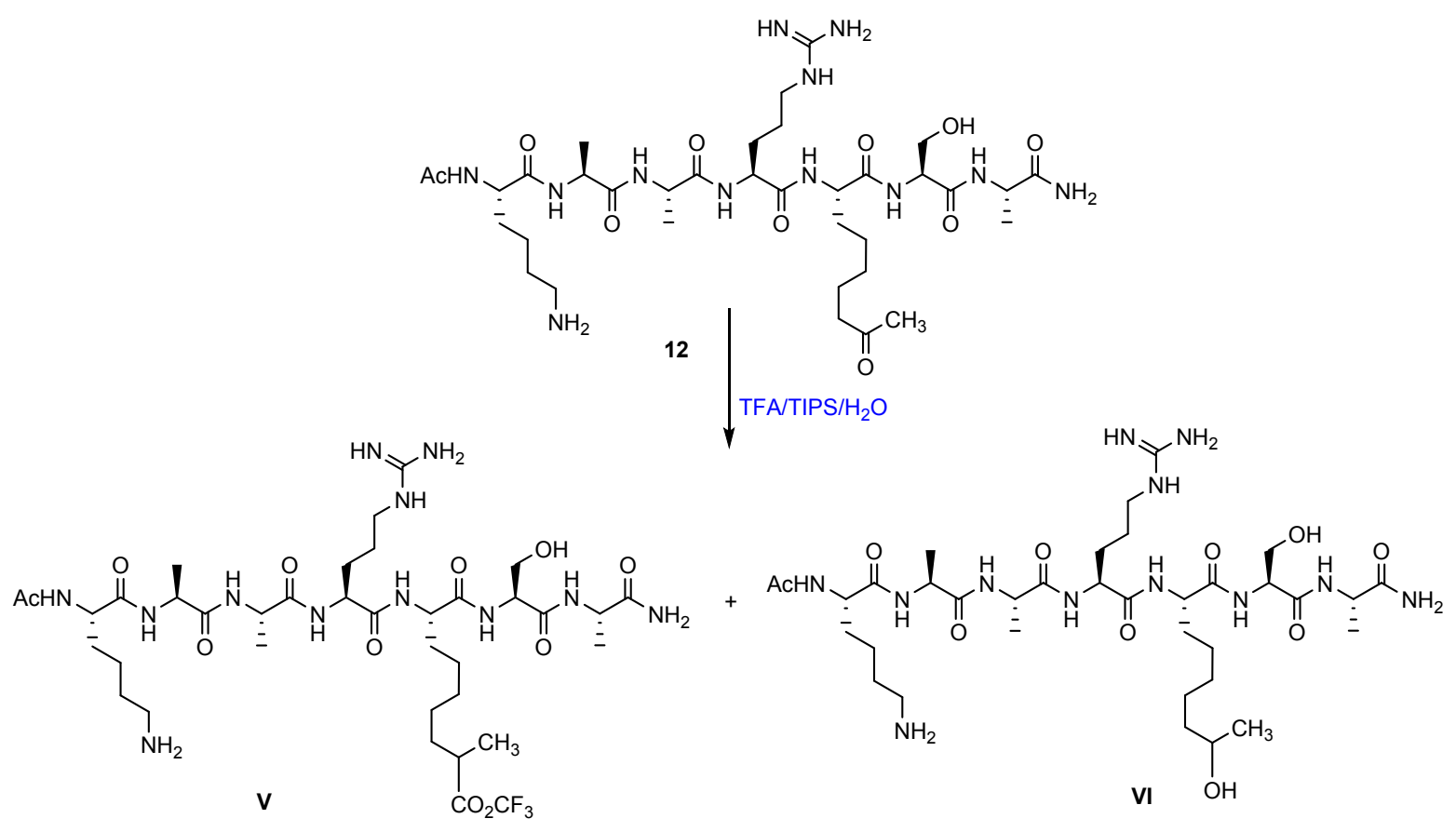

Figure S5. Hydride reduction of the ketone functionality 


\section{HDAC Assay}

HDAC activity was measured by using fluorescent BOC-Lys-AMC substrate in a black 96-well format. 50 nM HDAC1-MTA1-RBBP4 was incubated with inhibitor and $100 \mu \mathrm{M}$ BOC-Lys-AMC substrate for $30 \mathrm{~min}$ at $37^{\circ} \mathrm{C}$ in a final volume of $50 \mu \mathrm{l}$ (50 $\mathrm{mM}$ Tris $\mathrm{pH} 7.5,150 \mathrm{mM} \mathrm{NaCl}, 5 \%$ Glycerol). The assay was developed by the addition of $50 \mu \mathrm{l}$ of developer solution ( $2 \mu \mathrm{M}$ TSA, $10 \mathrm{mg} \mathrm{ml}^{-1}$ Trypsin, $50 \mathrm{mM}$ Tris $\mathrm{pH}$ 7.5, $100 \mathrm{mM} \mathrm{NaCl}$ ). Fluorescence was measured at 335/460 nm using a Victor X5 plate reader (Perkin Elmer). All measurements were performed in triplicate and data analysed using GraphPad Prism (version 7.0, GraphPad Software, Inc). In the case of titrations $\mathrm{IC}_{50}$ values were calculated by nonlinear curve fitting with a one-site binding (hyperbola) model $\left(Y=B_{\max }{ }^{*} X /\left(K_{d}+X\right)\right.$.

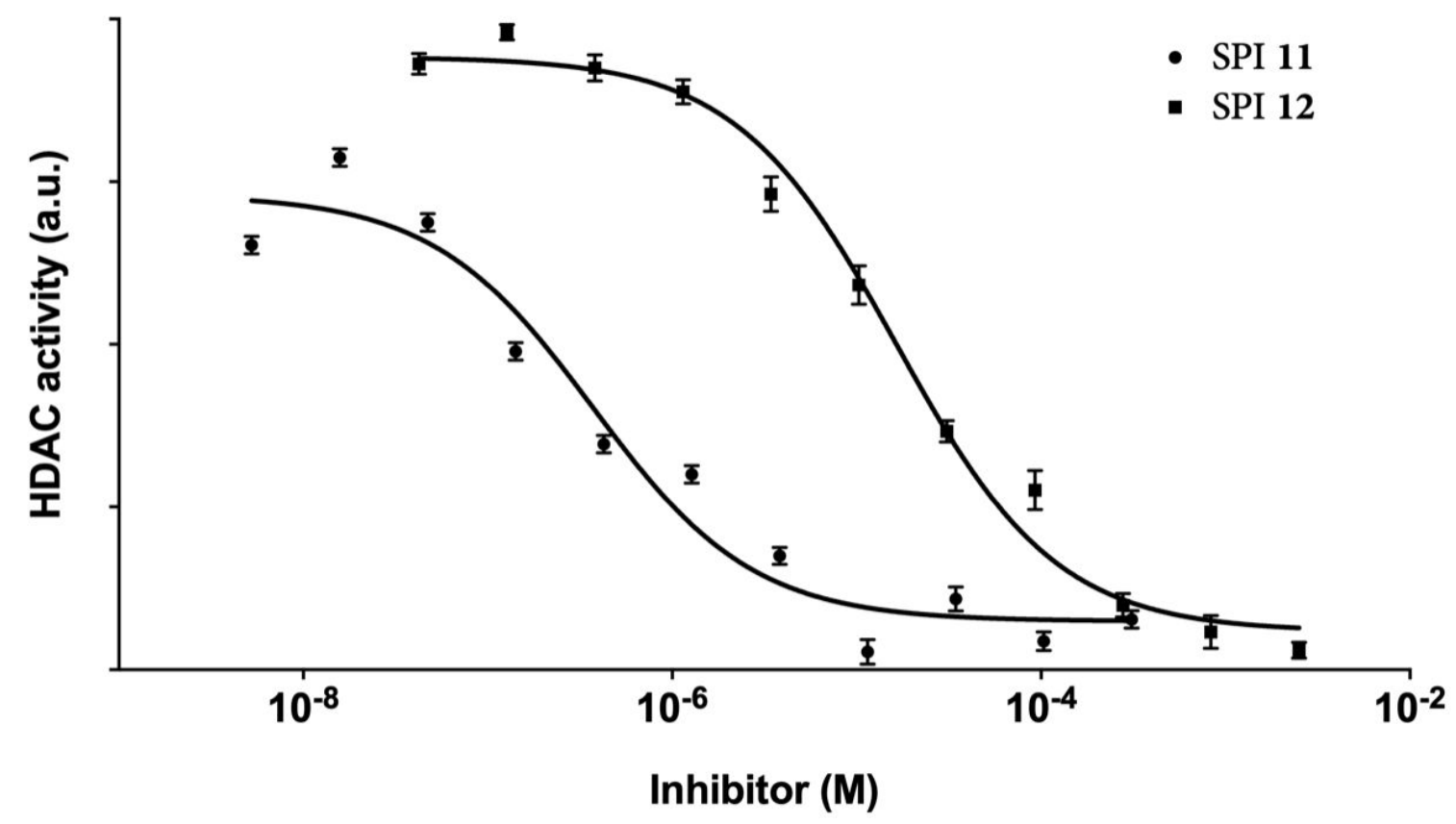

\begin{tabular}{|c|c|c|c|c|c|c|}
\hline \multirow[t]{2}{*}{ Sequence } & \multirow[t]{2}{*}{ Yield } & \multirow[t]{2}{*}{ Purity } & \multirow[t]{2}{*}{$\mathrm{IC}_{50}$} & \multicolumn{2}{|c|}{ Retention time } & \multirow[t]{2}{*}{ Peptide content } \\
\hline & & & & 20 min & $50 \mathrm{~min}$ & \\
\hline Ac-KAARAsuSA-NH ${ }_{2} 11$ & $29 \%$ & $99 \%$ & $390 \mathrm{nM}$ & 8.9 & 14.1 & $69 \%$ \\
\hline Ac-KAARAodSA-NH ${ }_{2} 12$ & $32 \%$ & $99 \%$ & $17 \mu \mathrm{M}$ & 10.0 & 16.3 & $72 \%$ \\
\hline Ac-KAARAonSA-NH ${ }_{2} 13$ & $28 \%$ & $99 \%$ & ND & 10.0 & 16.3 & $76 \%$ \\
\hline Ac-KAARK(Ac)SA-NH ${ }_{2} 14$ & $34 \%$ & $99 \%$ & ND & 13.0 & 21.7 & $78 \%$ \\
\hline
\end{tabular}




\section{NMR Spectra}

${ }^{1} \mathrm{H},{ }^{13} \mathrm{C}, \mathrm{COSY}$ and HSQC NMR spectra for compound II
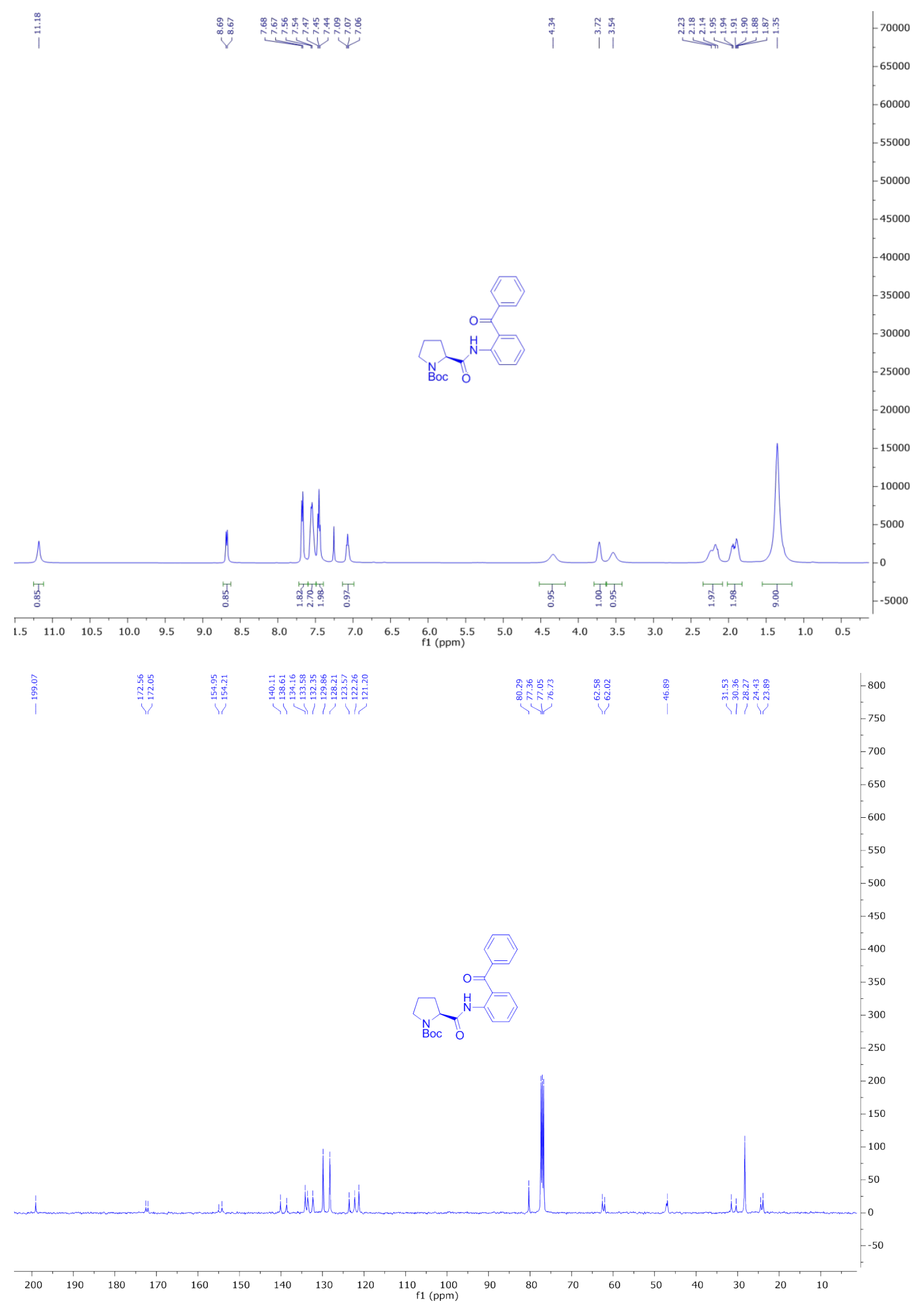


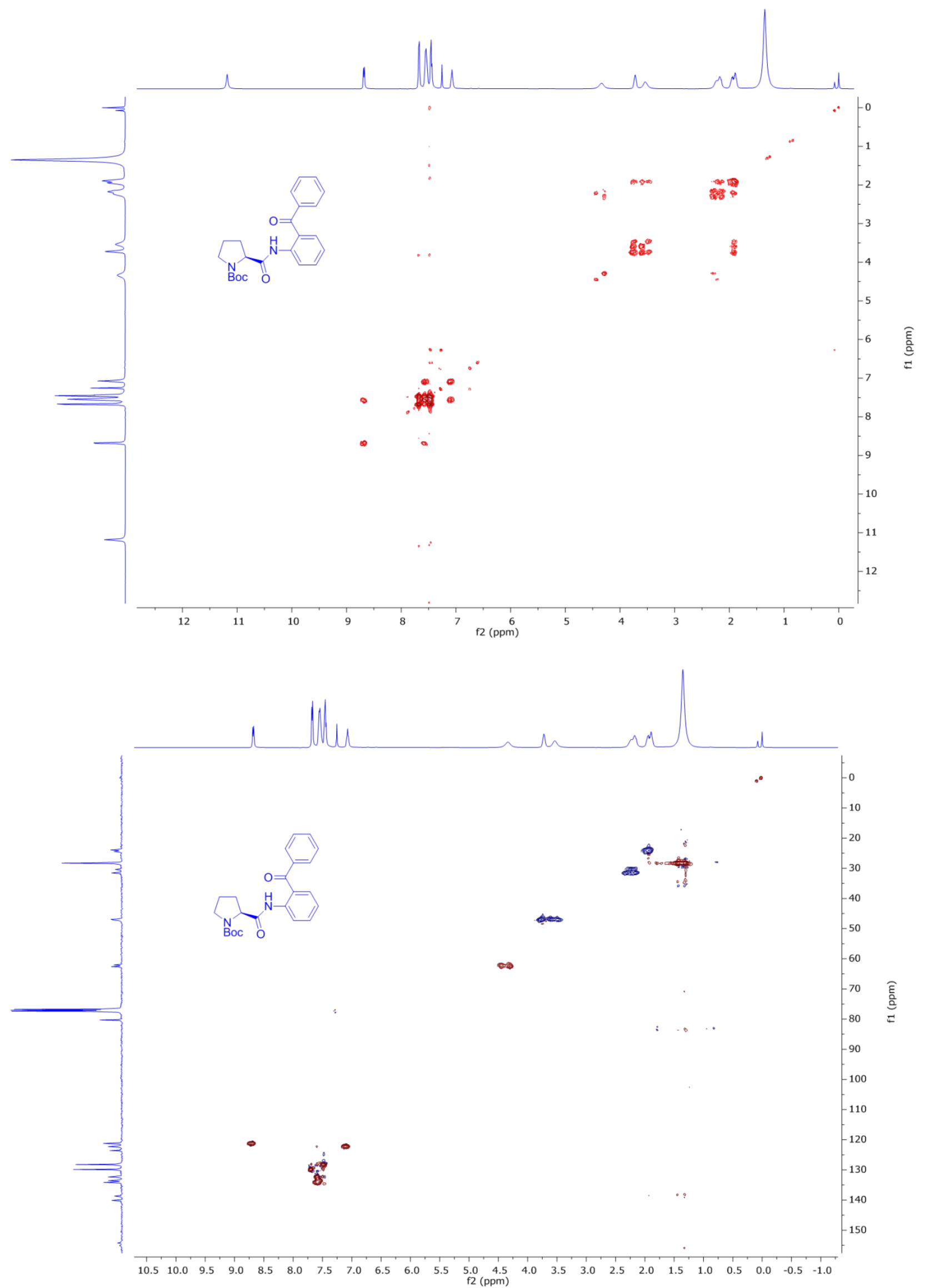


${ }^{1} \mathrm{H},{ }^{13} \mathrm{C}$, COSY and HSQC NMR spectra for compound III

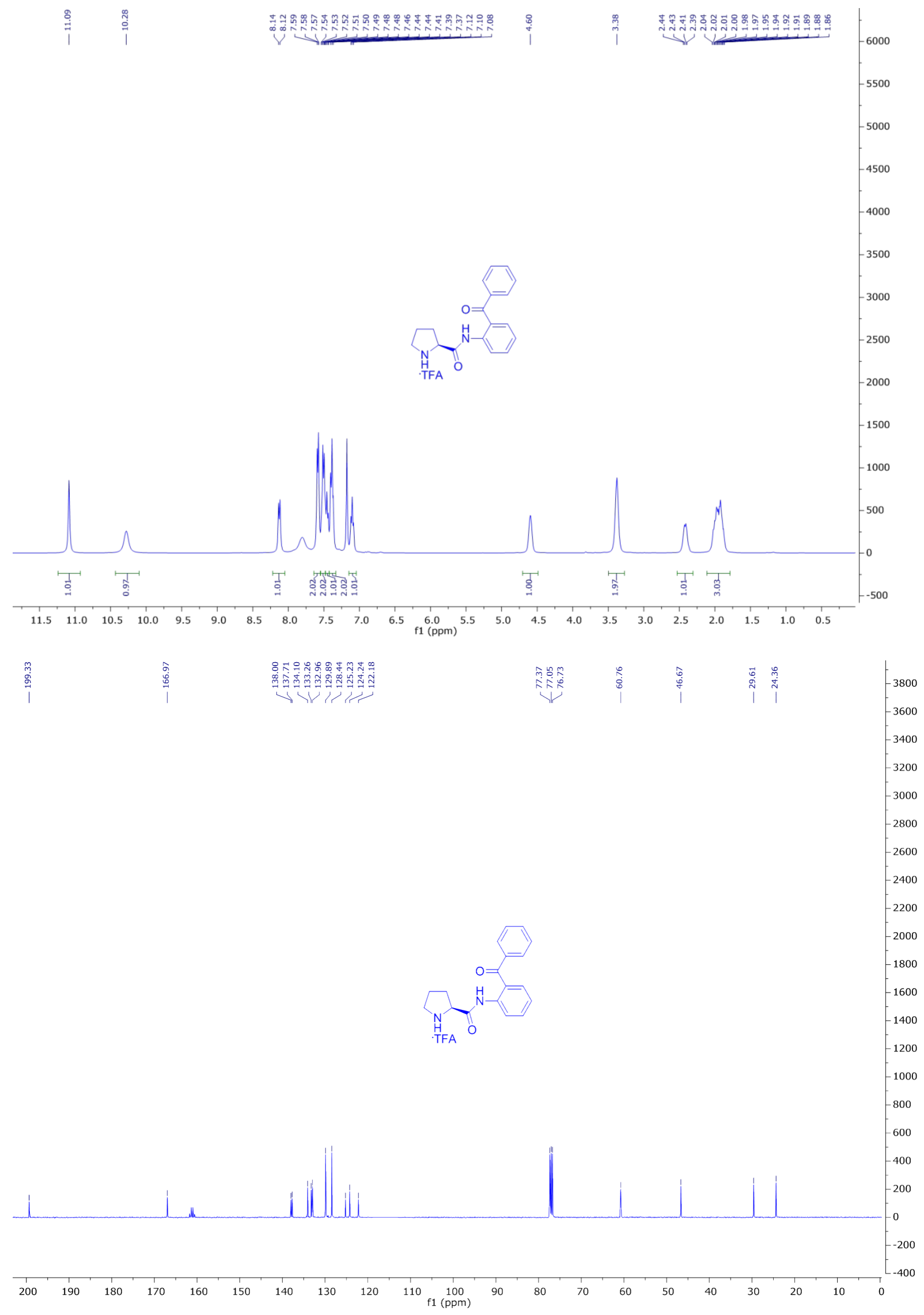



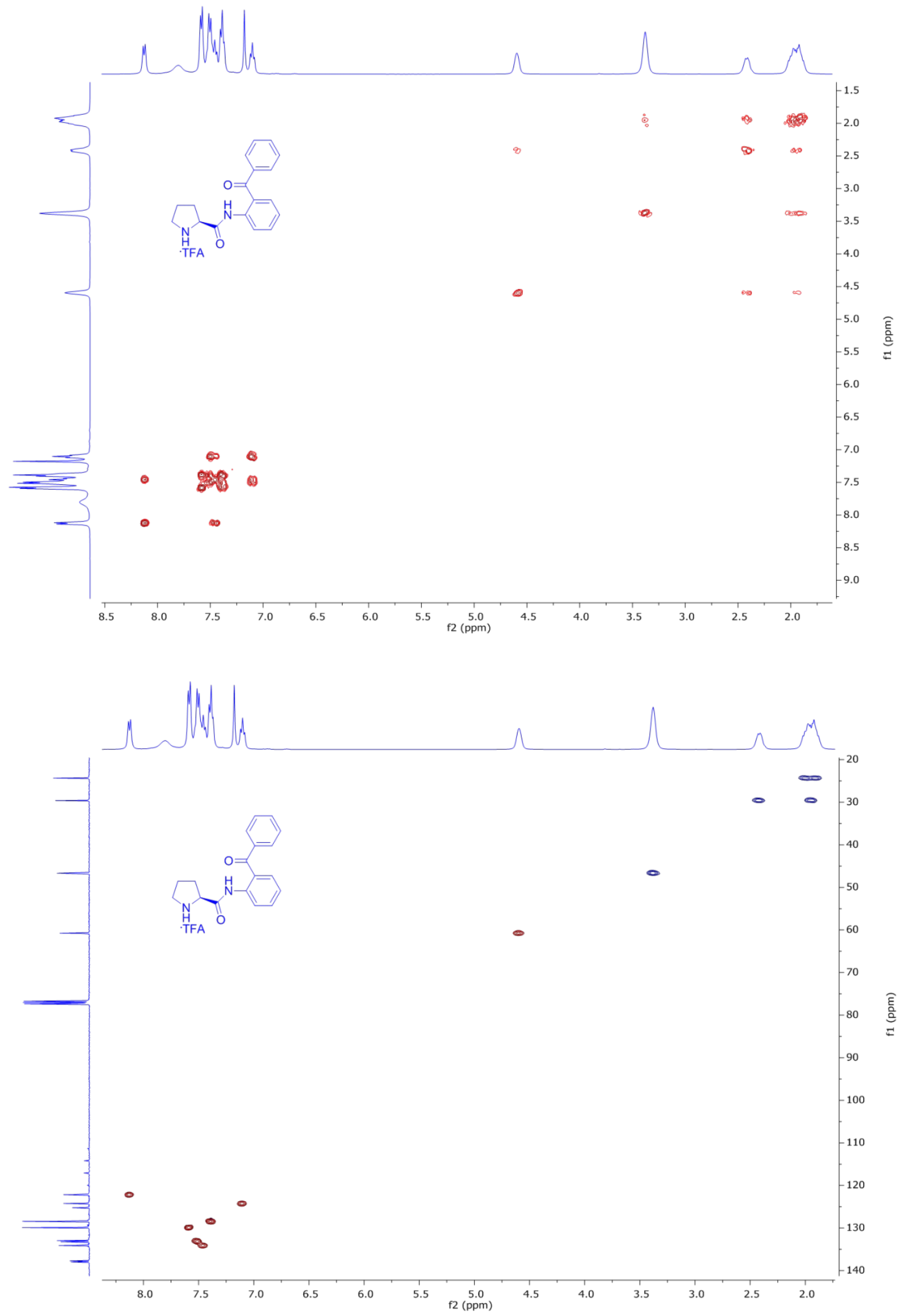
${ }^{1} \mathrm{H},{ }^{13} \mathrm{C}, \mathrm{COSY}, \mathrm{HSQC}$ and ${ }^{19} \mathrm{~F}$ NMR spectra for compound IV

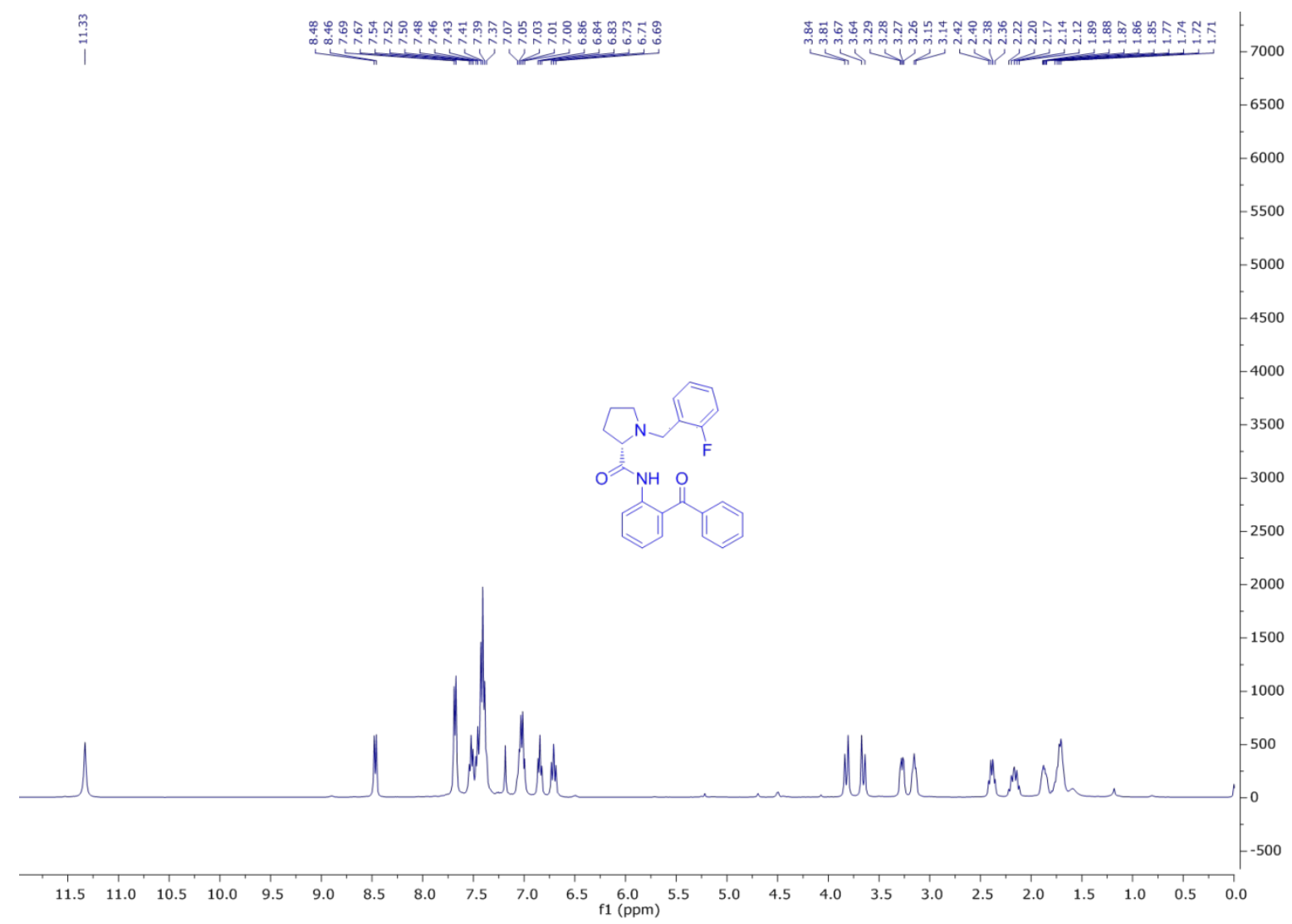

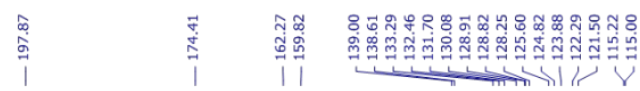

㝦

$-1300$

200

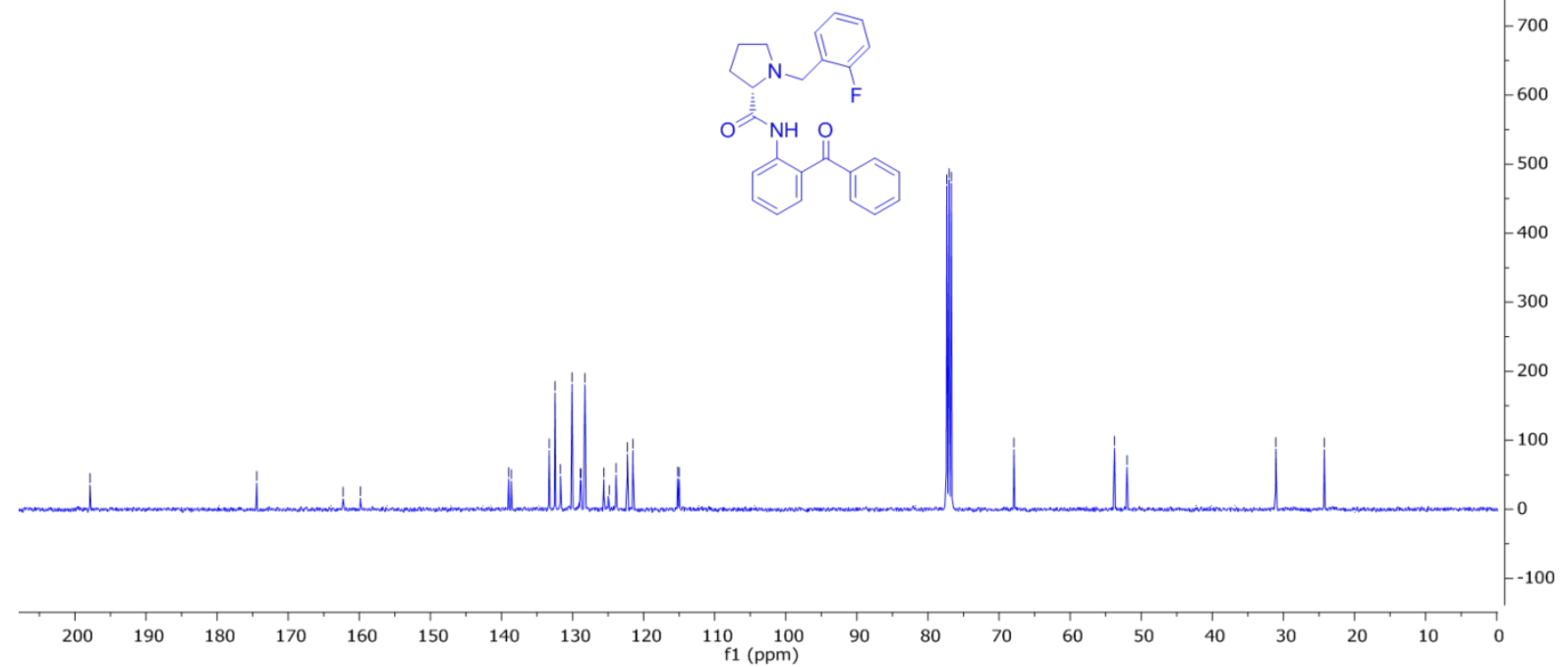



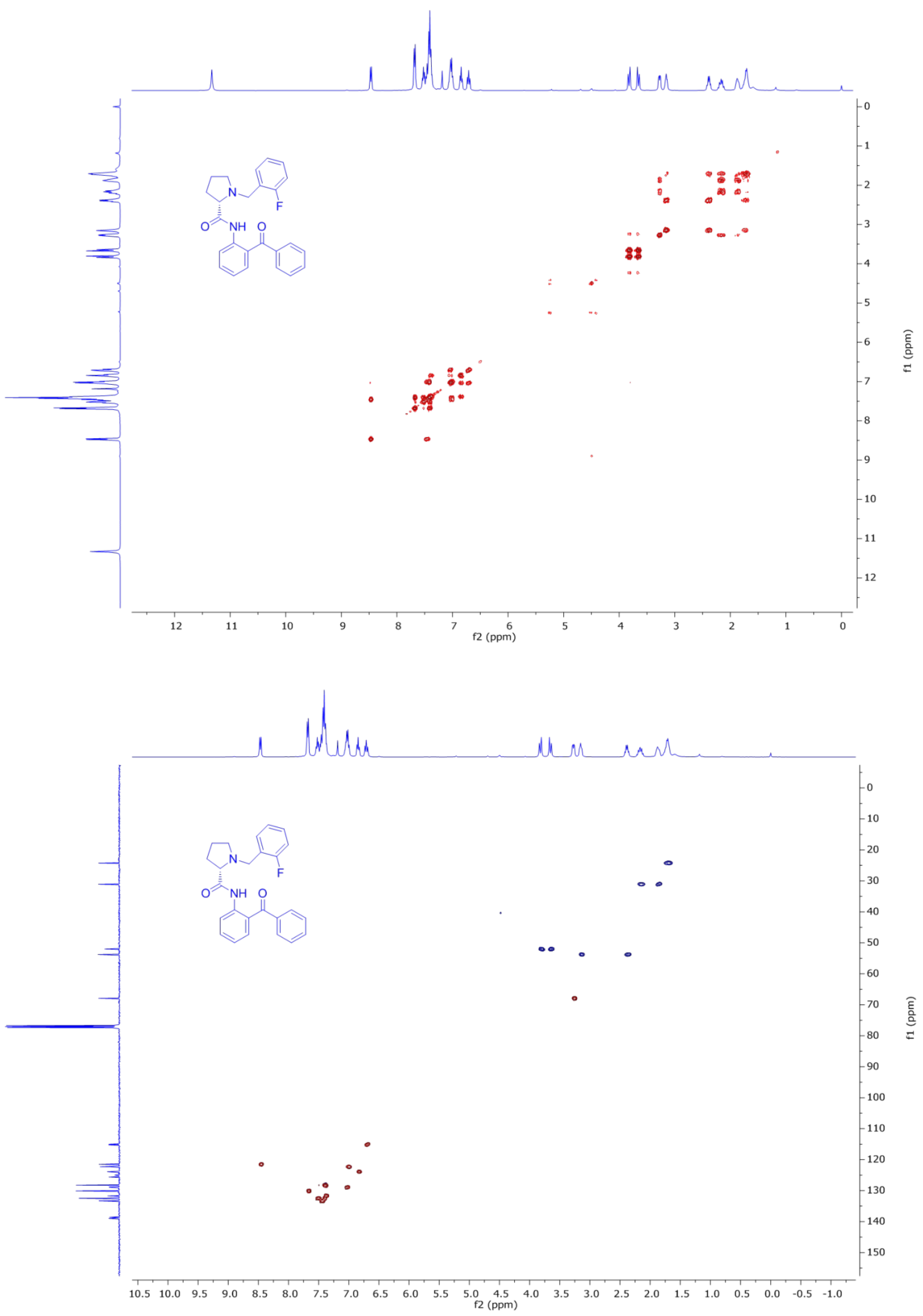

27 


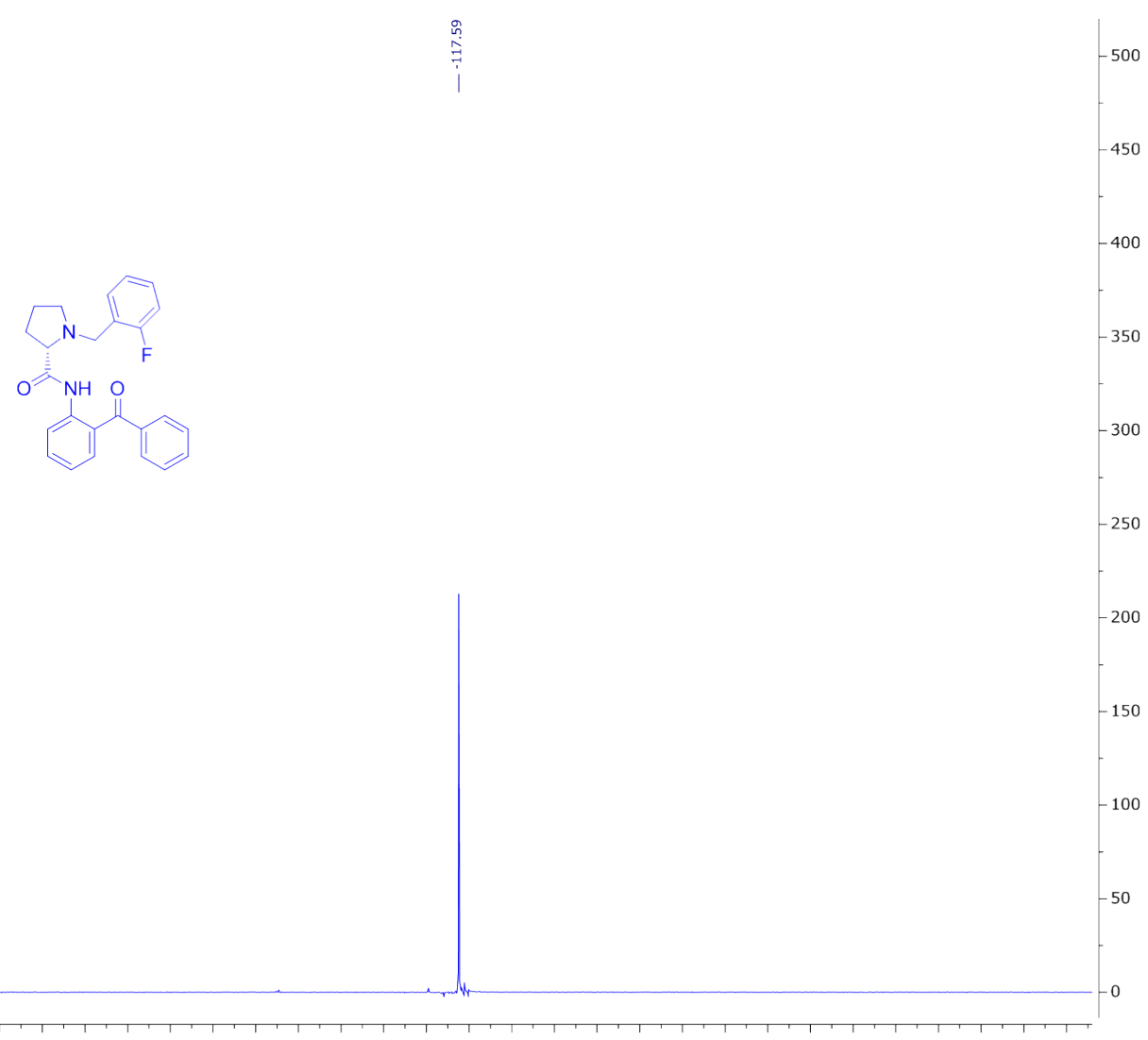

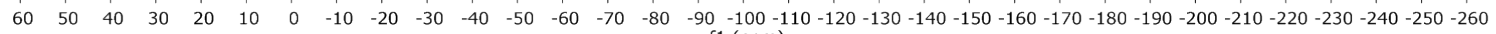
f1 (ppm) 
${ }^{1} \mathrm{H},{ }^{13} \mathrm{C}, \mathrm{COSY}, \mathrm{HSQC}$ and ${ }^{19} \mathrm{~F}$ NMR spectra for compound 1

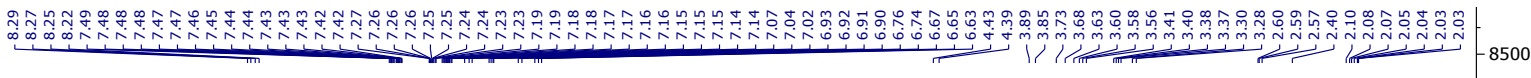
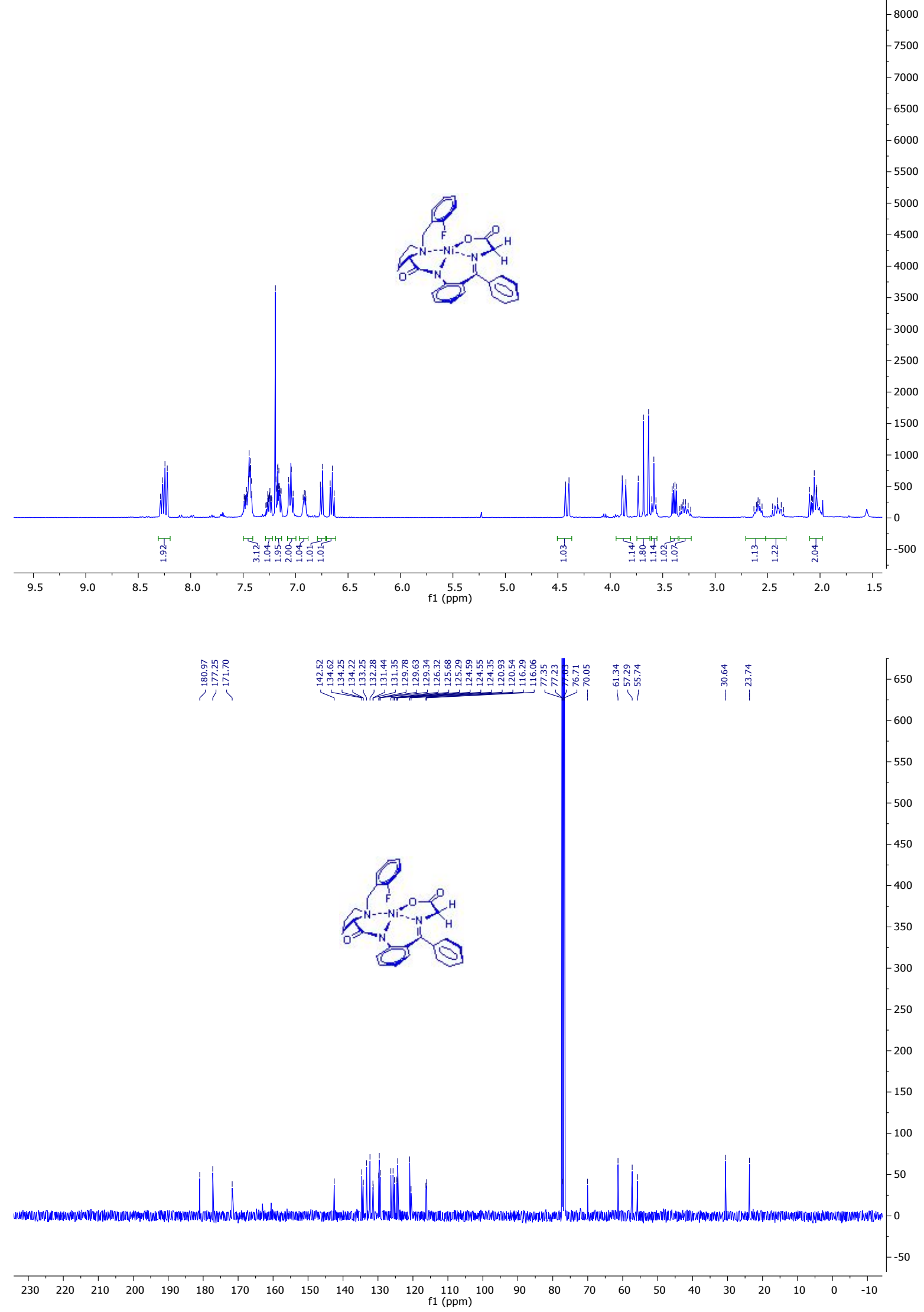

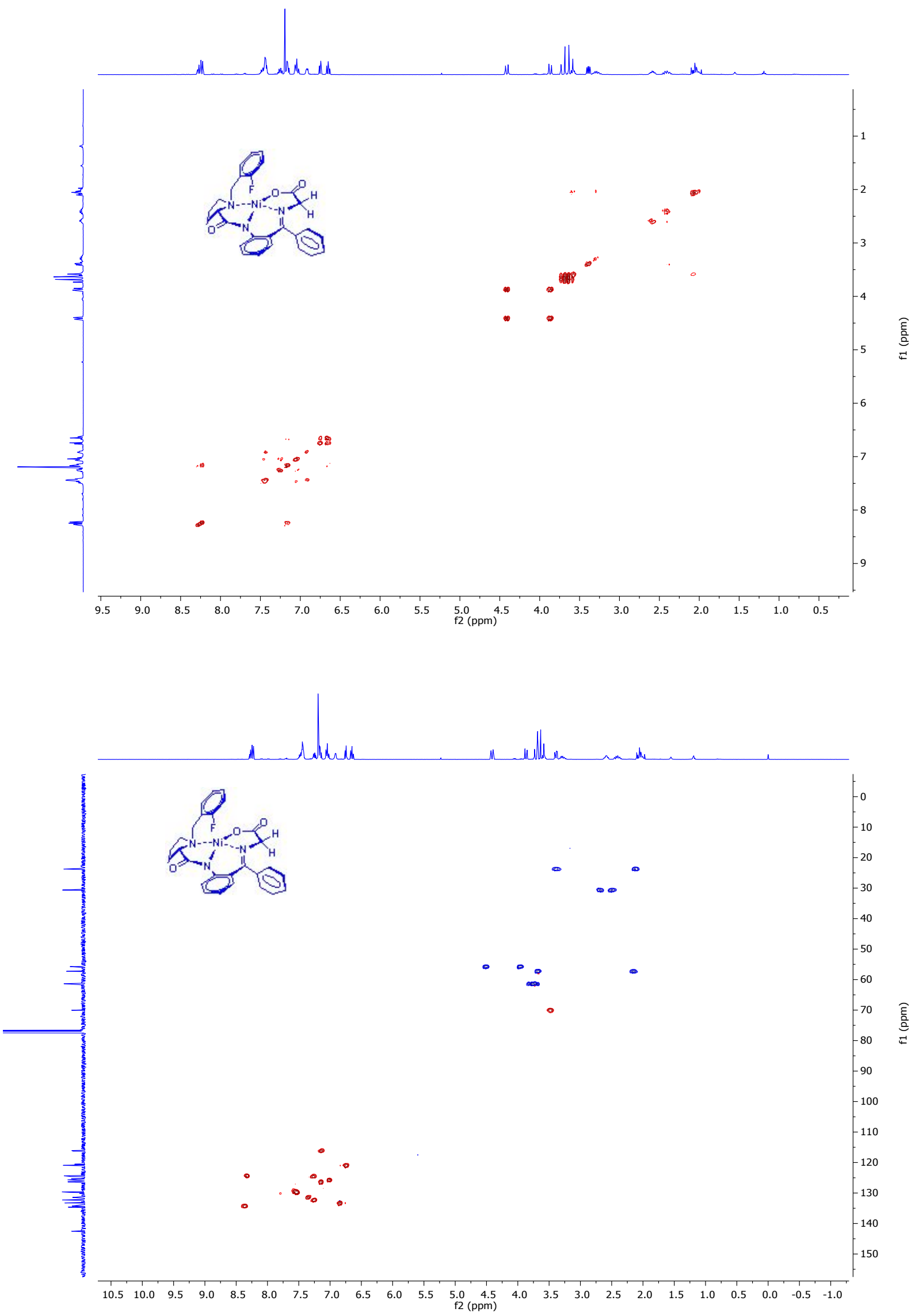


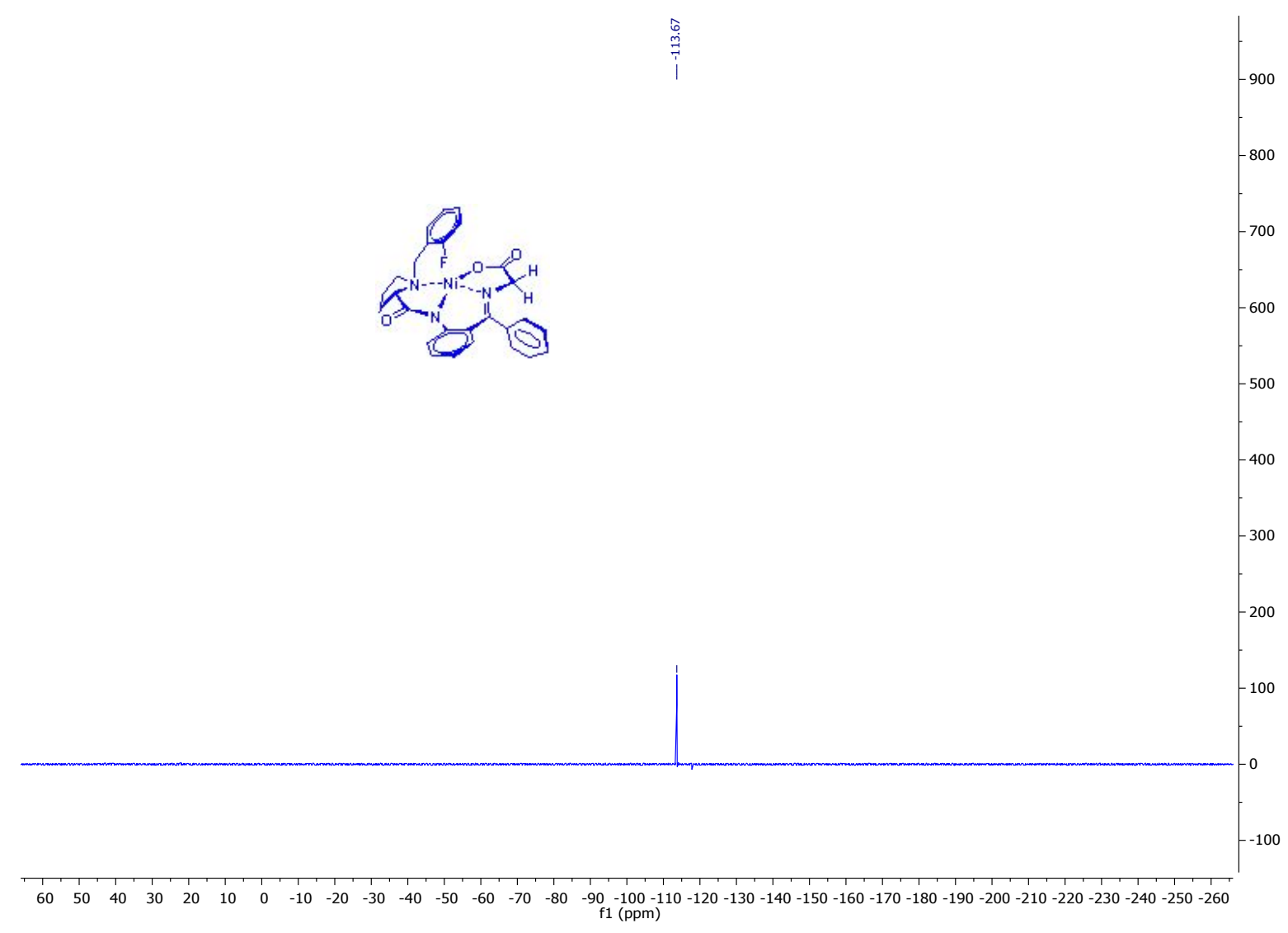

${ }^{1} \mathrm{H},{ }^{13} \mathrm{C}, \mathrm{COSY}$ and HSQC NMR spectra for compound $2 \mathrm{C}$ 


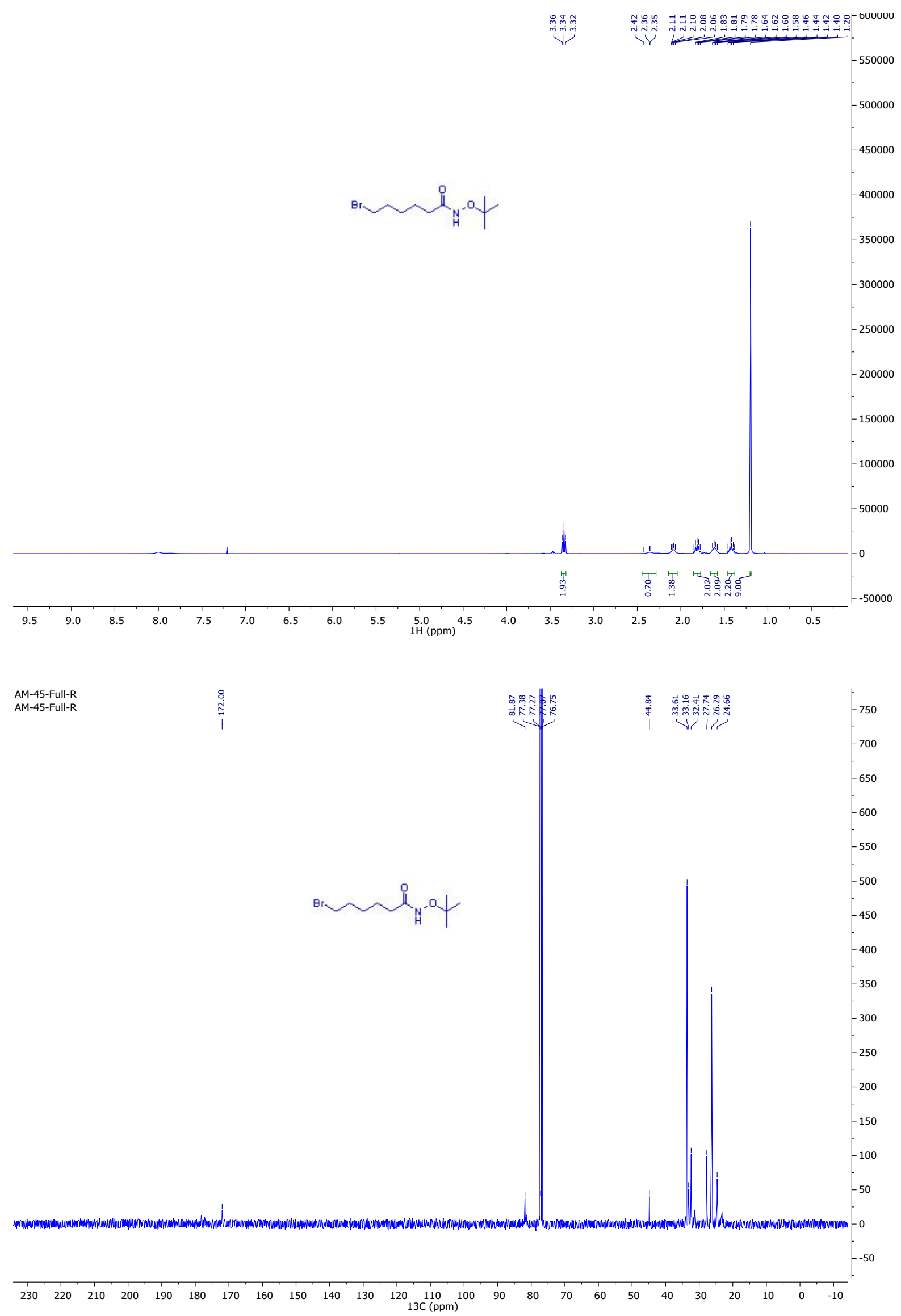



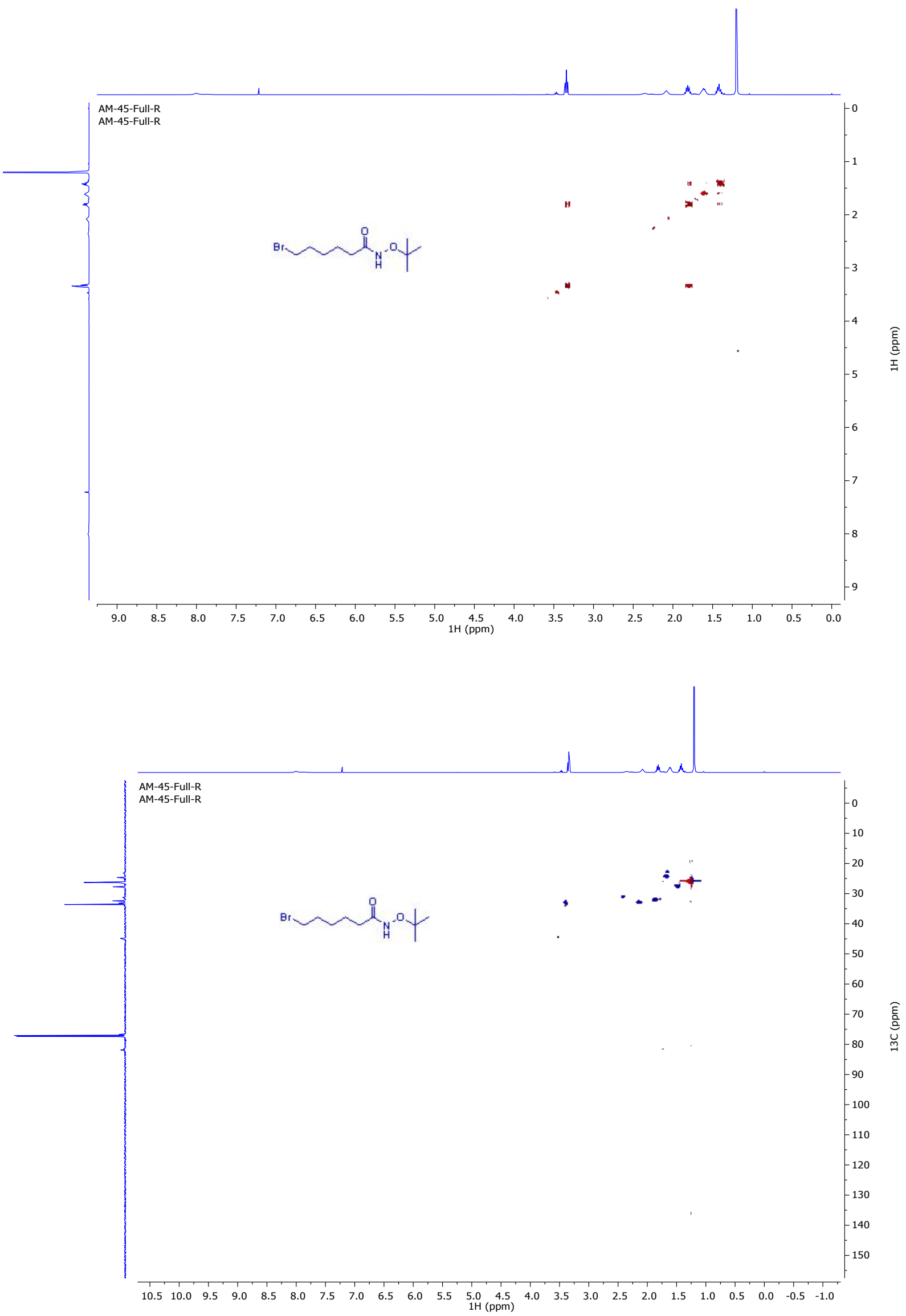
${ }^{1} \mathrm{H},{ }^{13} \mathrm{C},{ }^{19} \mathrm{~F}, \mathrm{COSY}$ and HSQC NMR spectra for compound 3

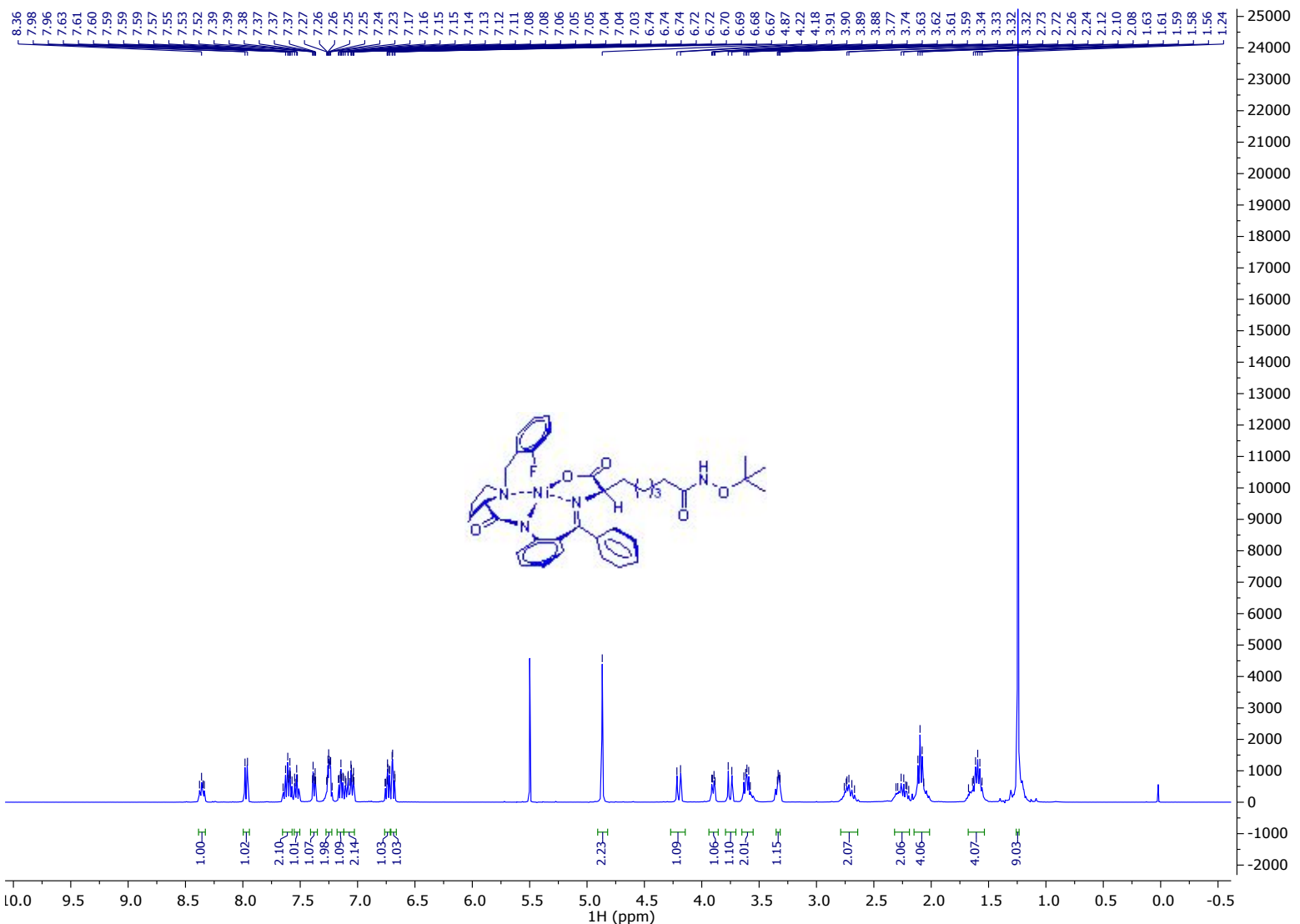




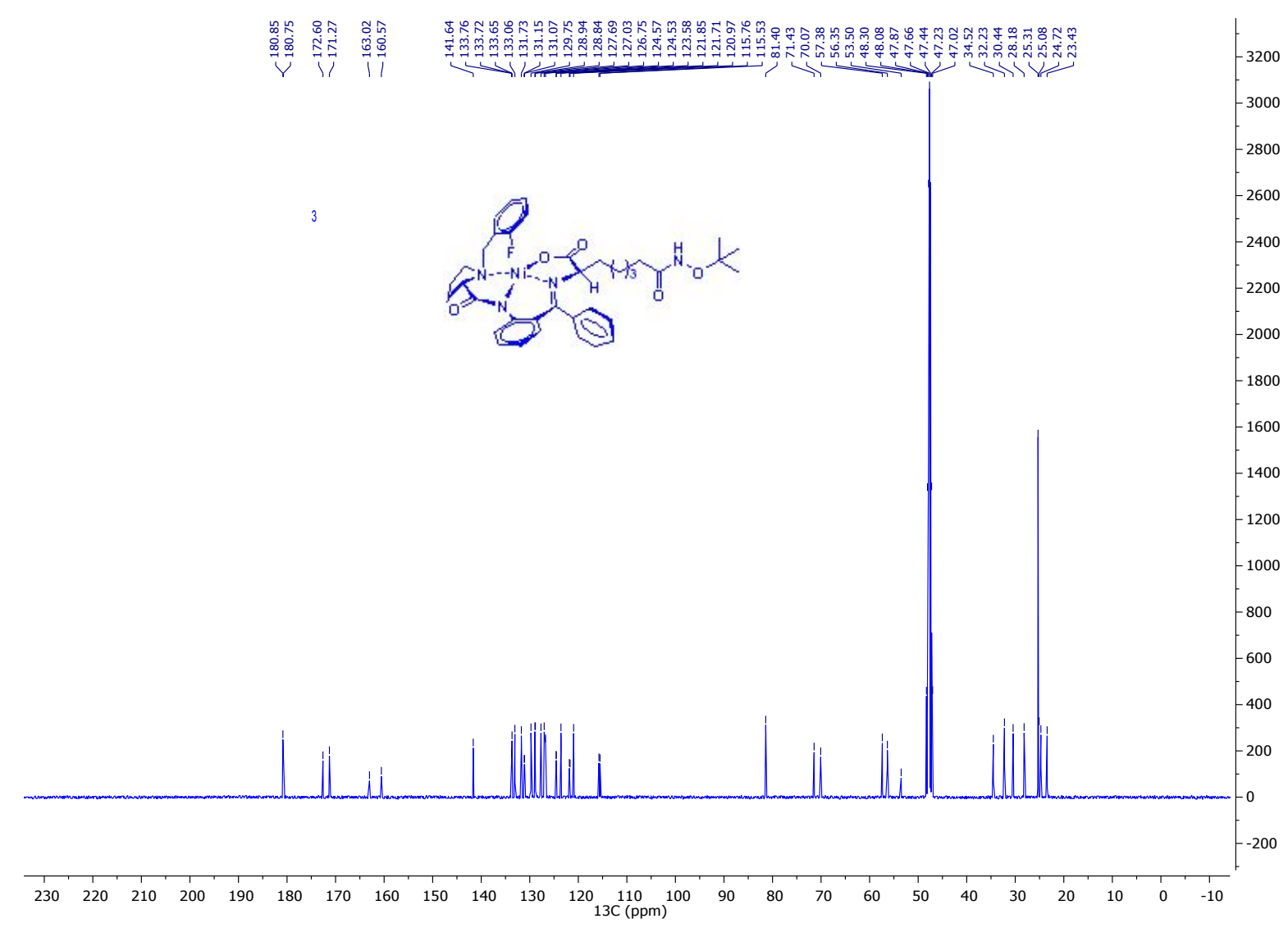




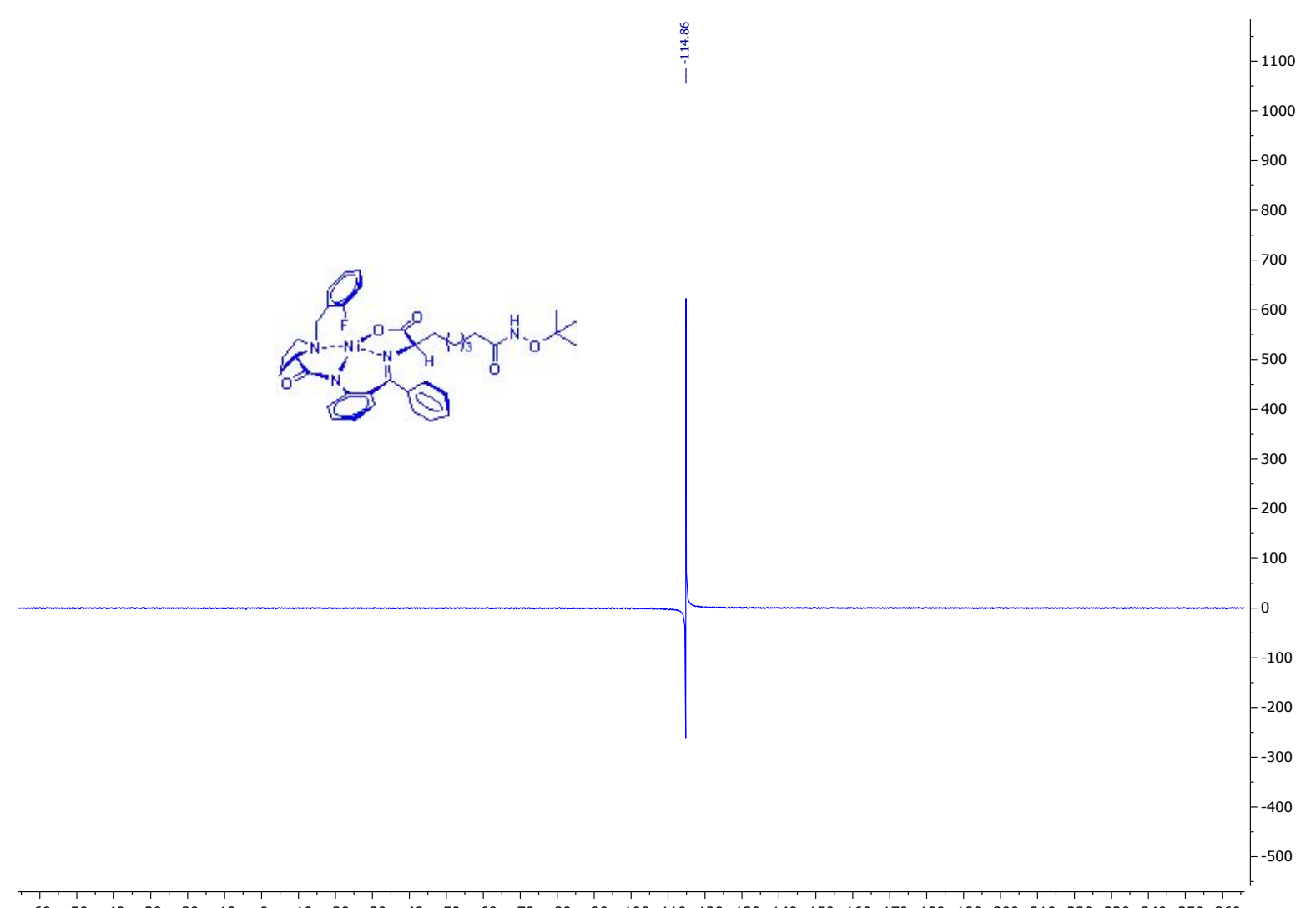

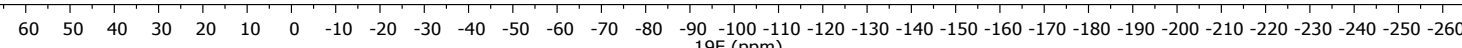

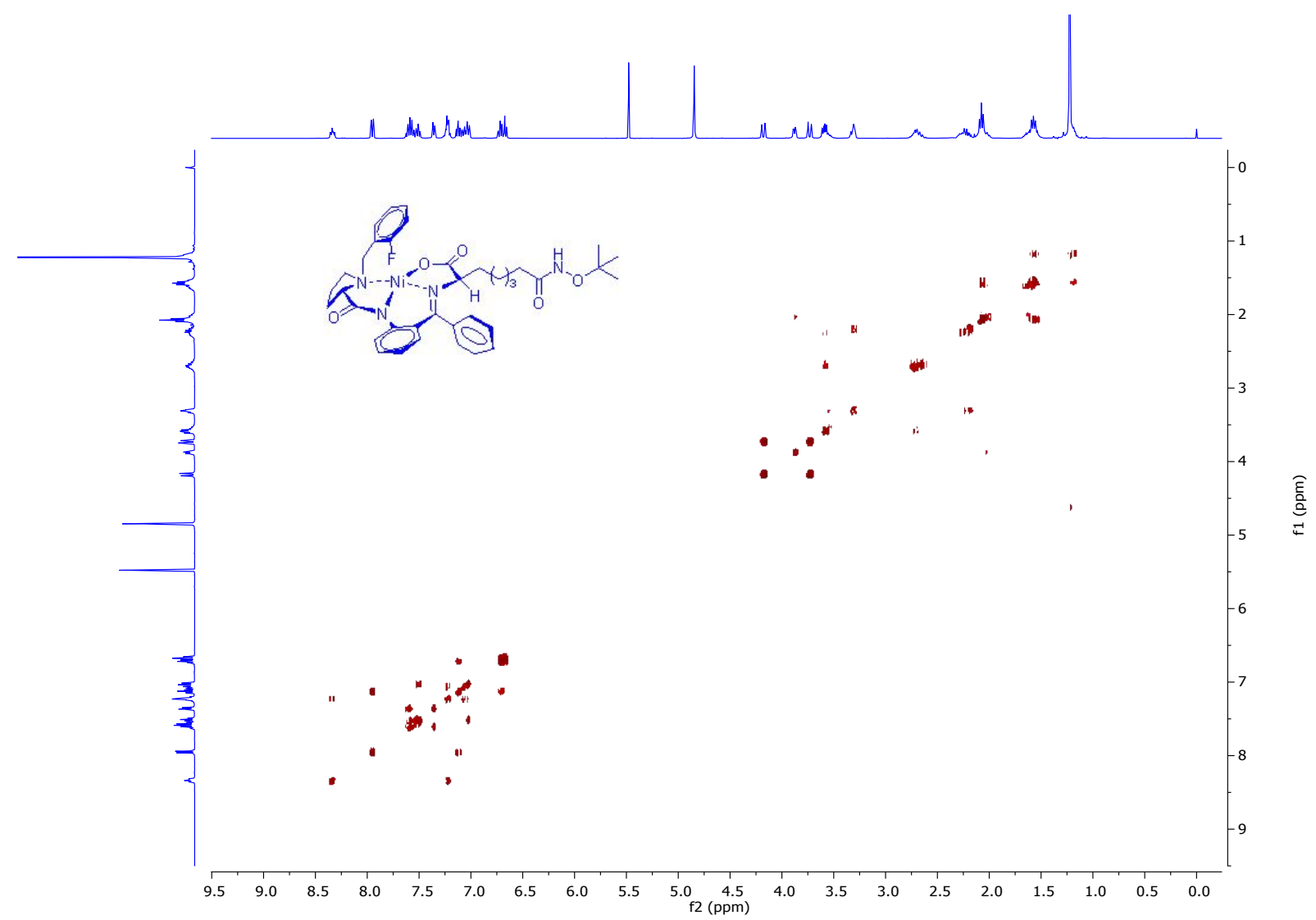




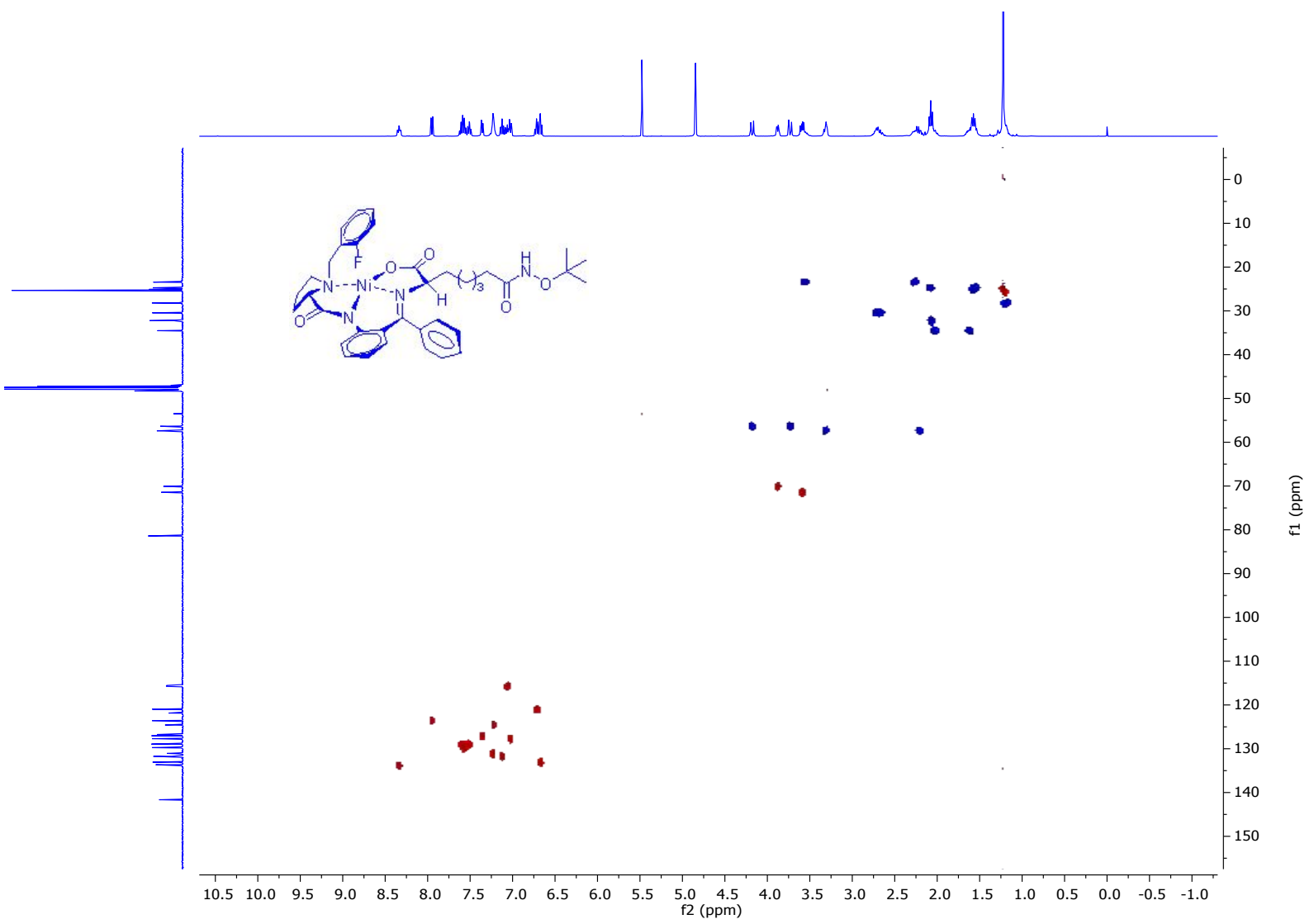


${ }^{1} \mathrm{H},{ }^{13} \mathrm{C}, \mathrm{COSY}$ and HSQC NMR spectra for compound 4
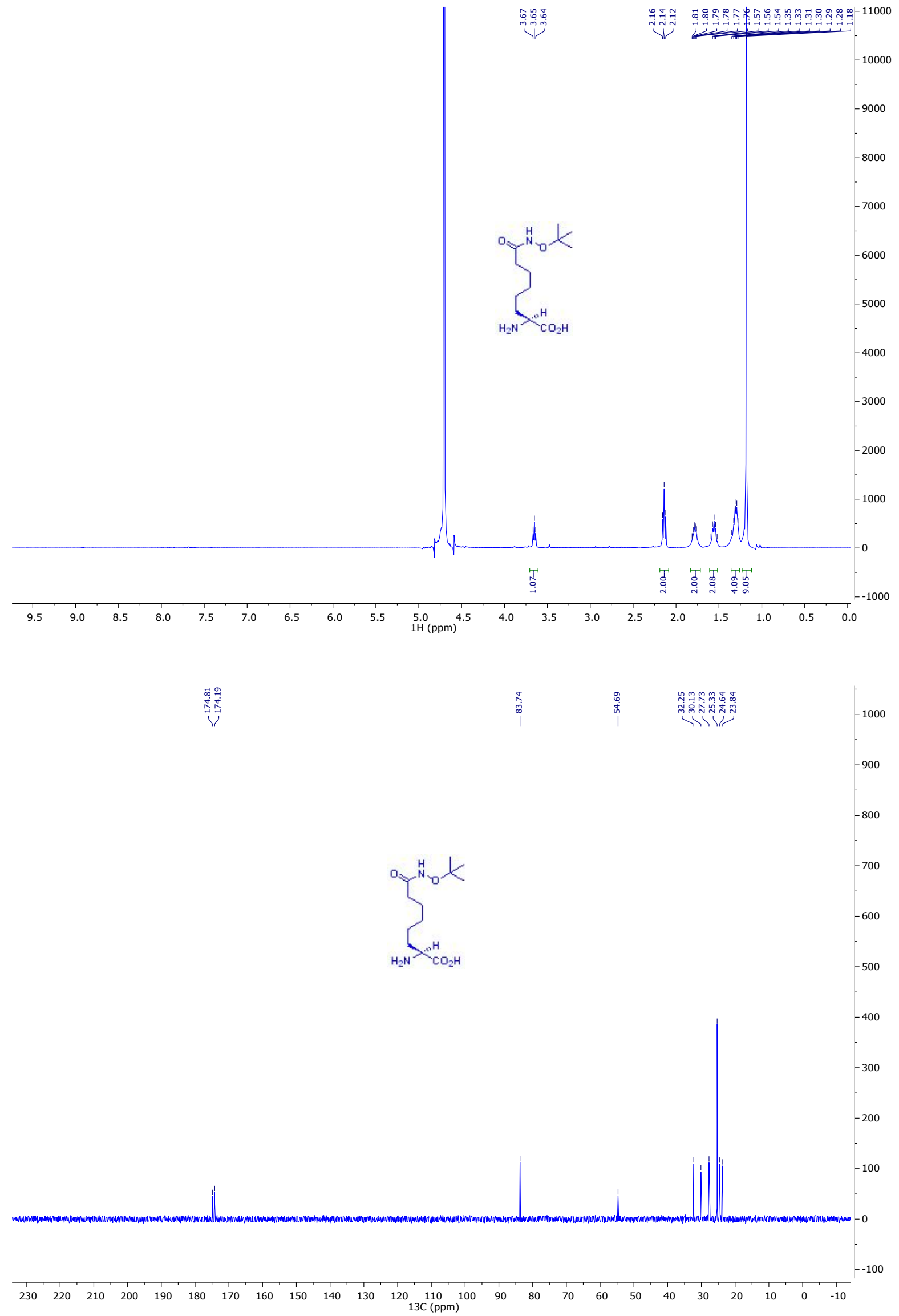

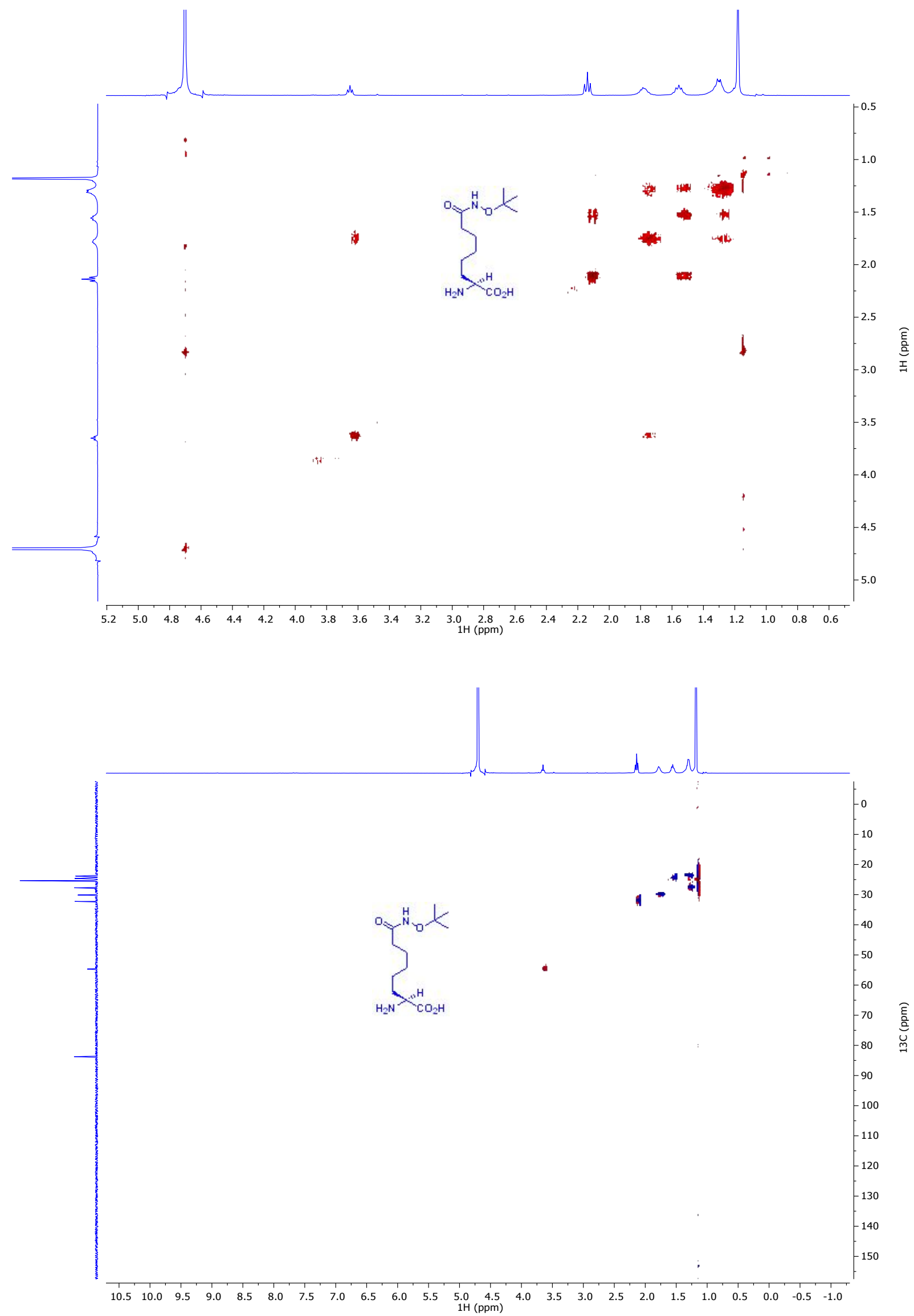
${ }^{1} \mathrm{H},{ }^{13} \mathrm{C}, \mathrm{COSY}$ and HSQC NMR spectra for compound 5
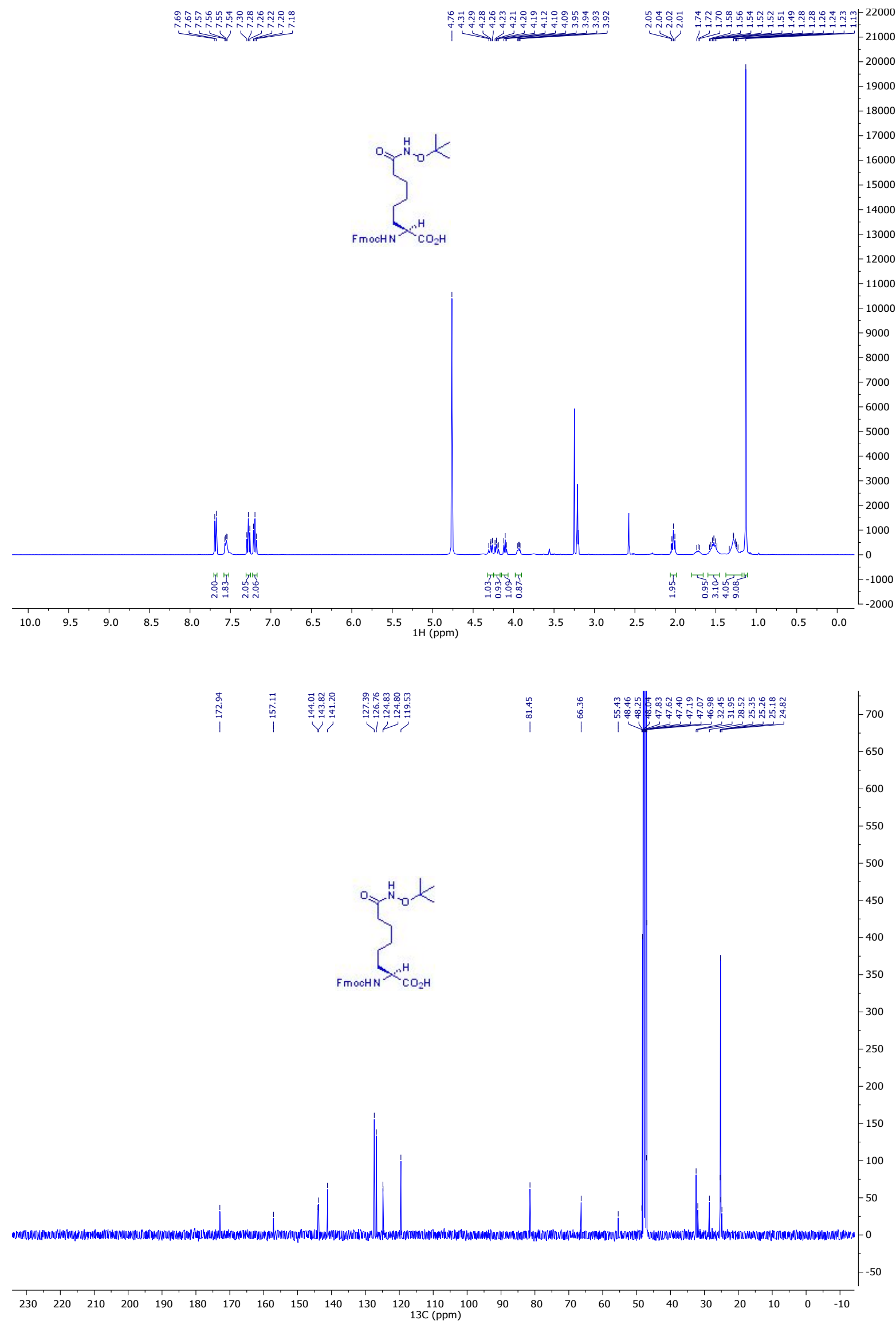

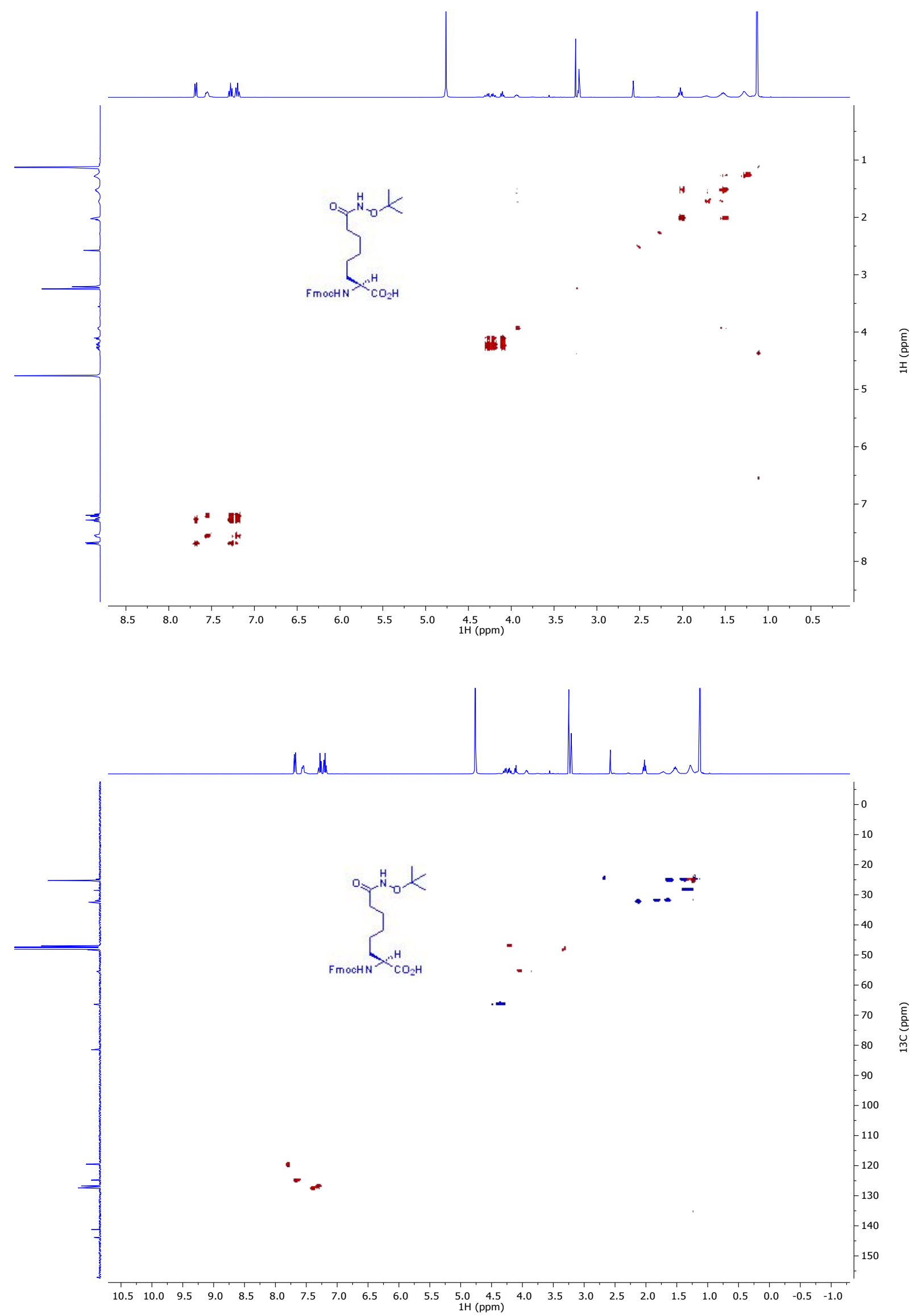
${ }^{1} \mathrm{H},{ }^{13} \mathrm{C}, \mathrm{COSY}$ and HSQC NMR spectra for compound 6

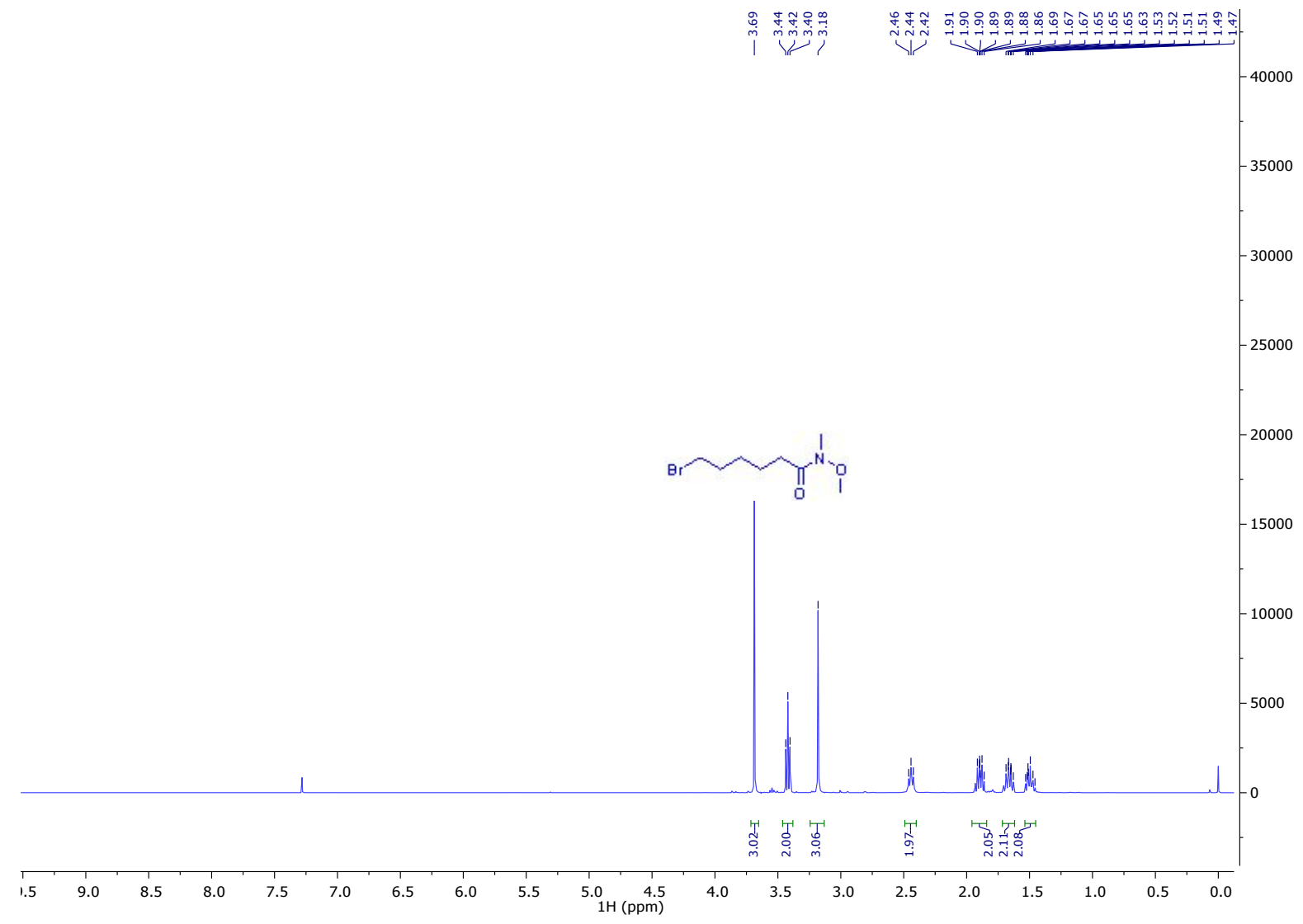




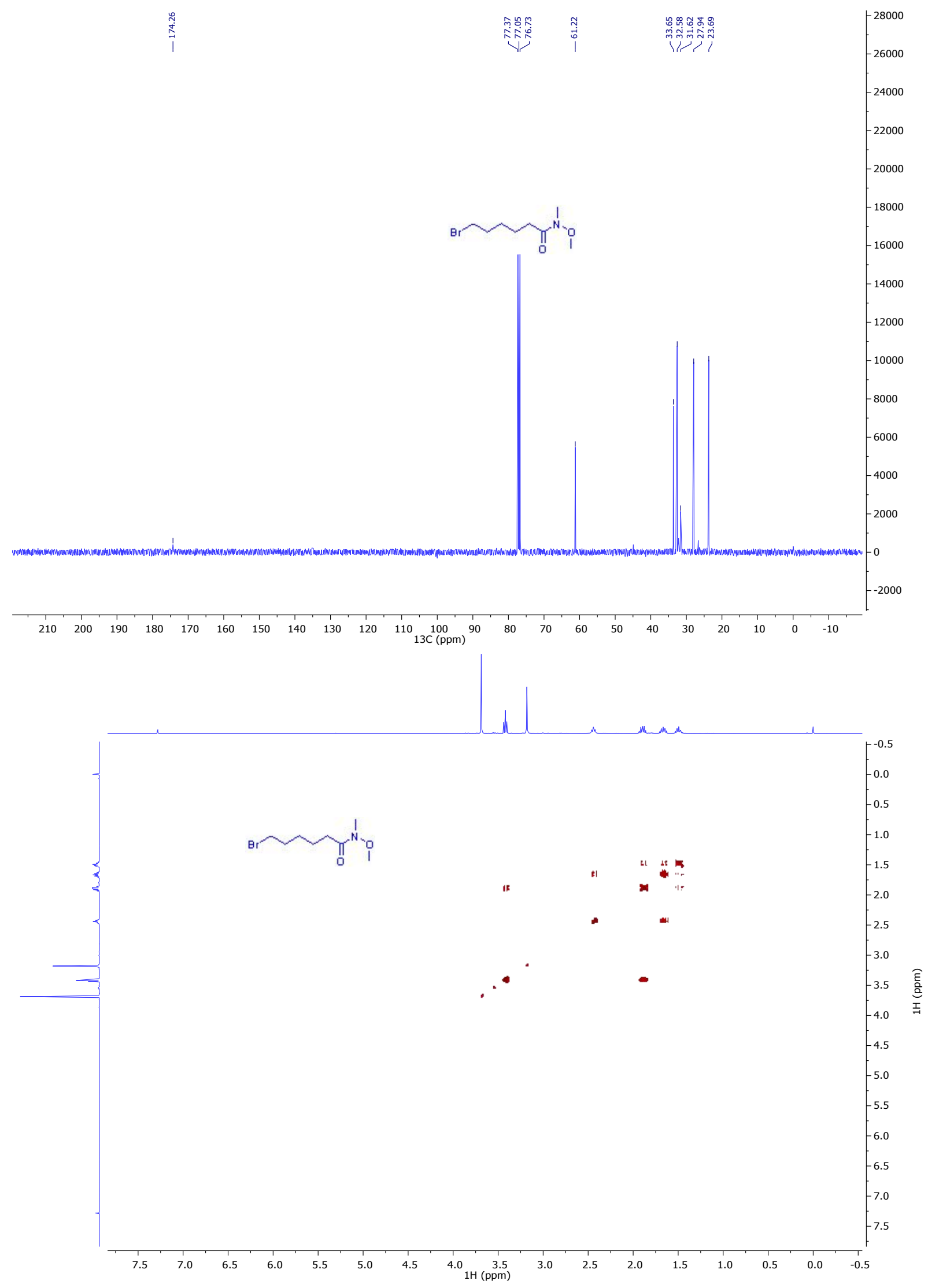




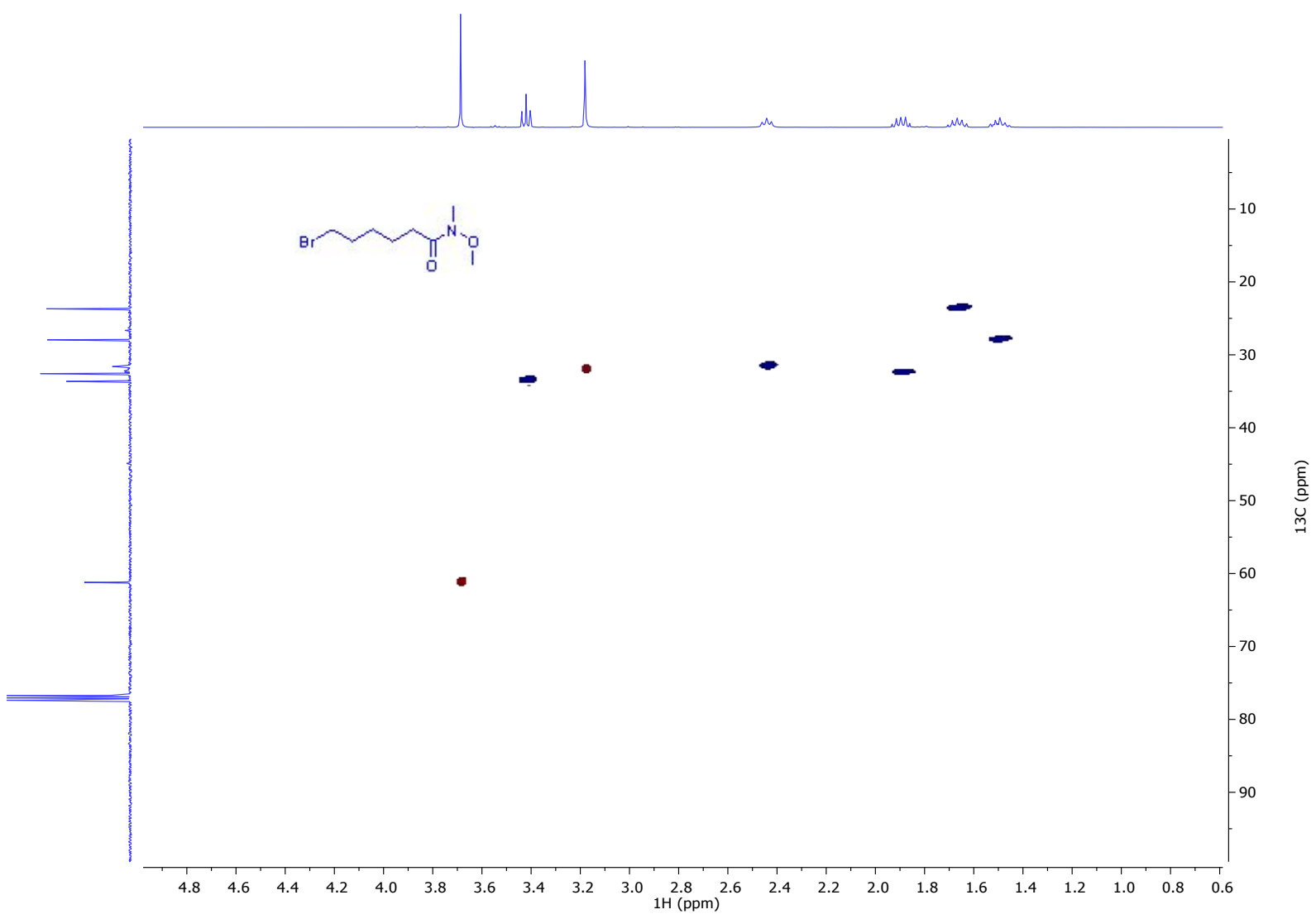

${ }^{1} \mathrm{H},{ }^{13} \mathrm{C}, \mathrm{COSY}$ and HSQC NMR spectra for compound $6 \mathrm{a}$

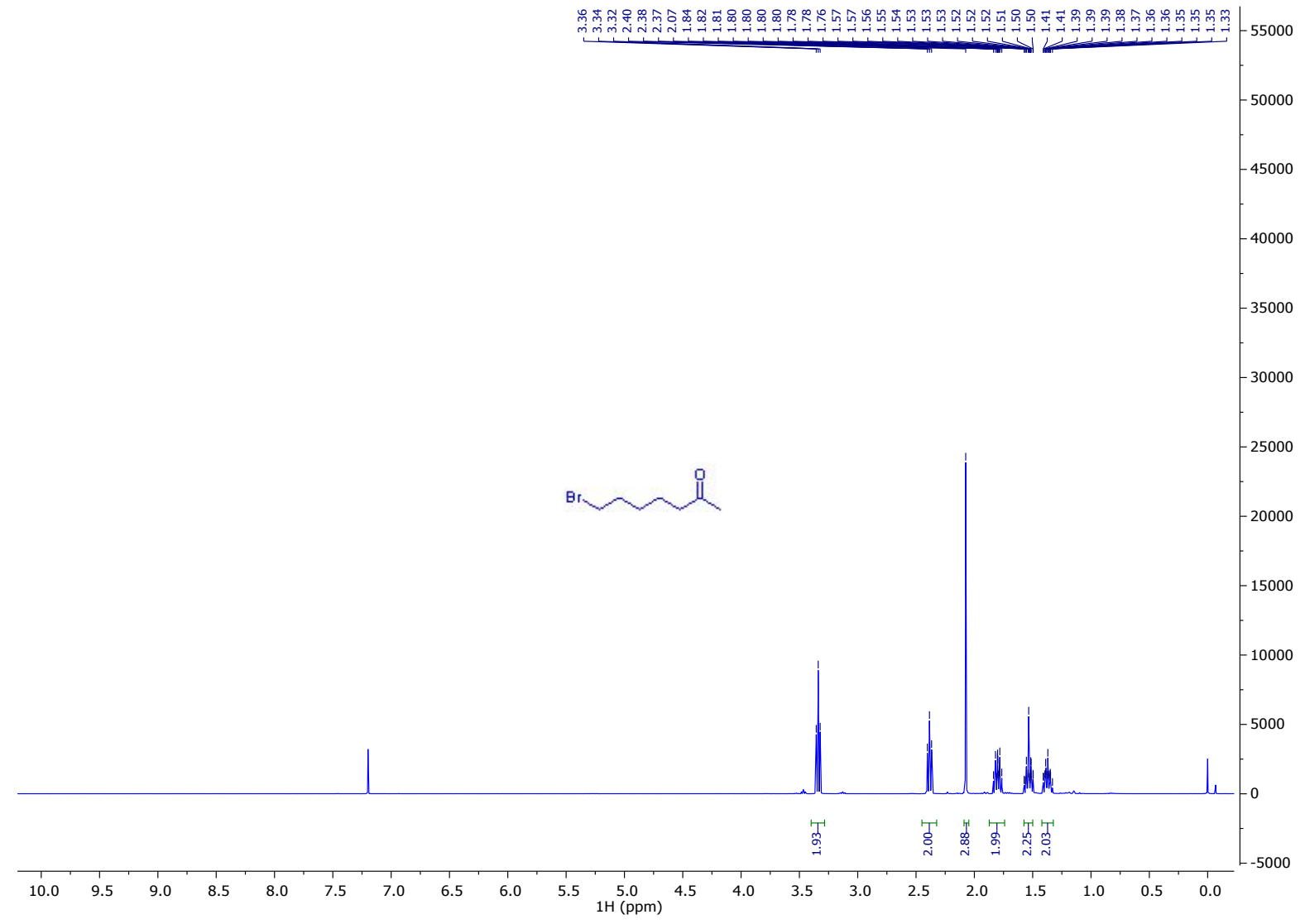




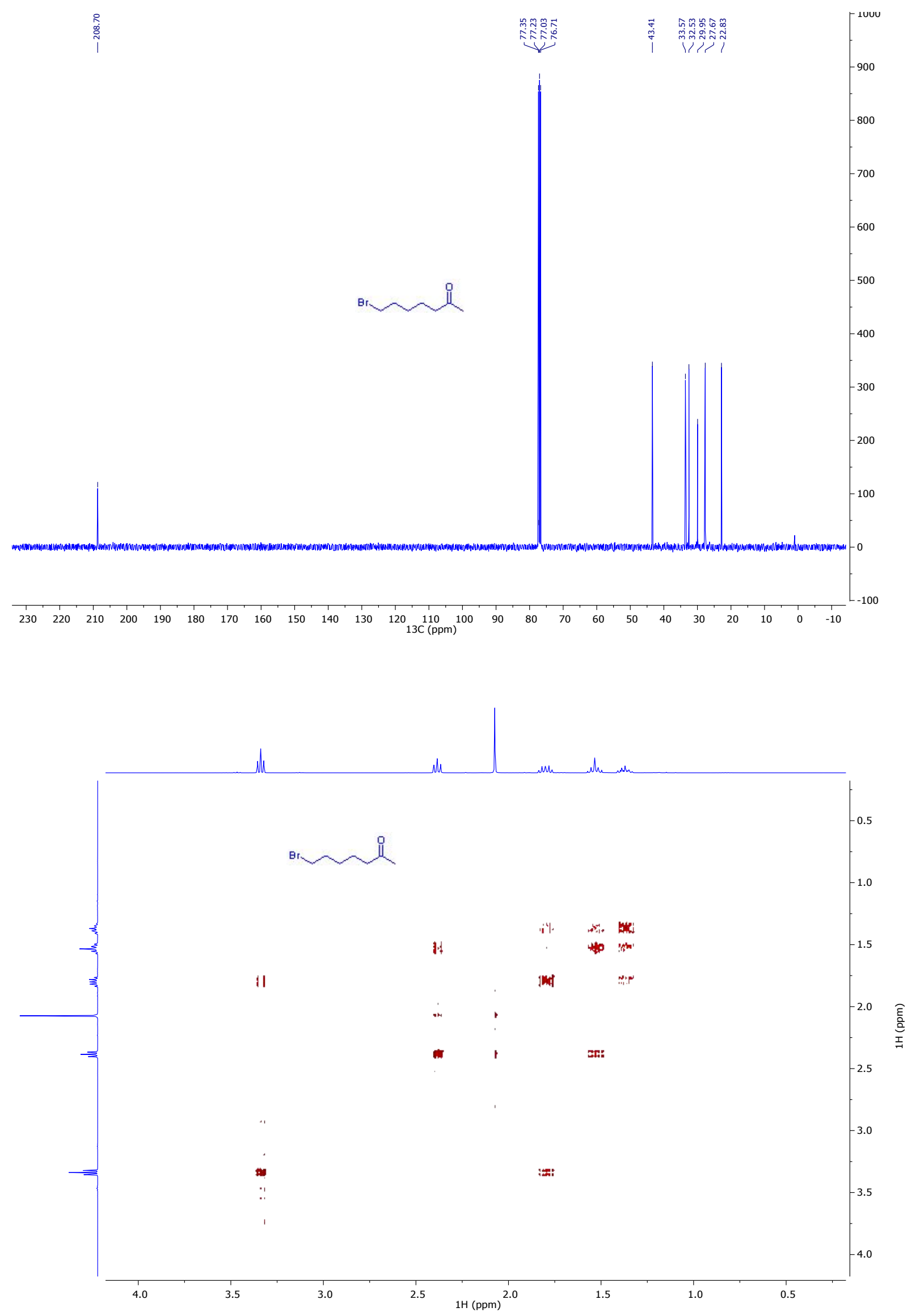




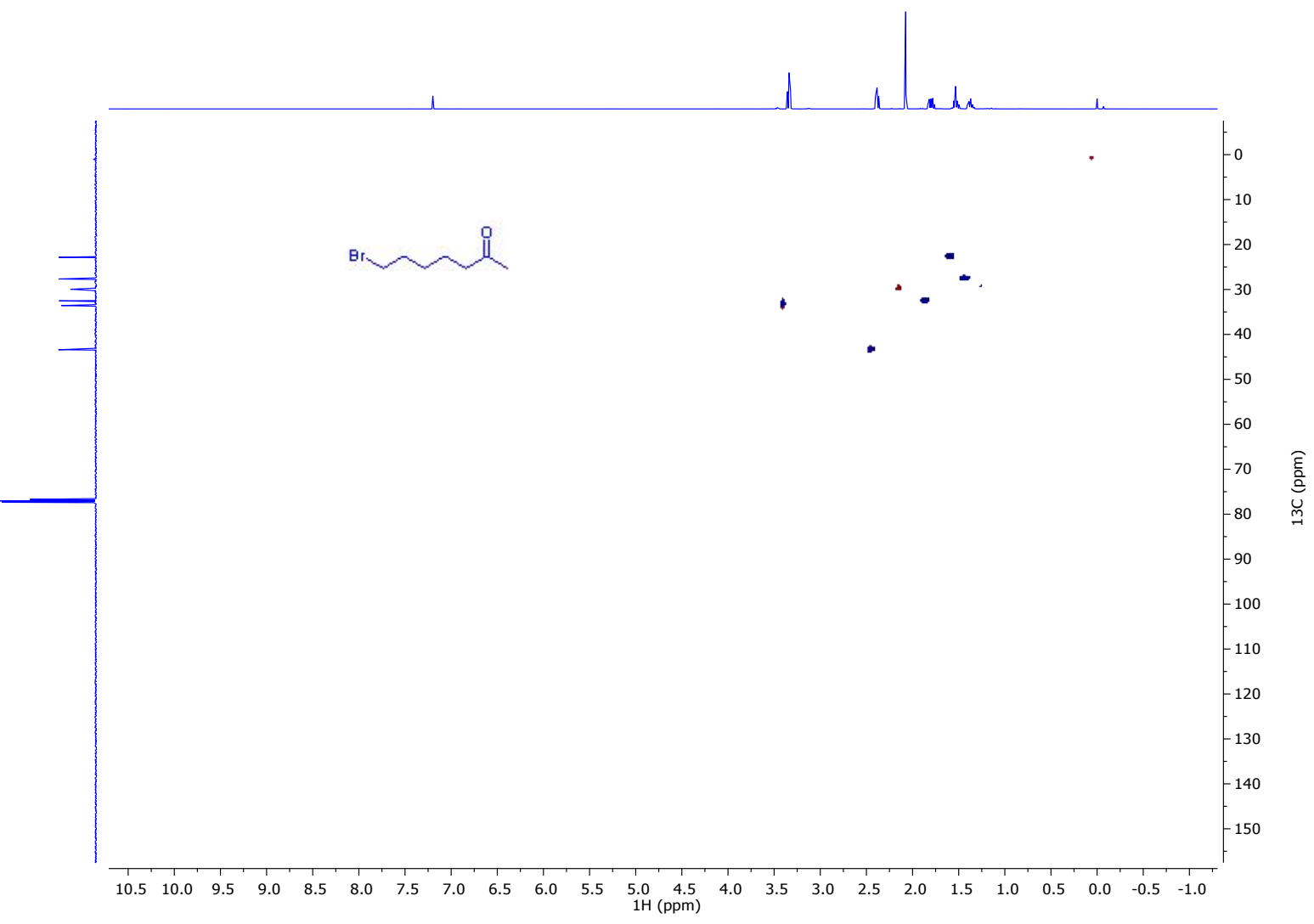

${ }^{1} \mathrm{H},{ }^{13} \mathrm{C}, \mathrm{COSY}$ and HSQC NMR spectra for compound $6 \mathrm{~b}$

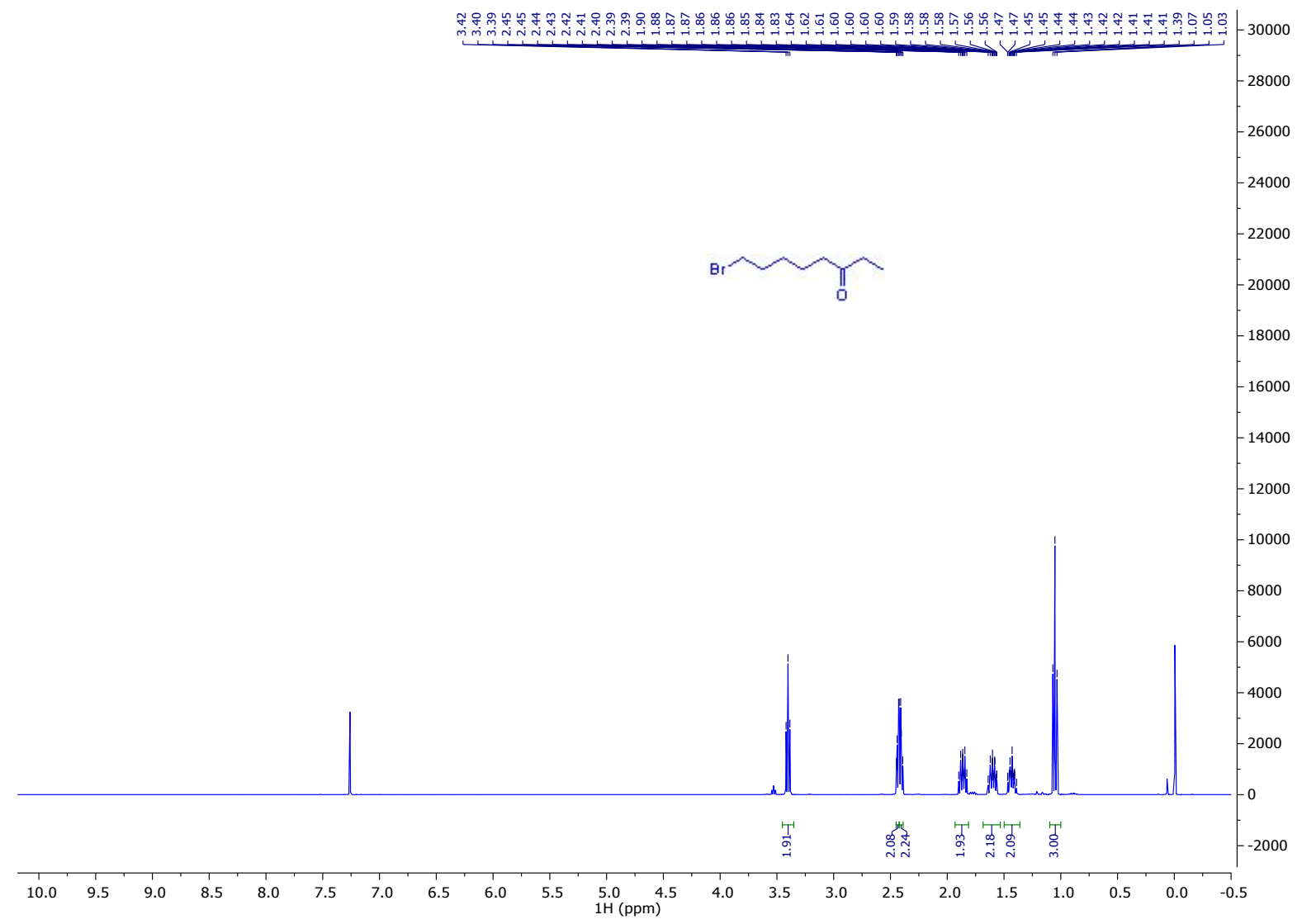



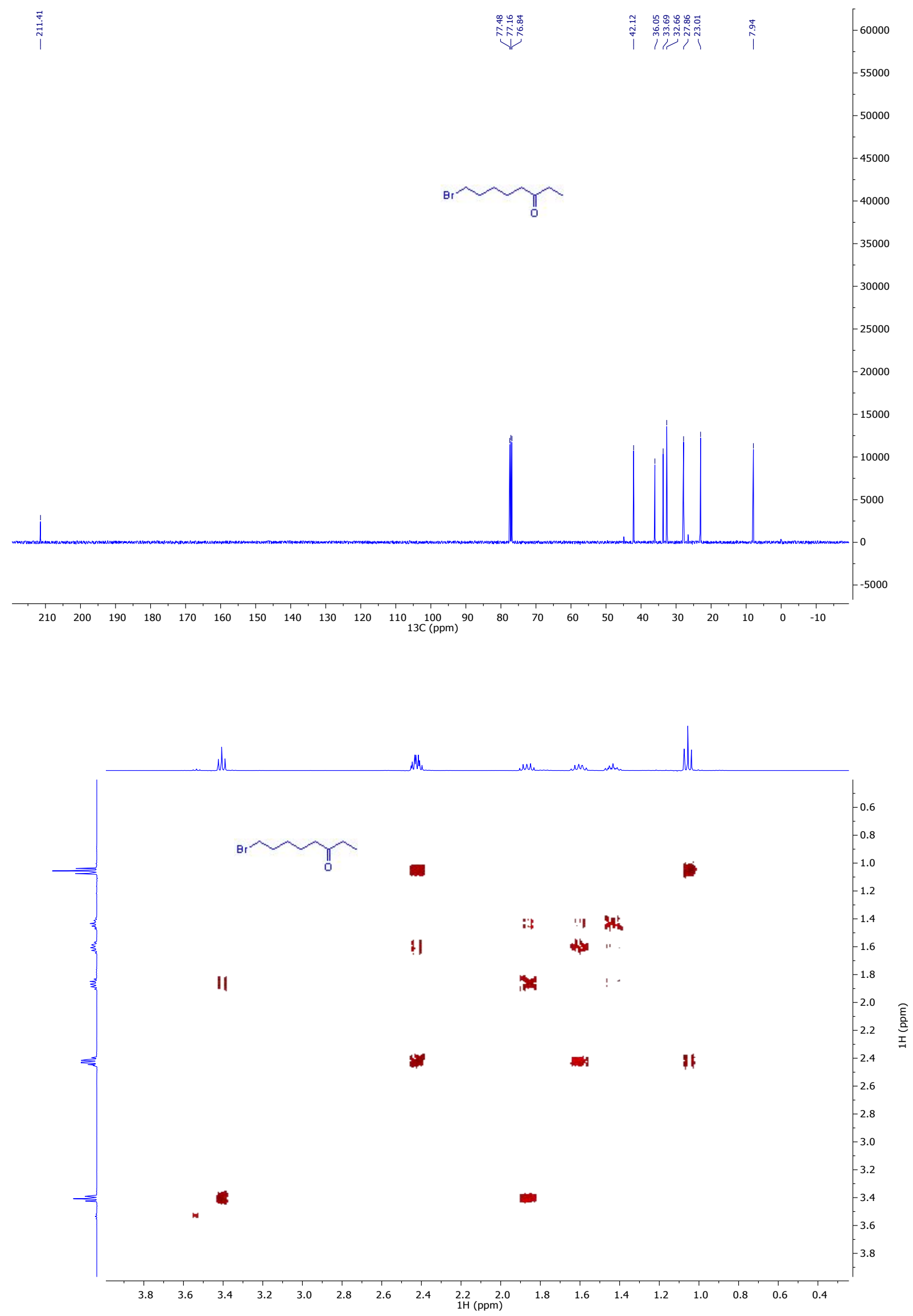


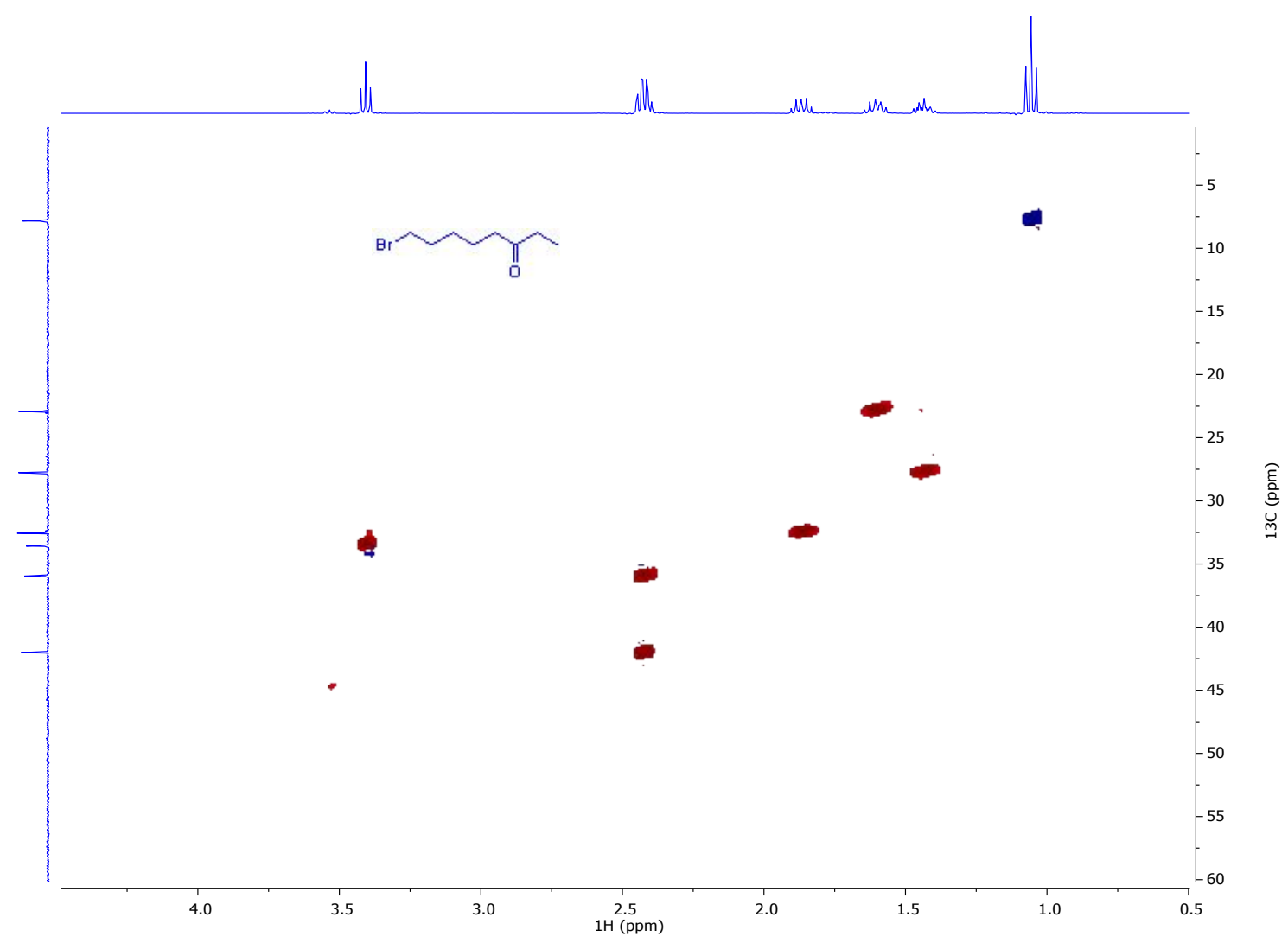

${ }^{1} \mathrm{H},{ }^{13} \mathrm{C}, \mathrm{COSY}, \mathrm{HSQC}$ and ${ }^{19} \mathrm{~F}$ NMR spectra for compound $7 \mathrm{a}$

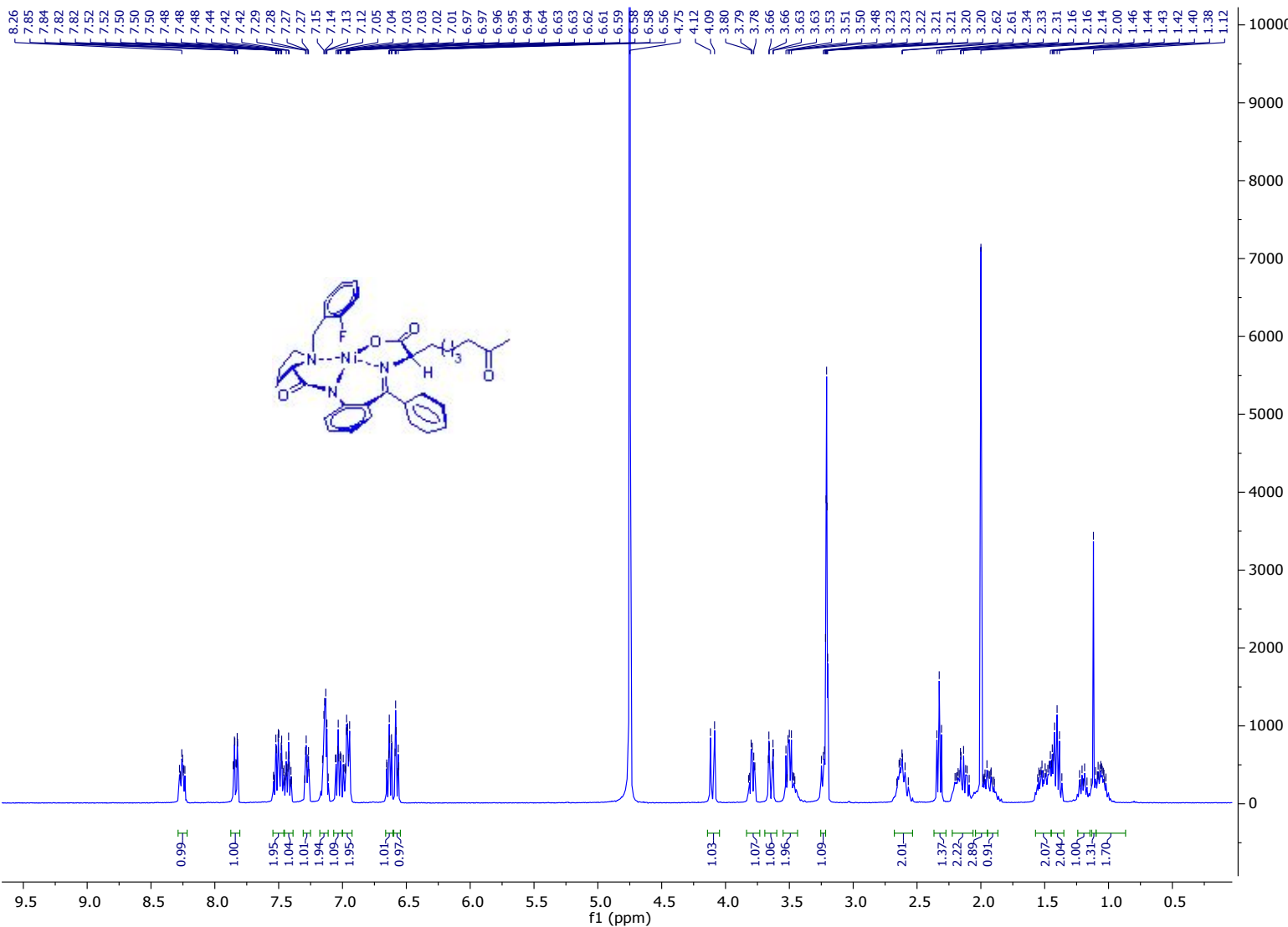




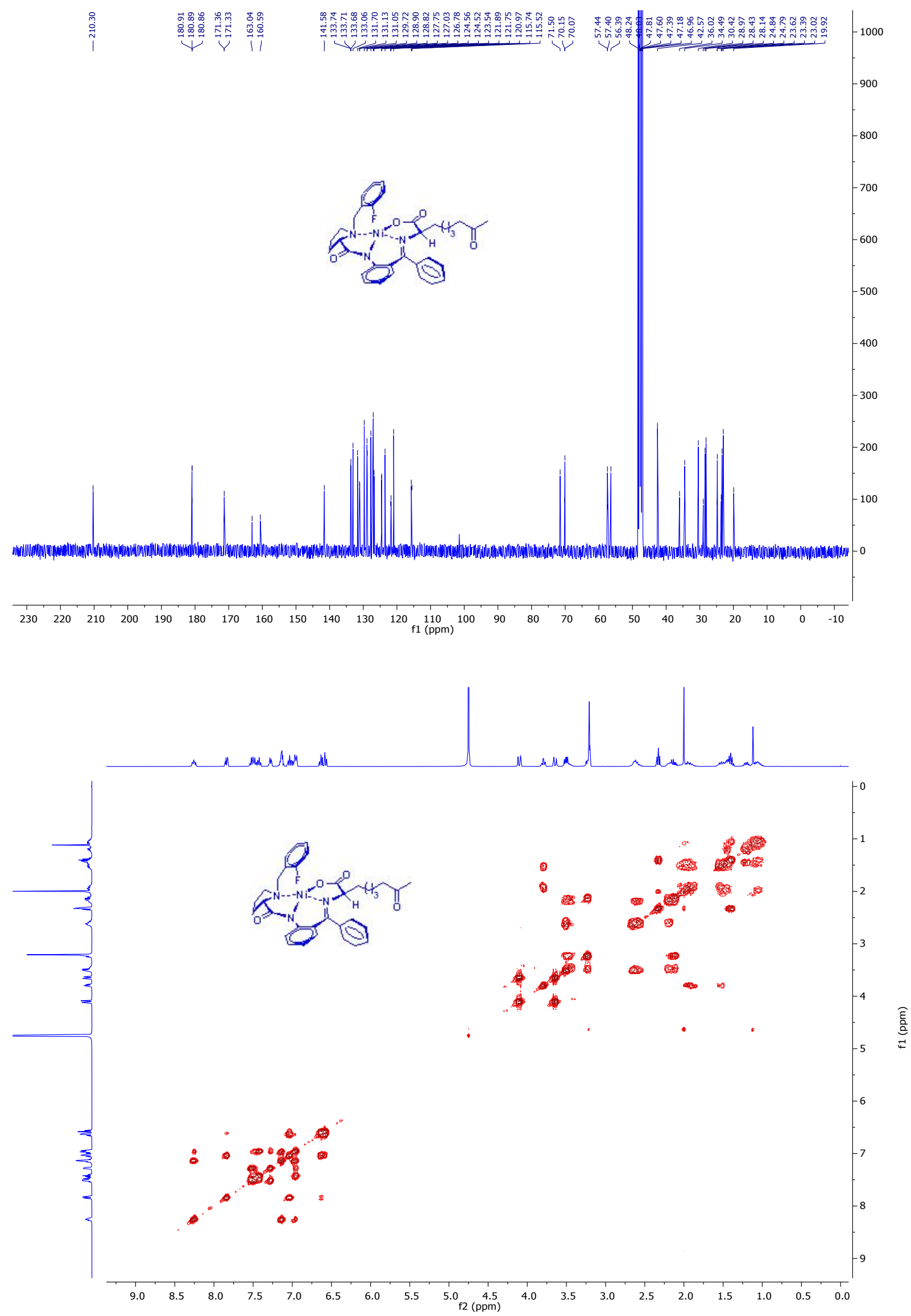




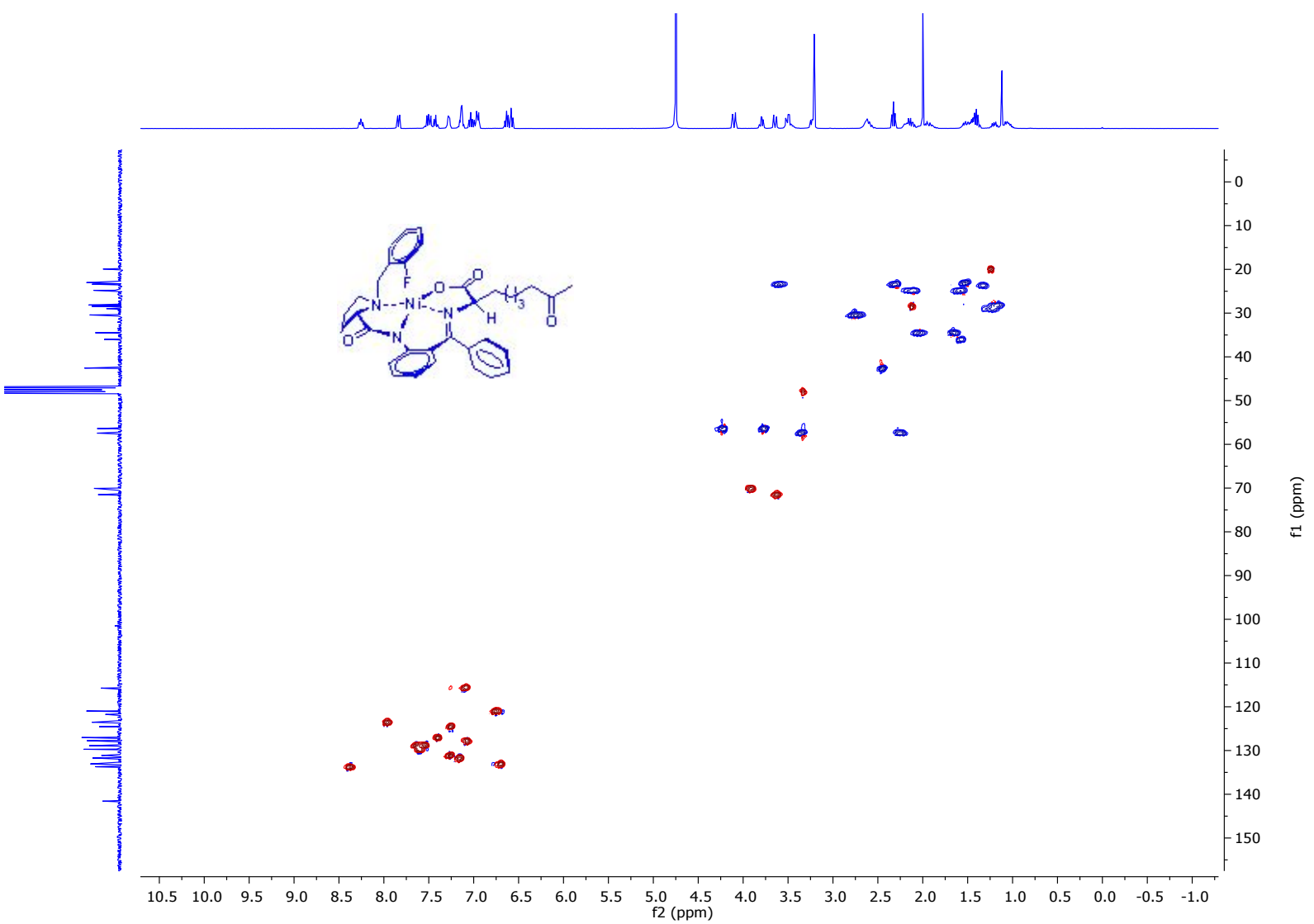




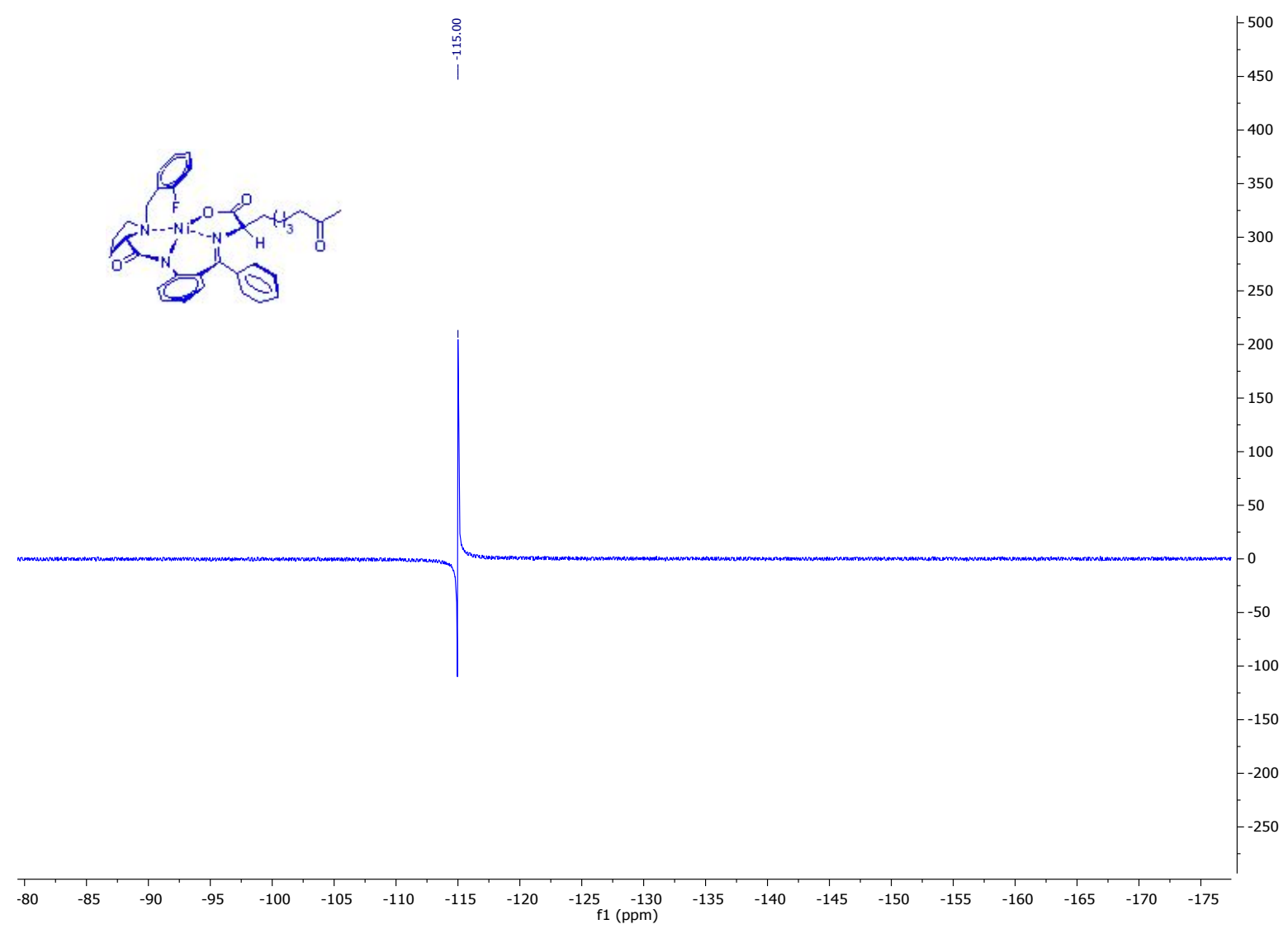

${ }^{1} \mathrm{H},{ }^{13} \mathrm{C}, \mathrm{COSY}$ and HSQC NMR spectra for compound $8 \mathrm{a}$

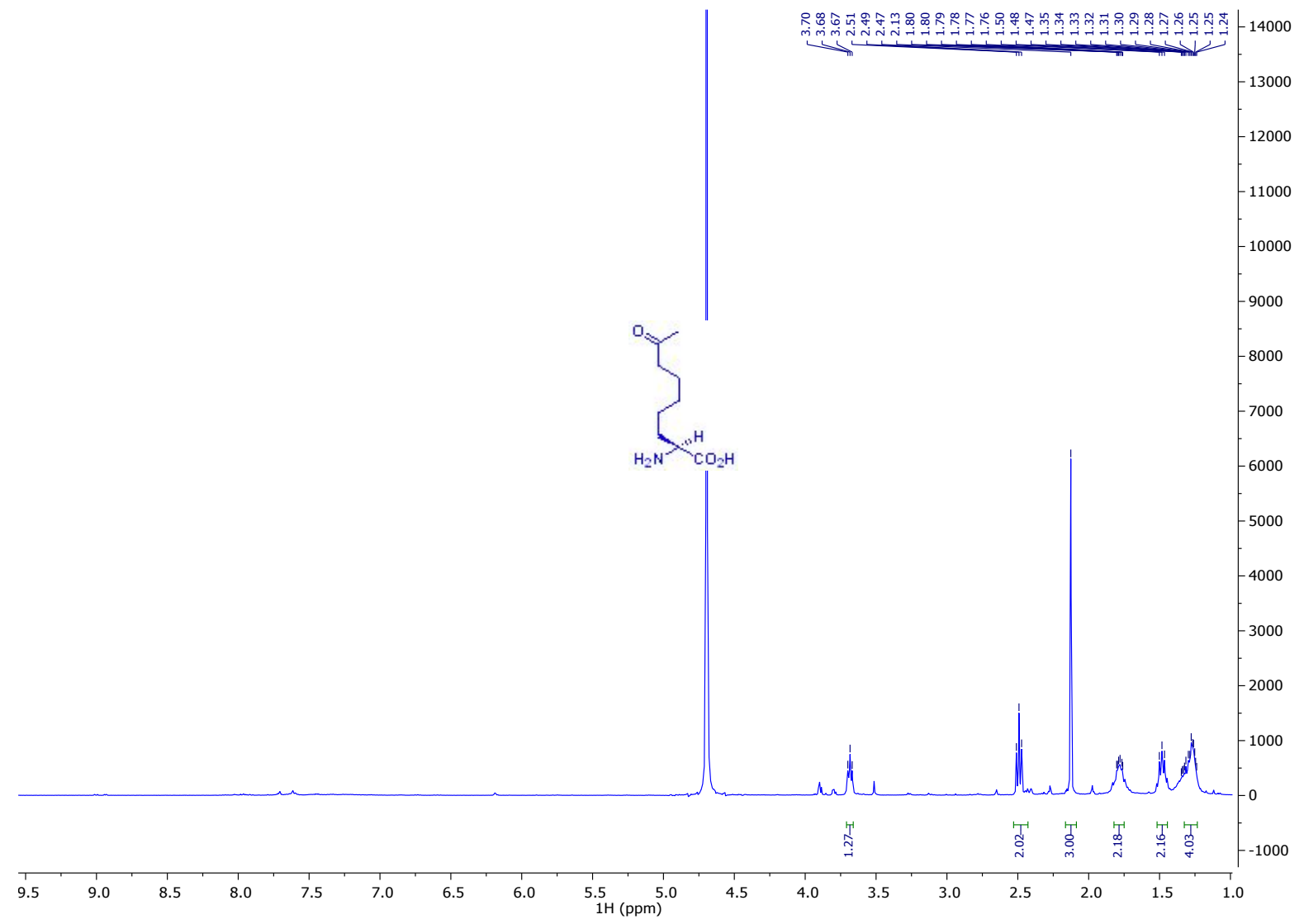



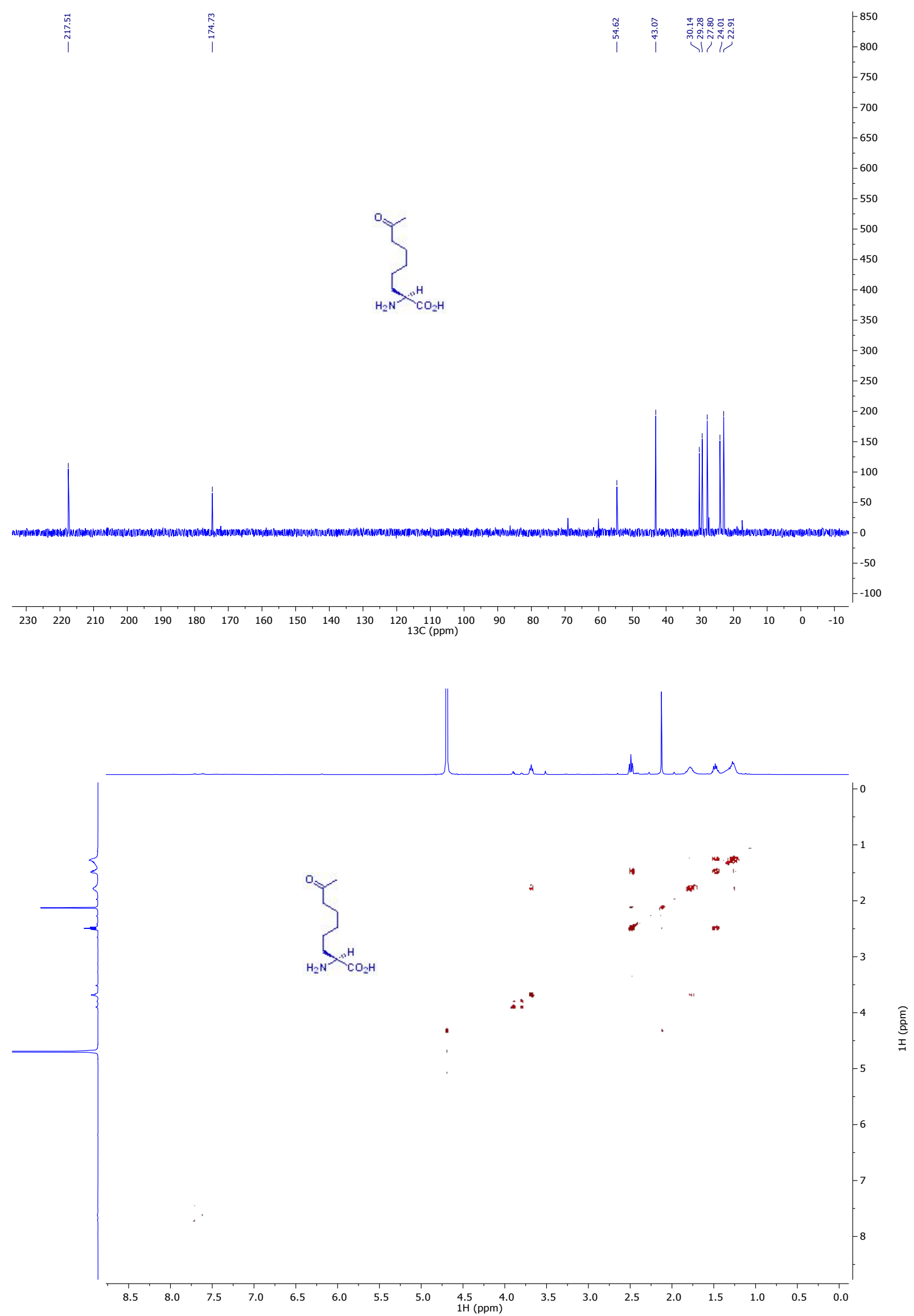


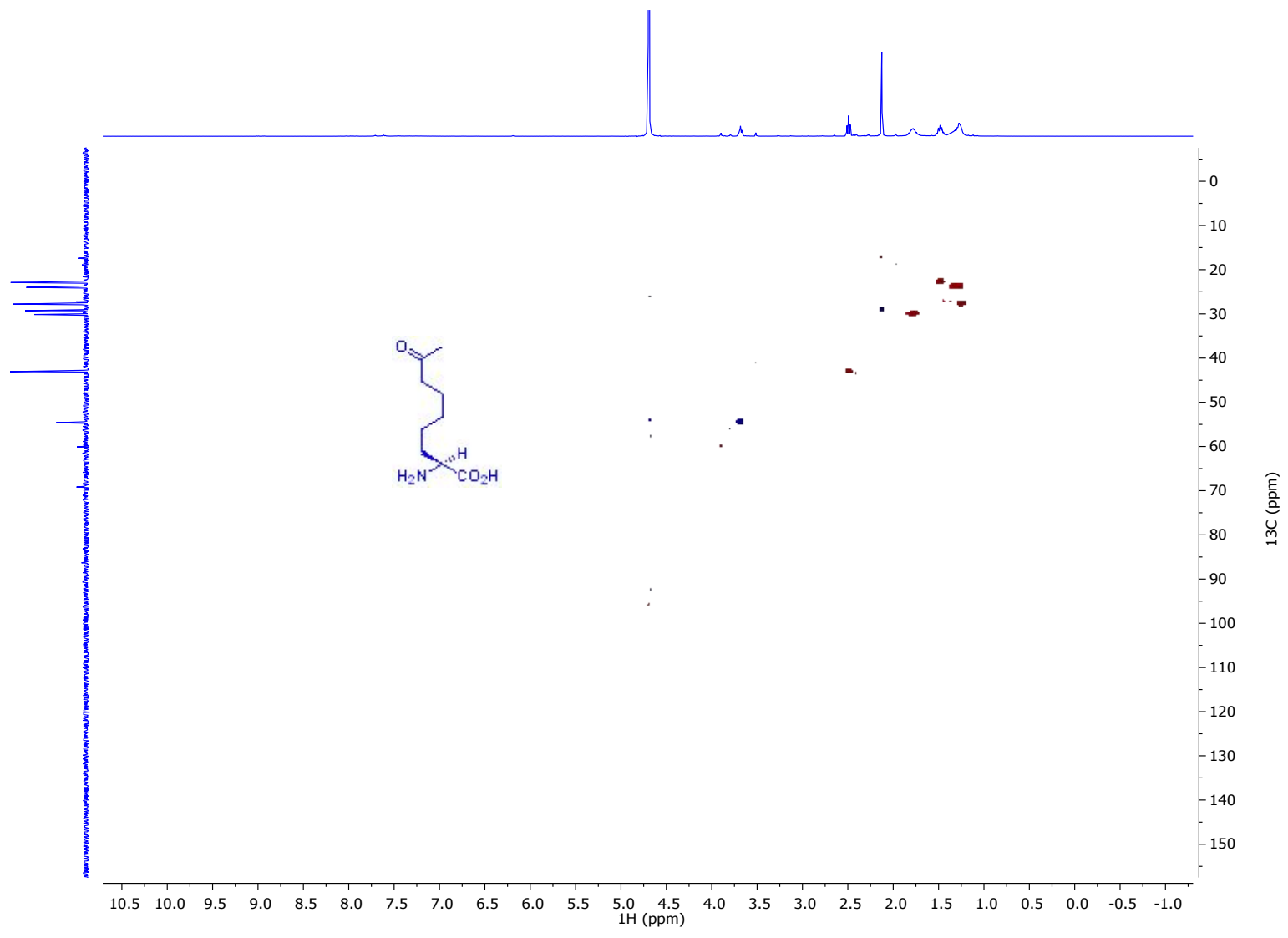

${ }^{1} \mathrm{H},{ }^{13} \mathrm{C}$, COSY and HSQC NMR spectra for compound 9

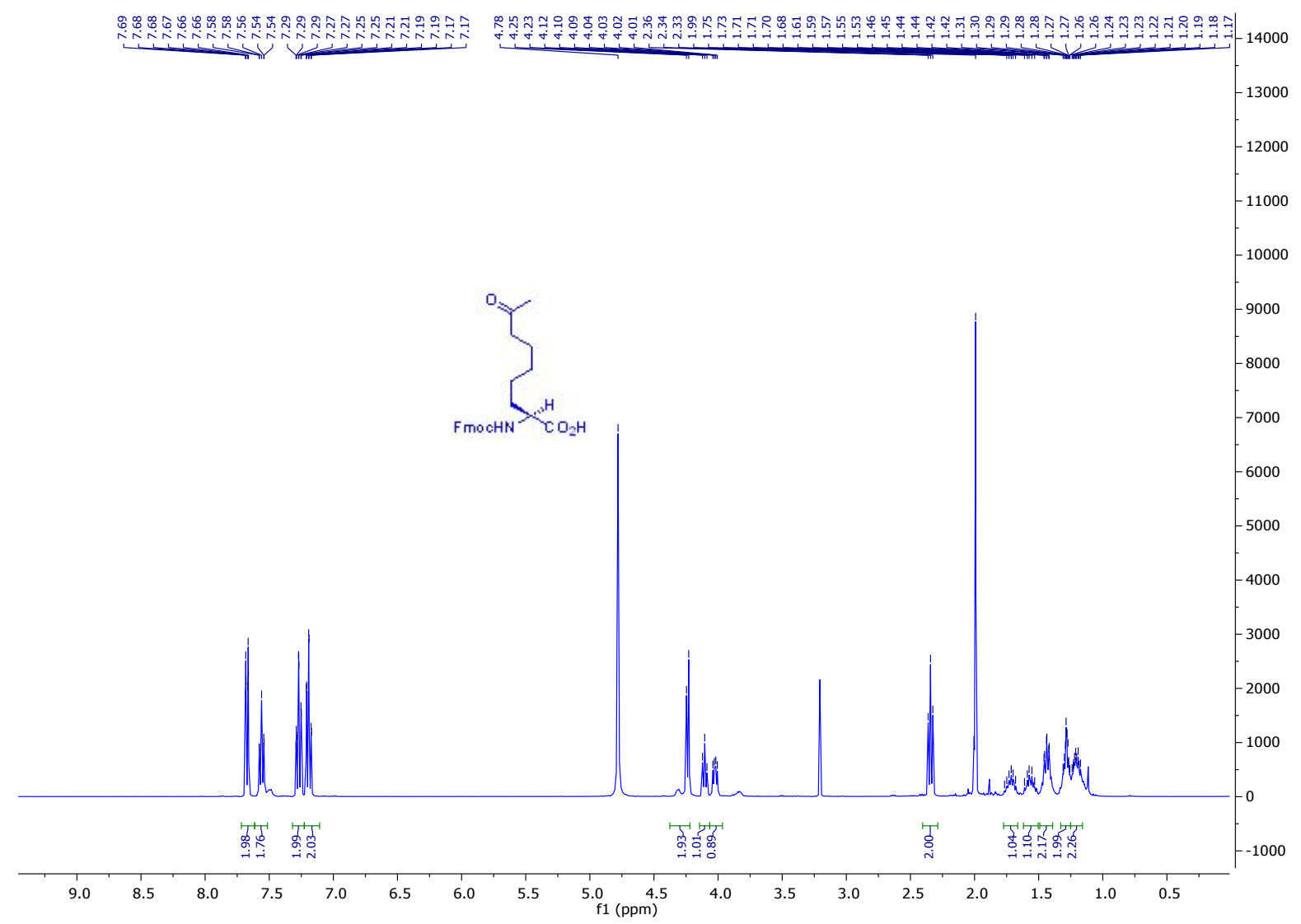



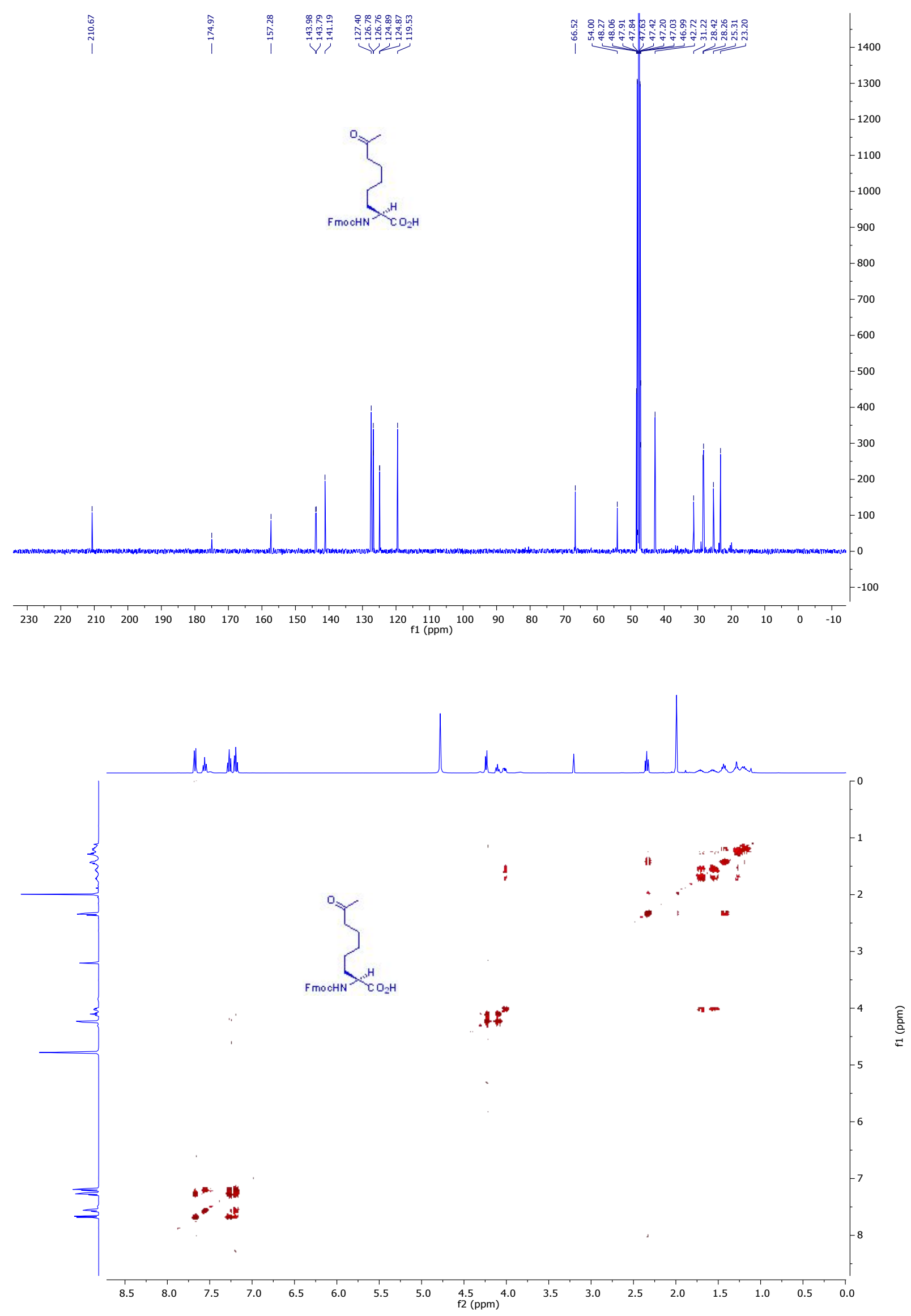


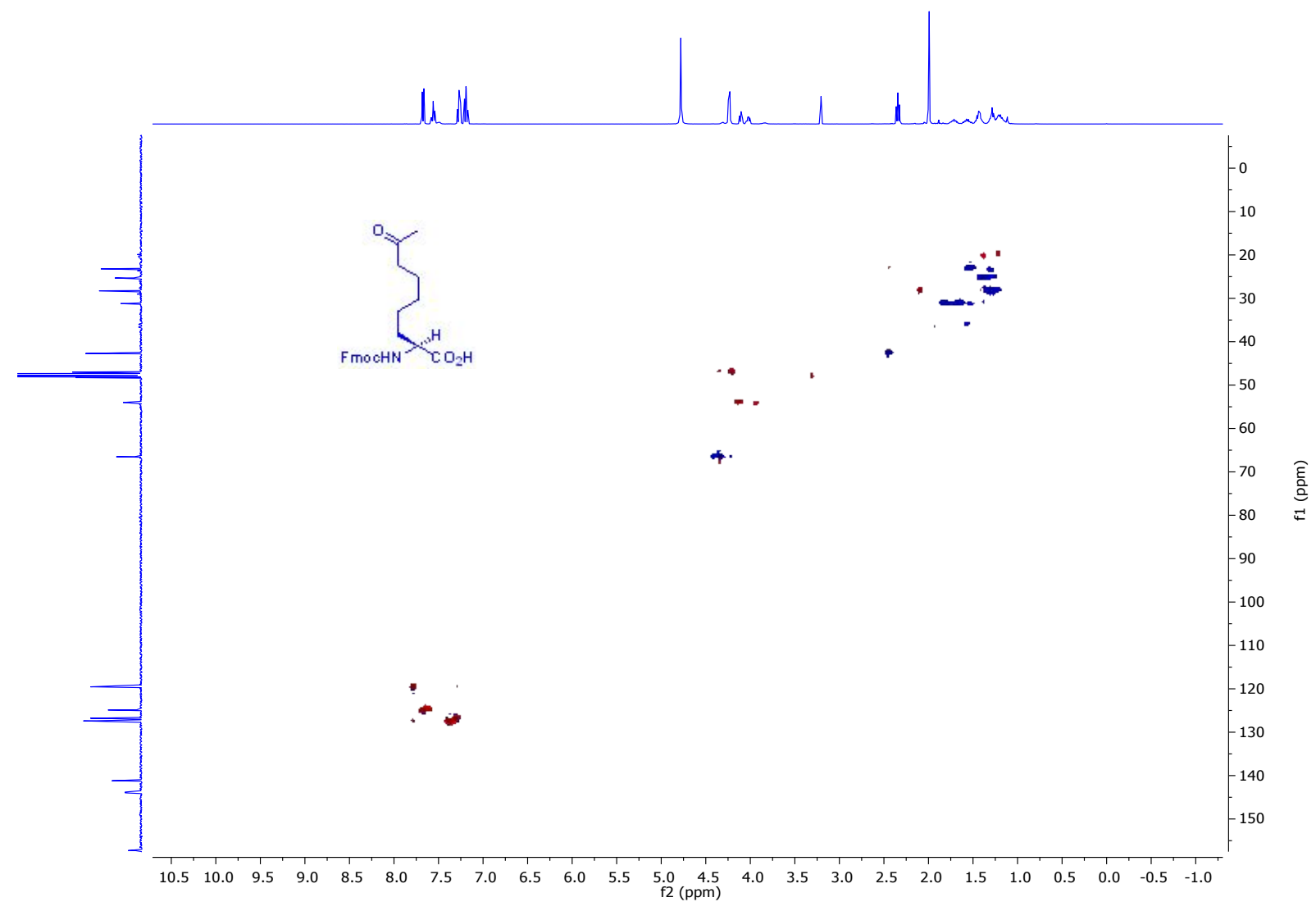

${ }^{1} \mathrm{H},{ }^{13} \mathrm{C},{ }^{19} \mathrm{~F}, \mathrm{COSY}$ and HSQC NMR spectra for compound $7 \mathrm{~b}$

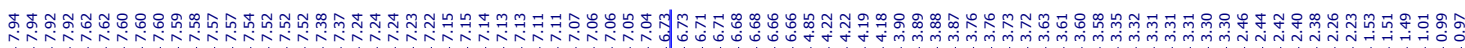

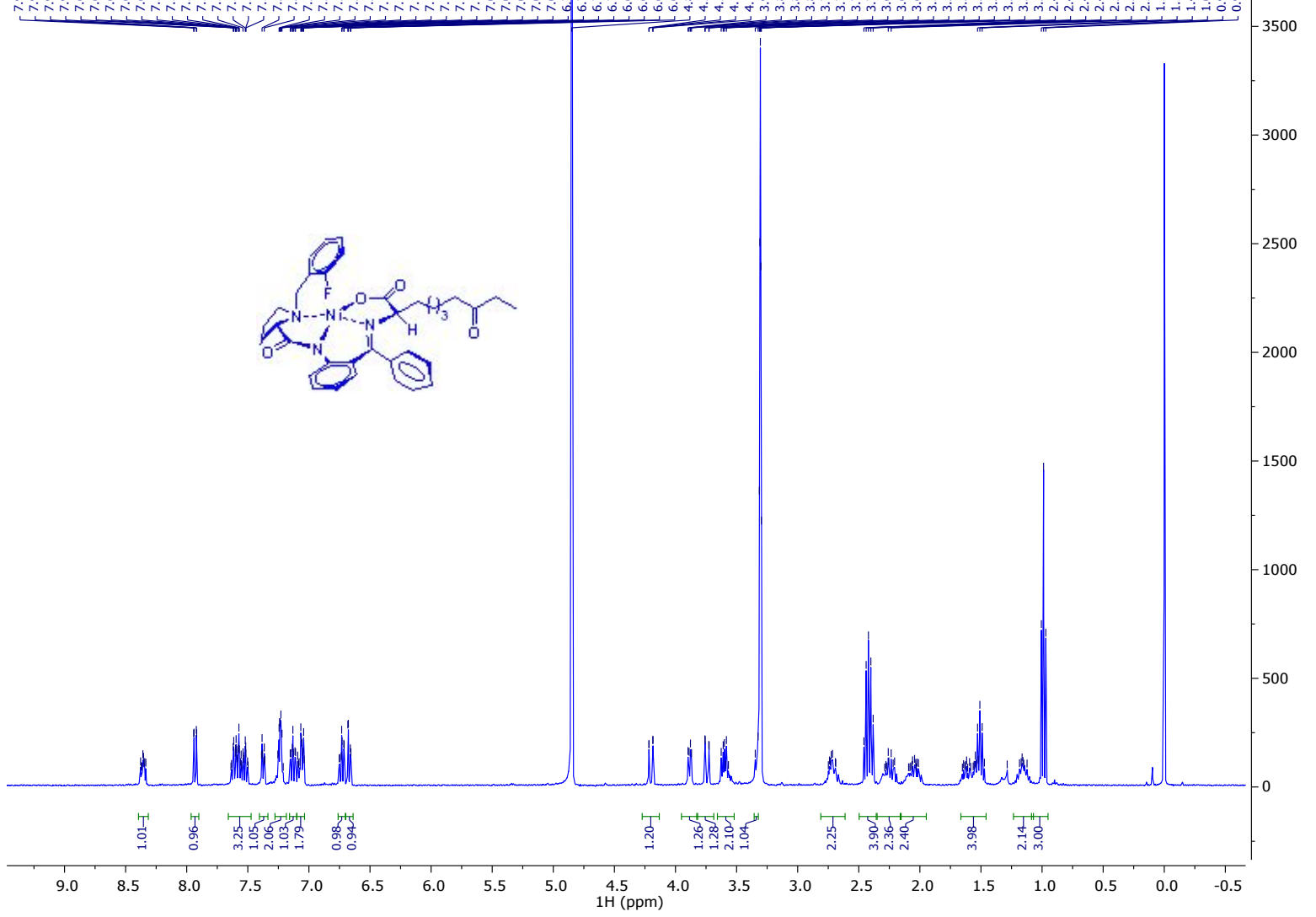



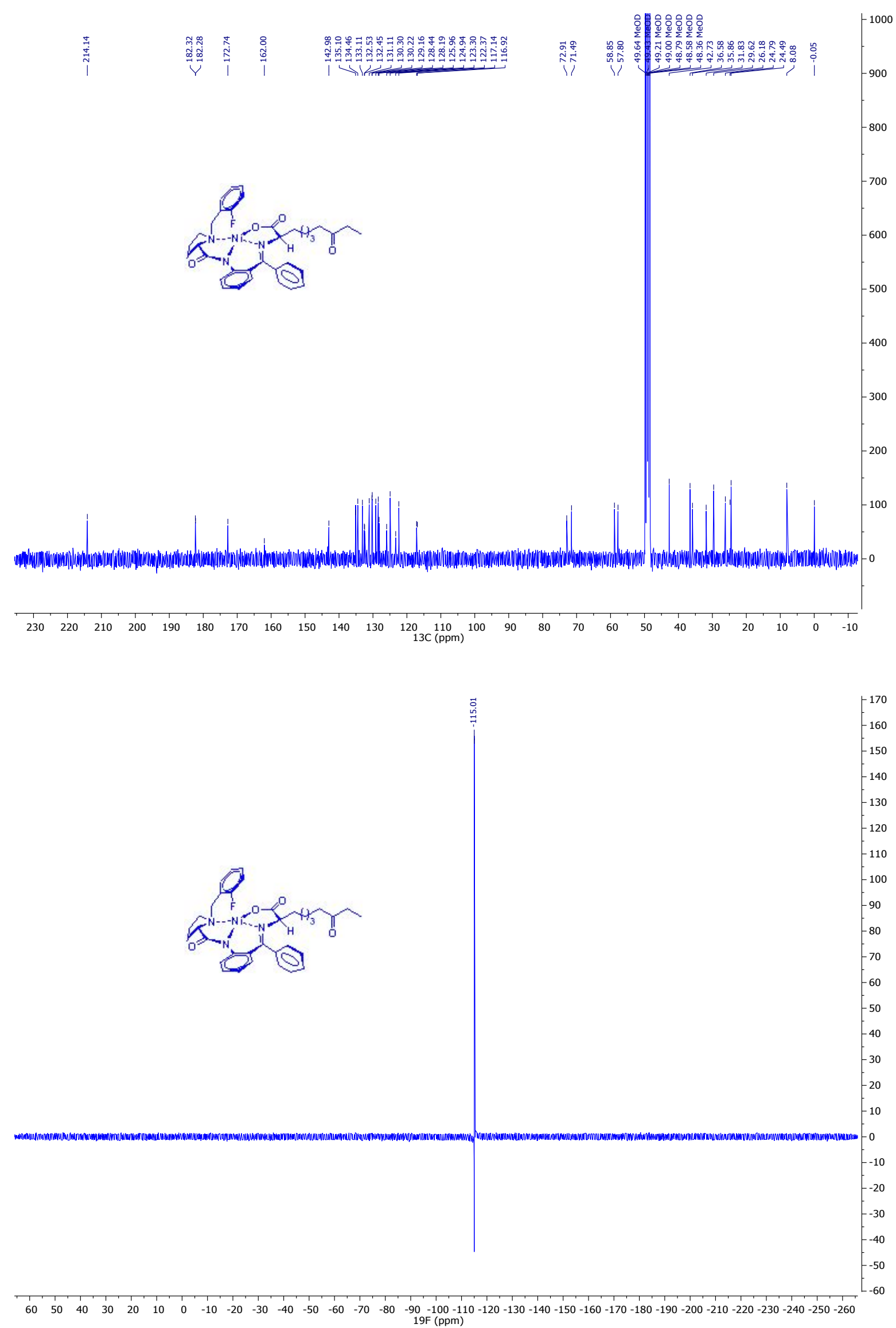

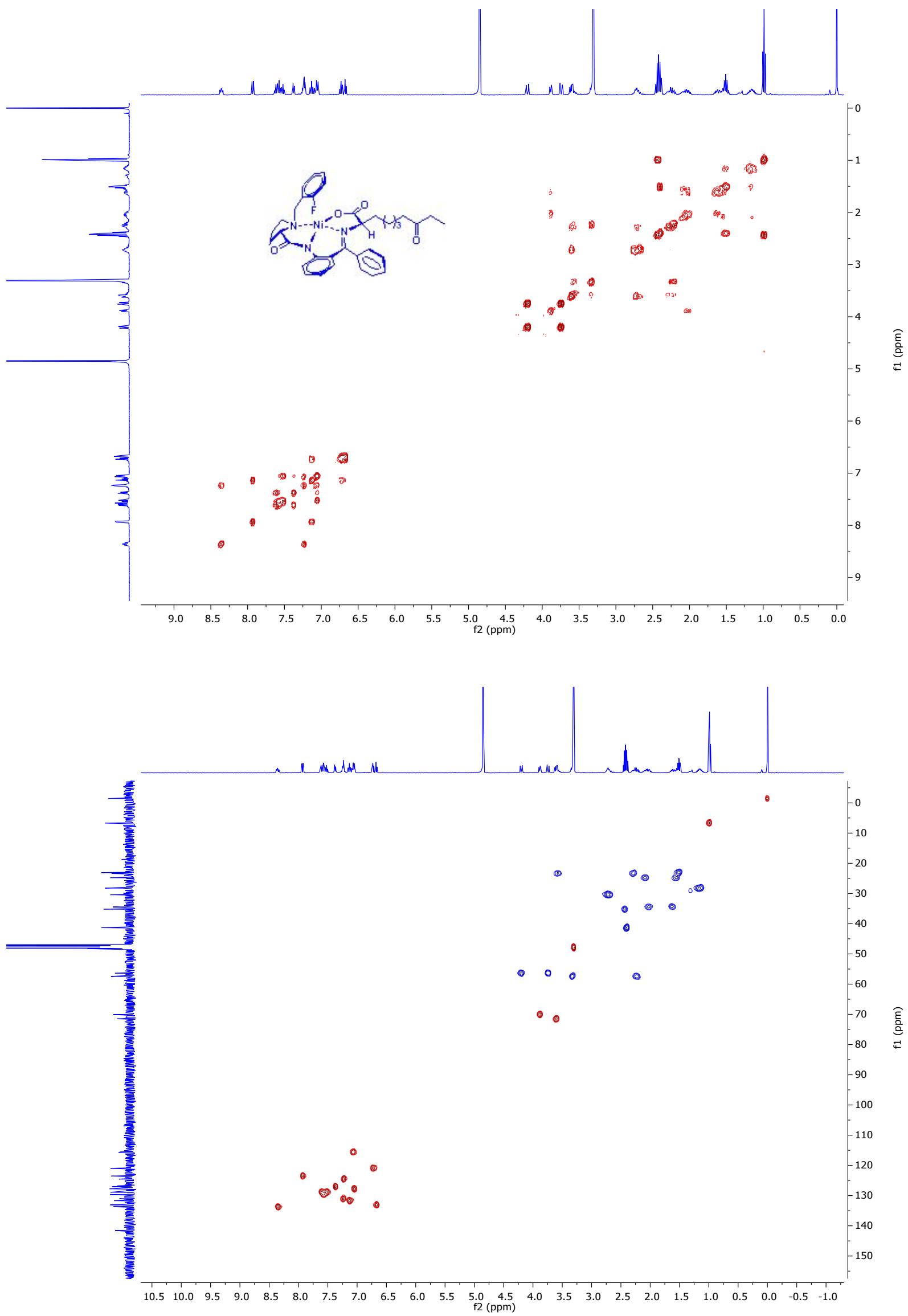

57 
${ }^{1} \mathrm{H},{ }^{13} \mathrm{C}, \mathrm{COSY}$ and HSQC NMR spectra for compound $8 \mathrm{~b}$

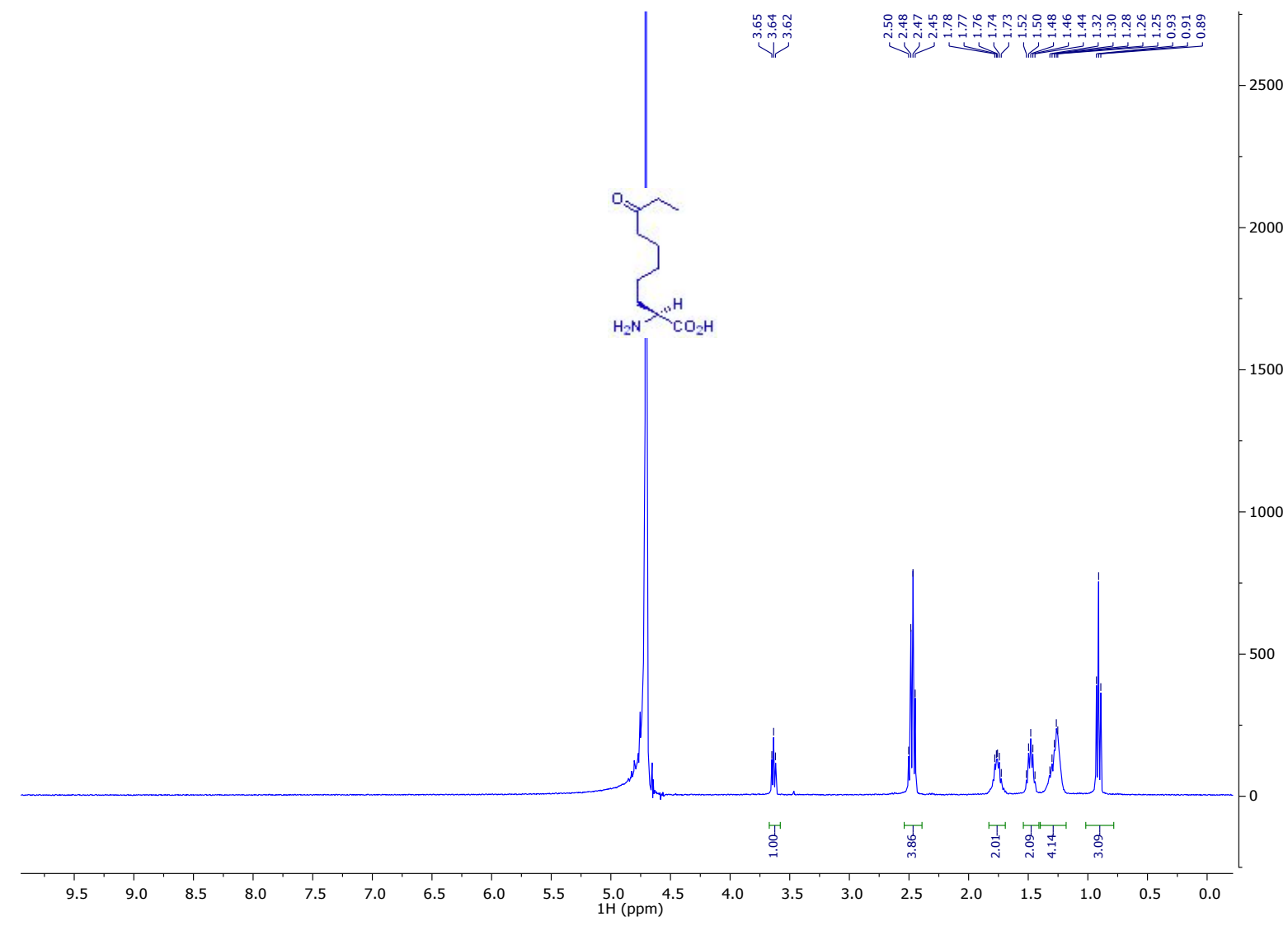




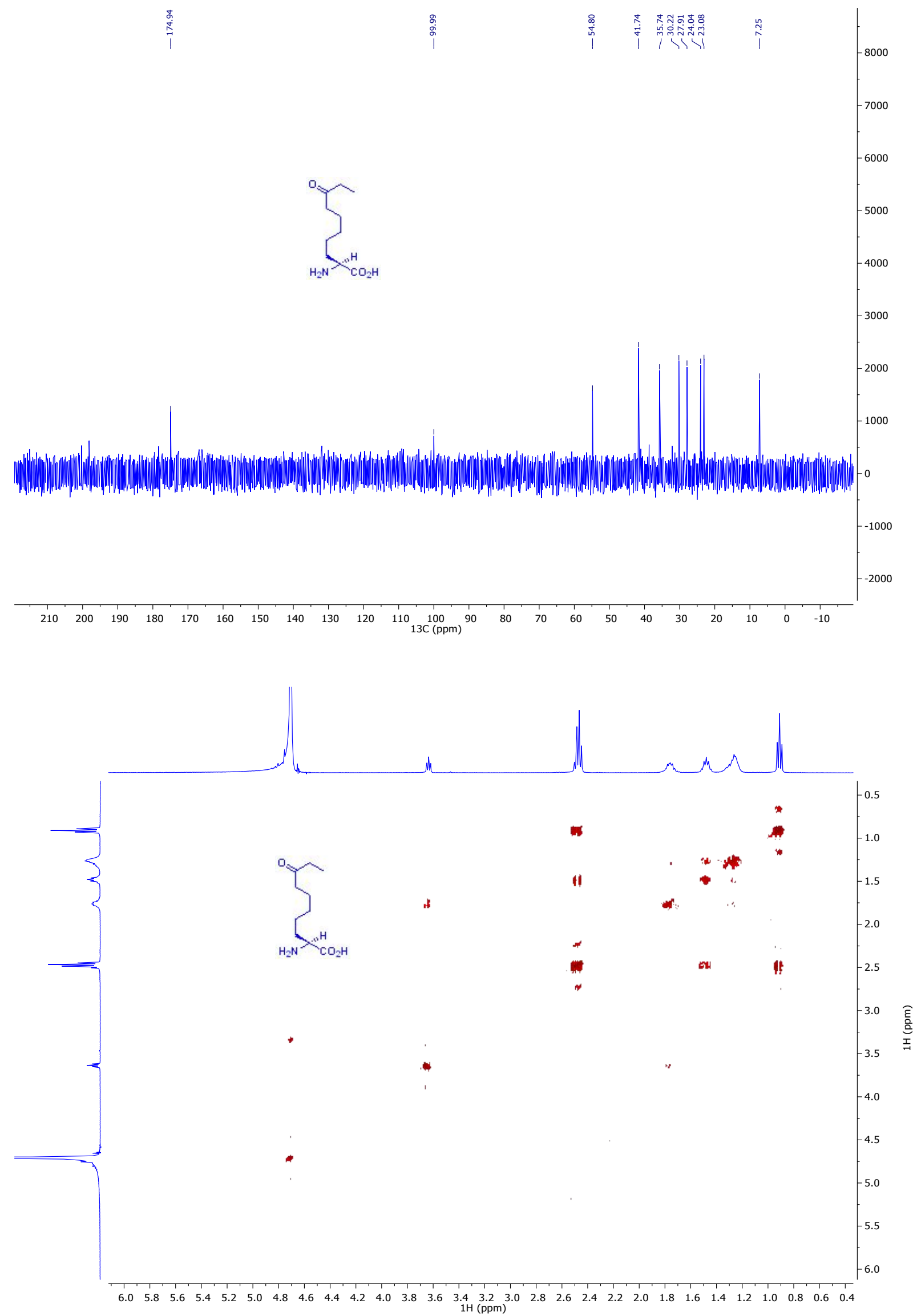



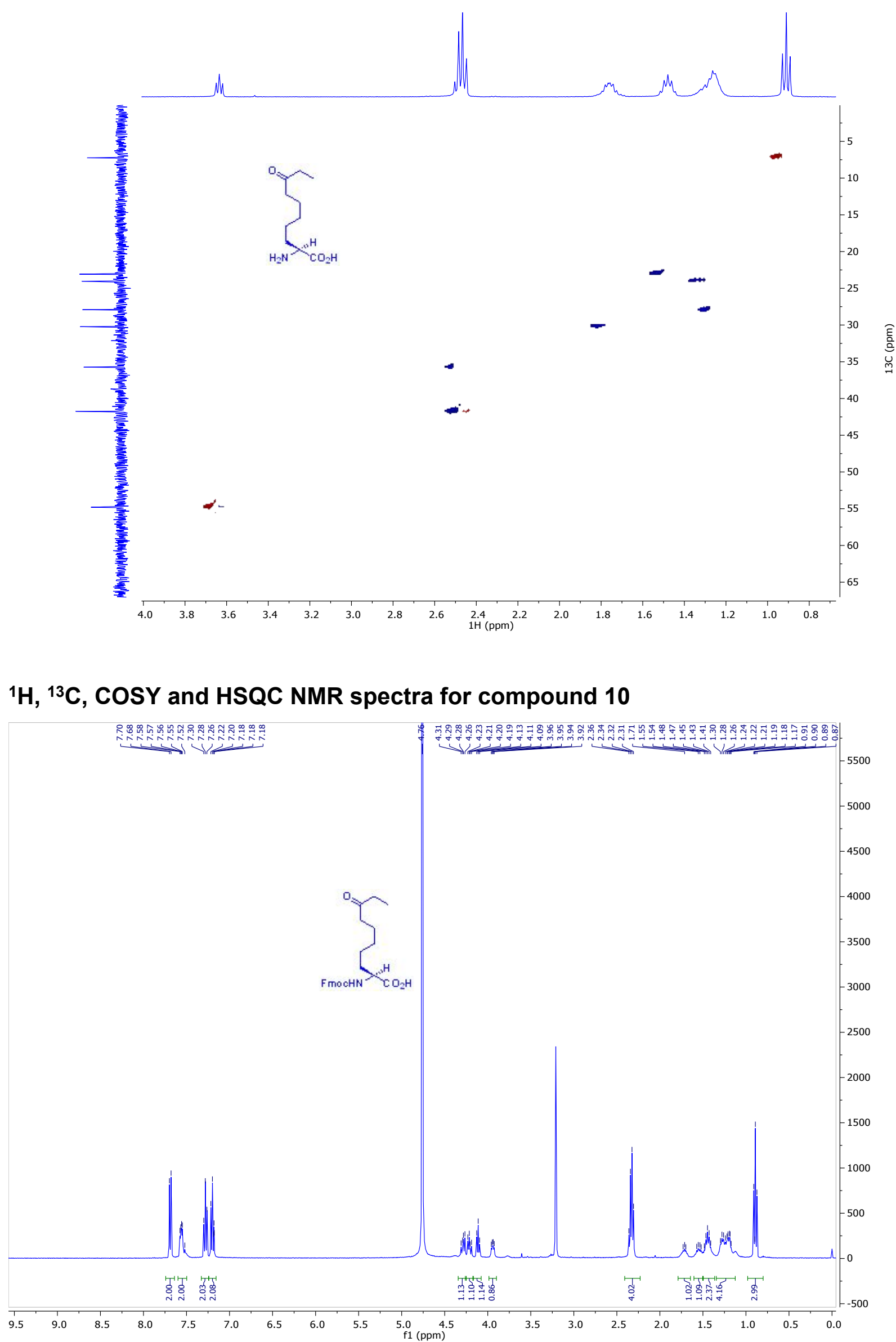

60 


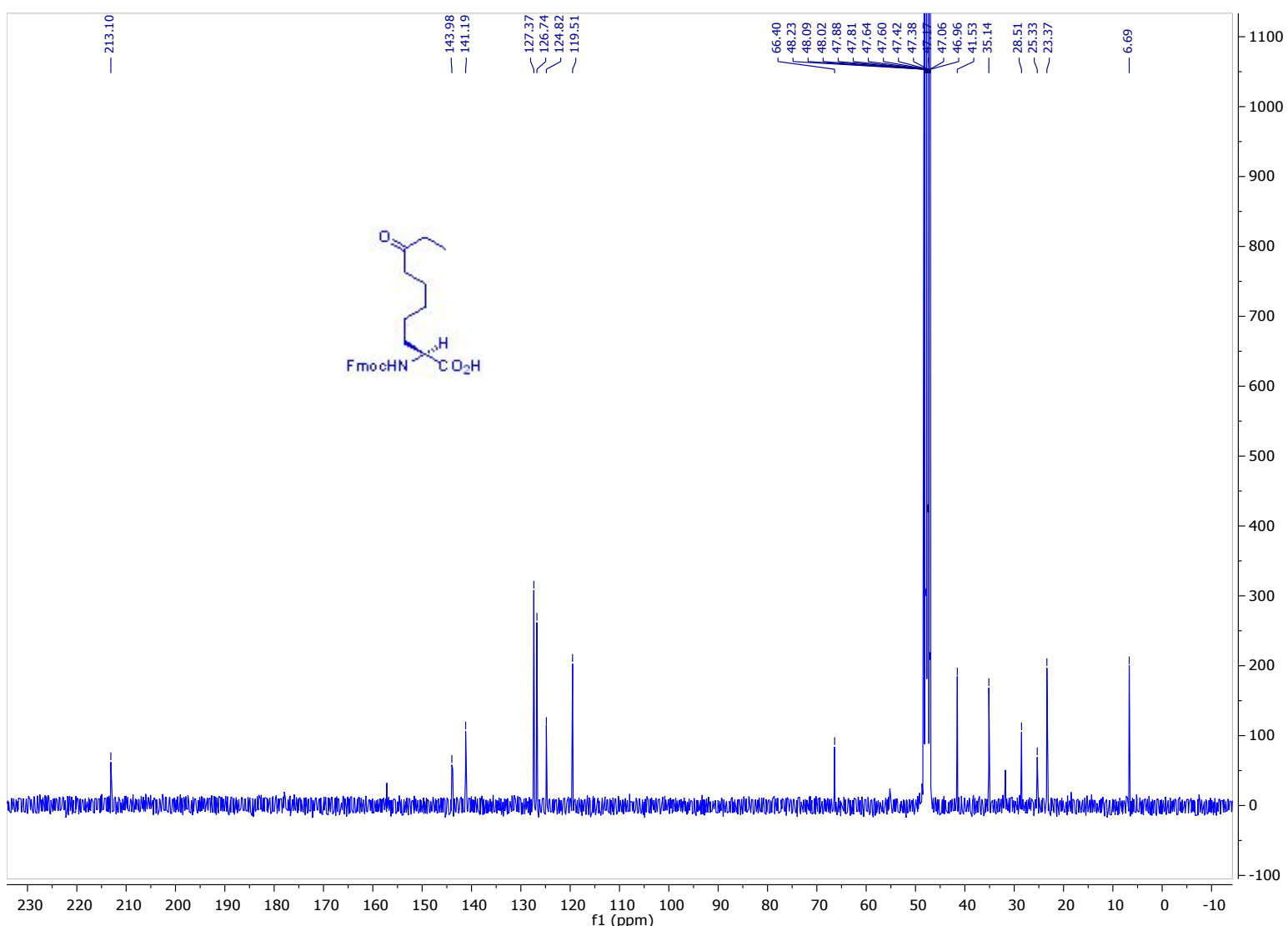



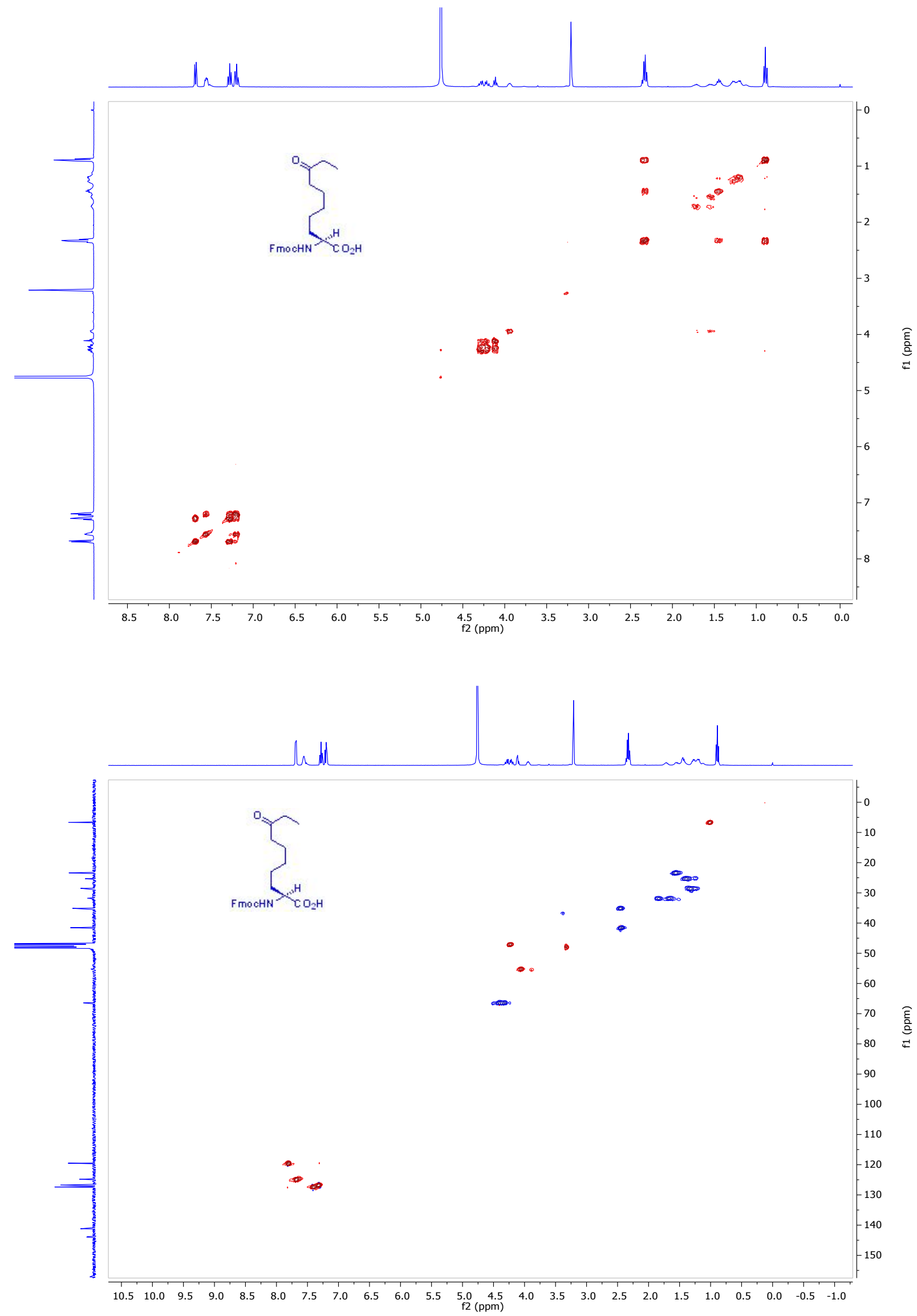


\section{HPLC Traces}

\section{Chiral HPLC of 5}

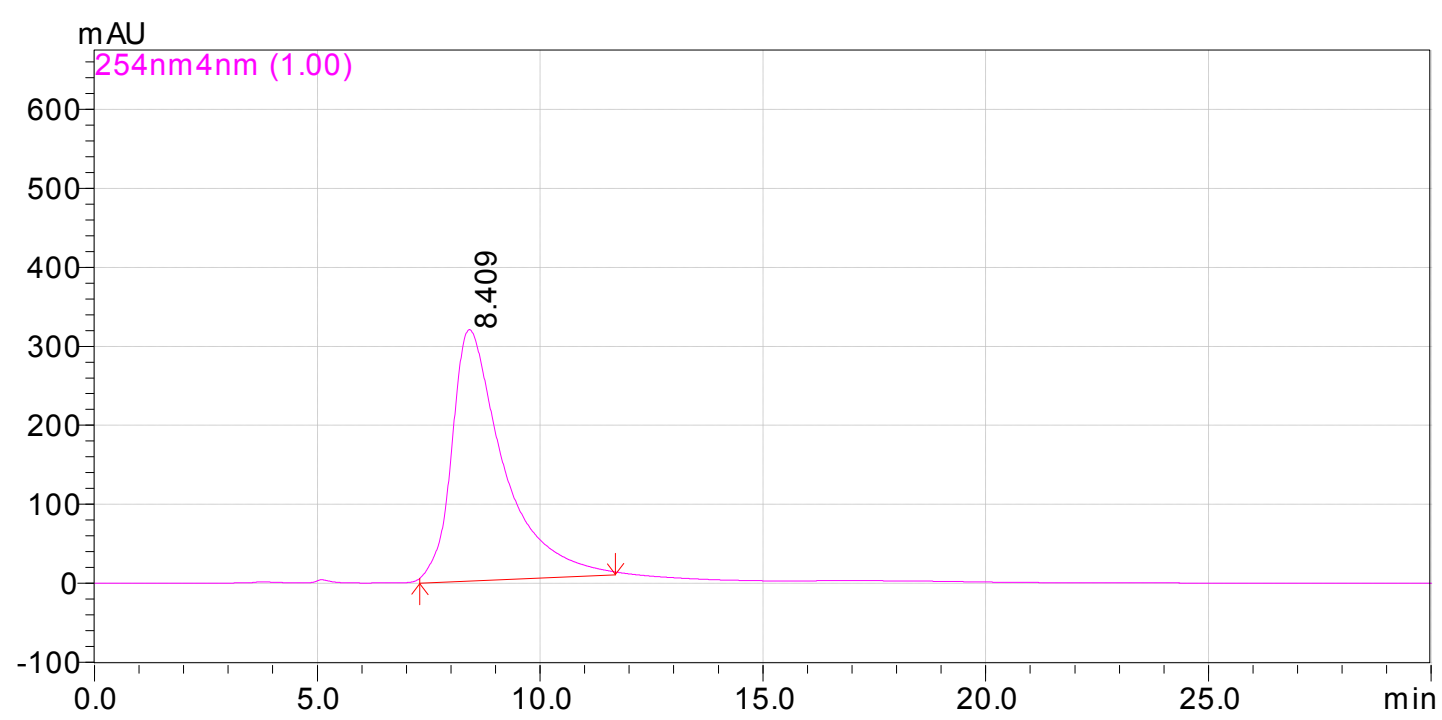

\section{Chiral HPLC of $5 a$}

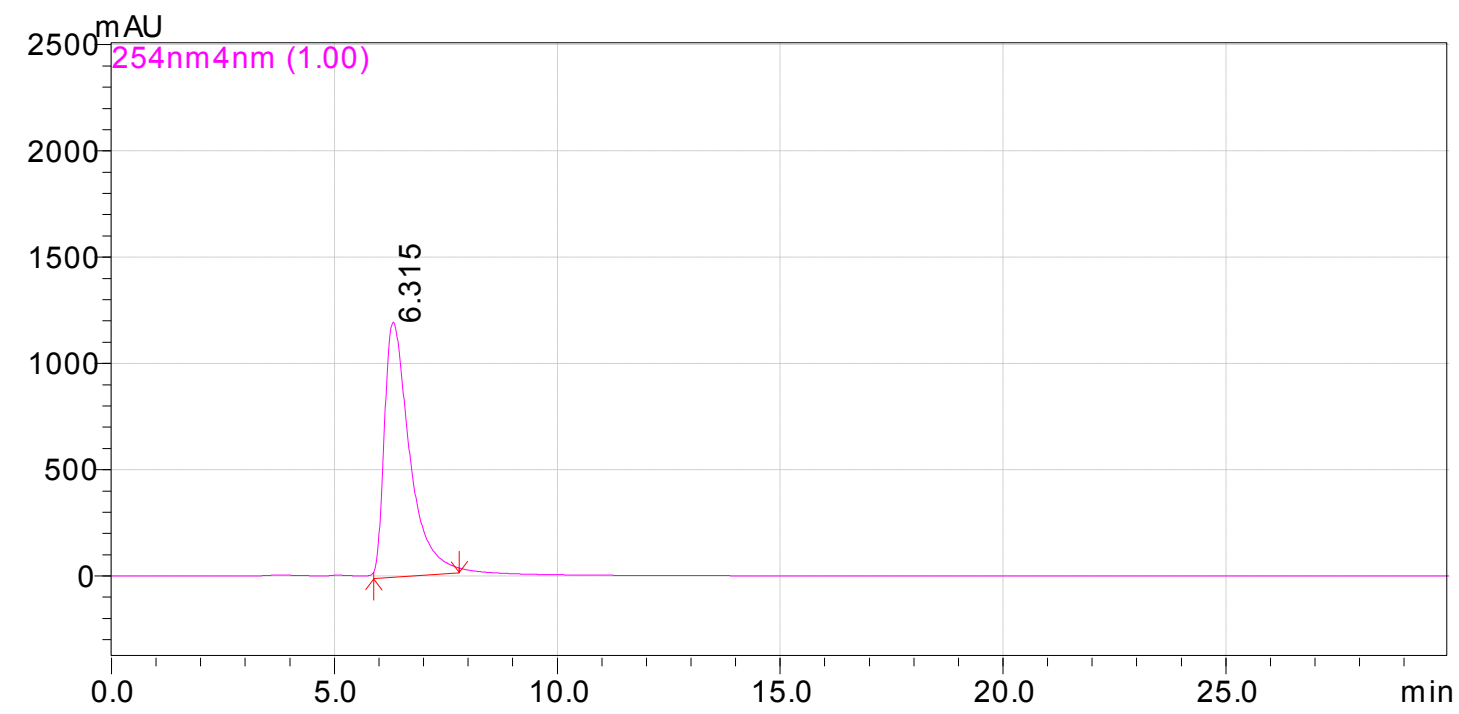


Chiral HPLC of 5 and $5 a$

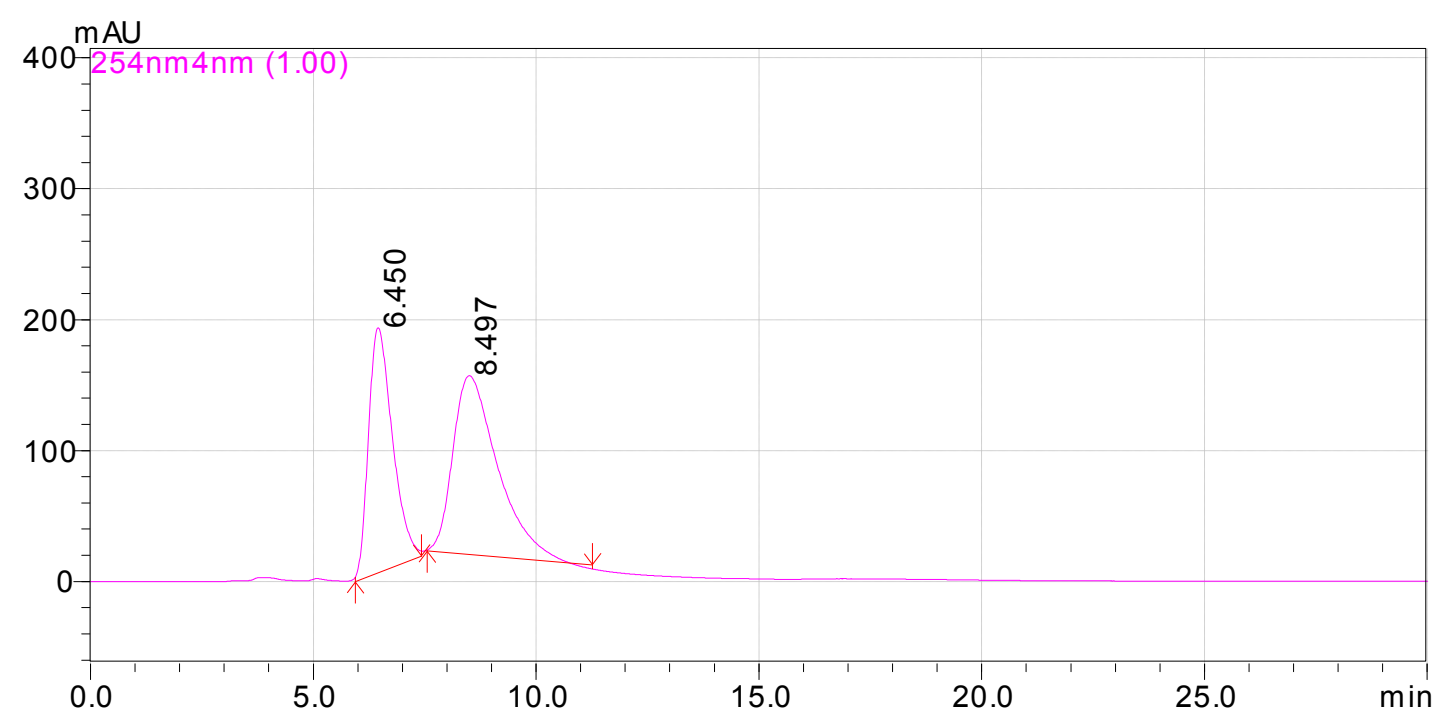

\section{HPLC of 11}

HPLC of 11, 20 minute gradient

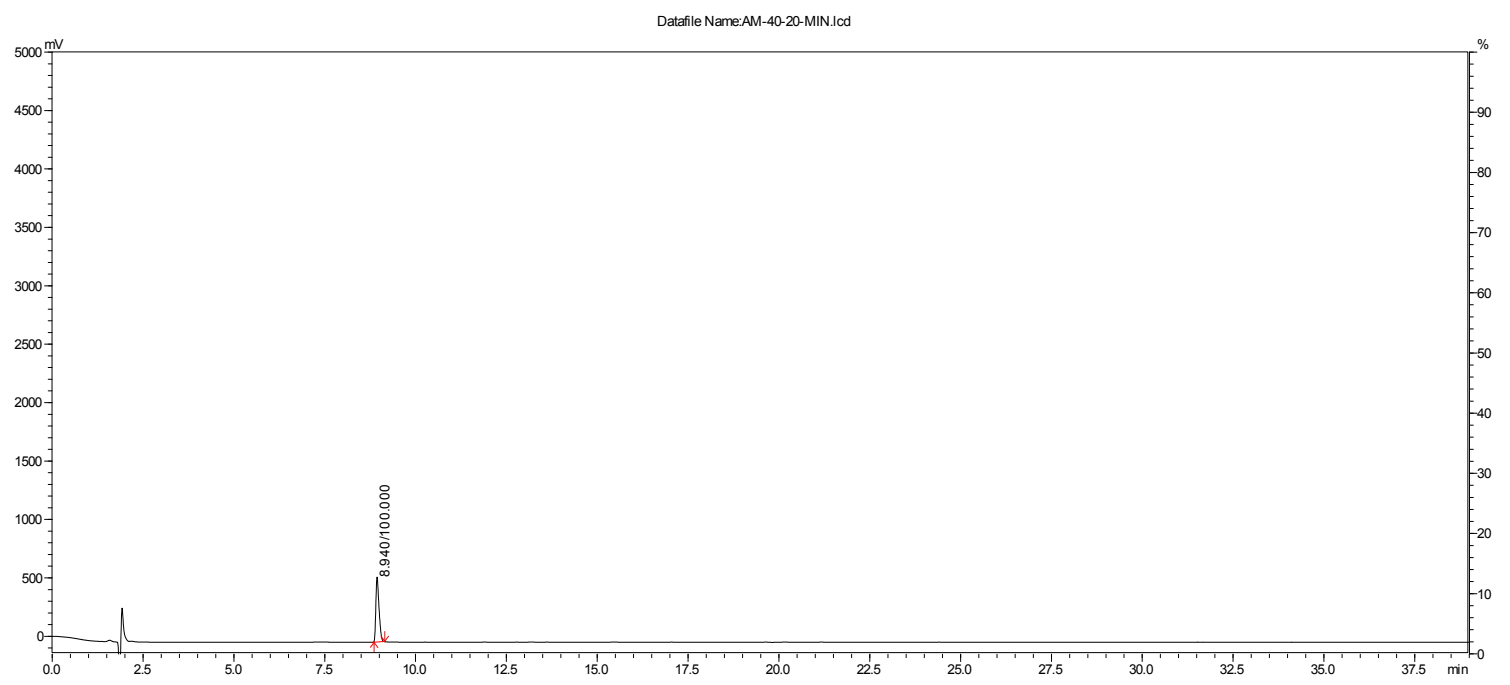

HPLC of 11, 20 minute gradient zoom 


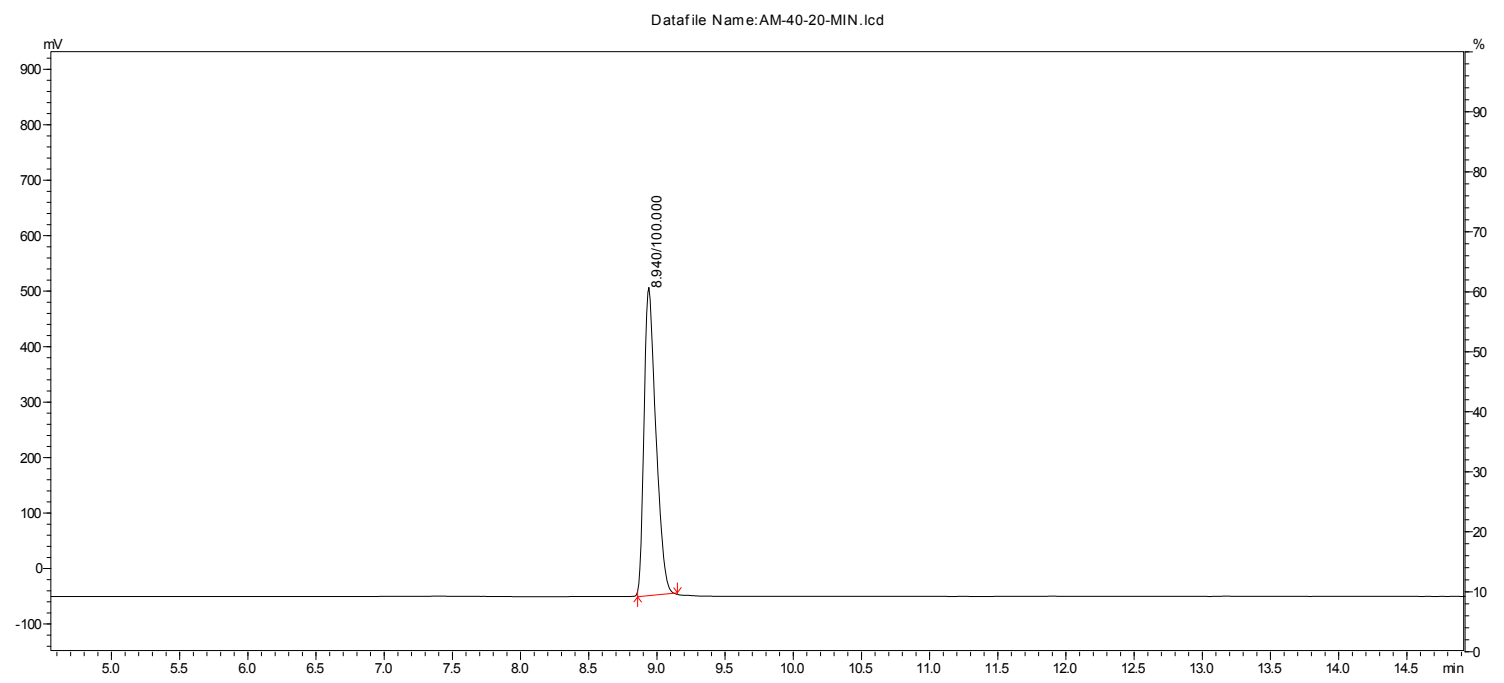

HPLC of 11, 50 minute gradient

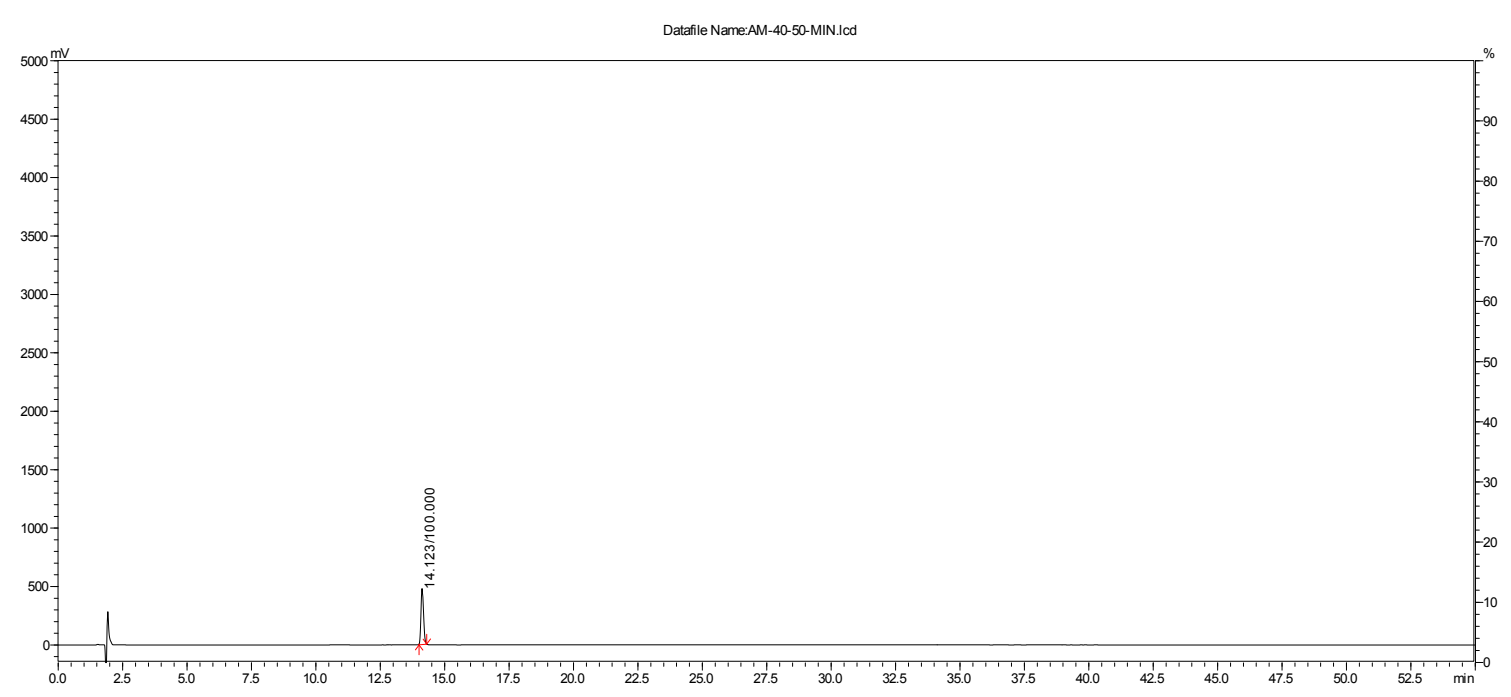

HPLC of 11, 50 minute gradient zoom

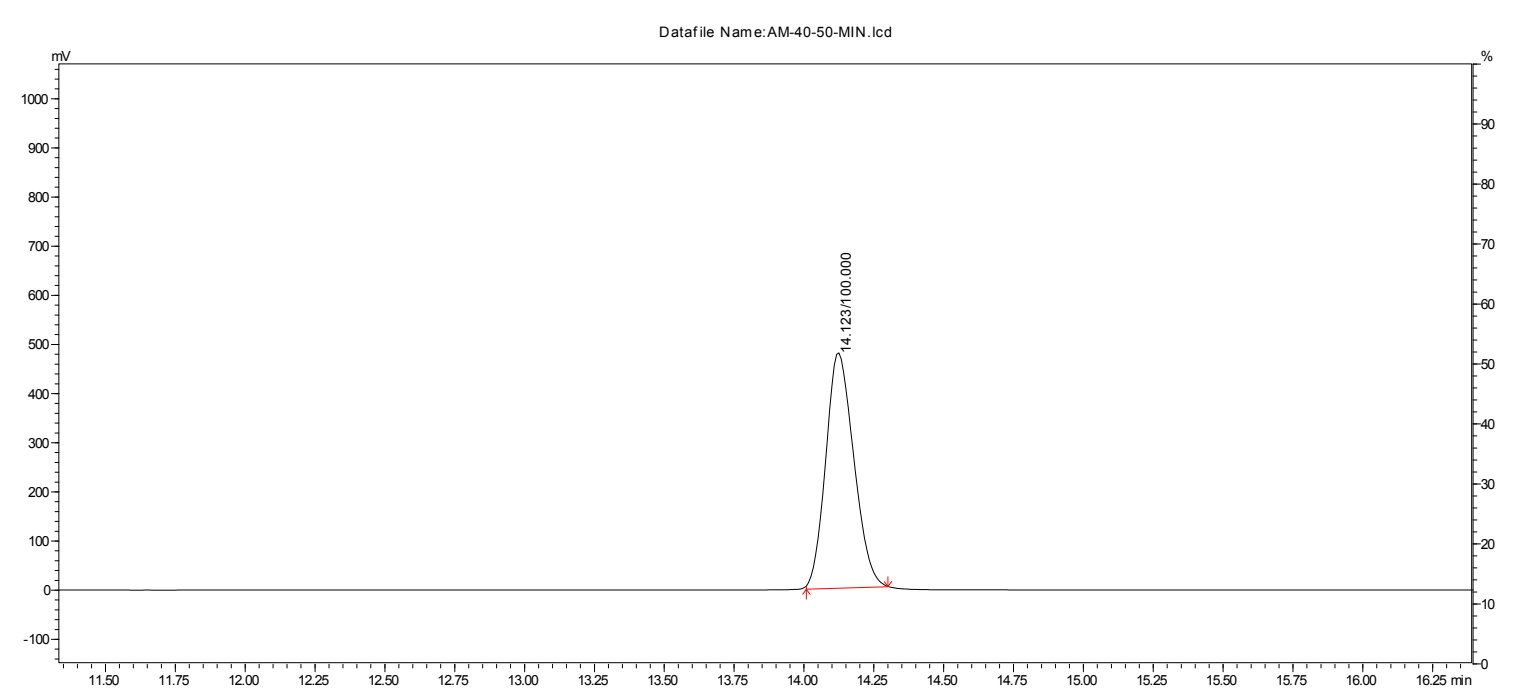

HPLC of 12

HPLC of 12, 20 minute gradient 


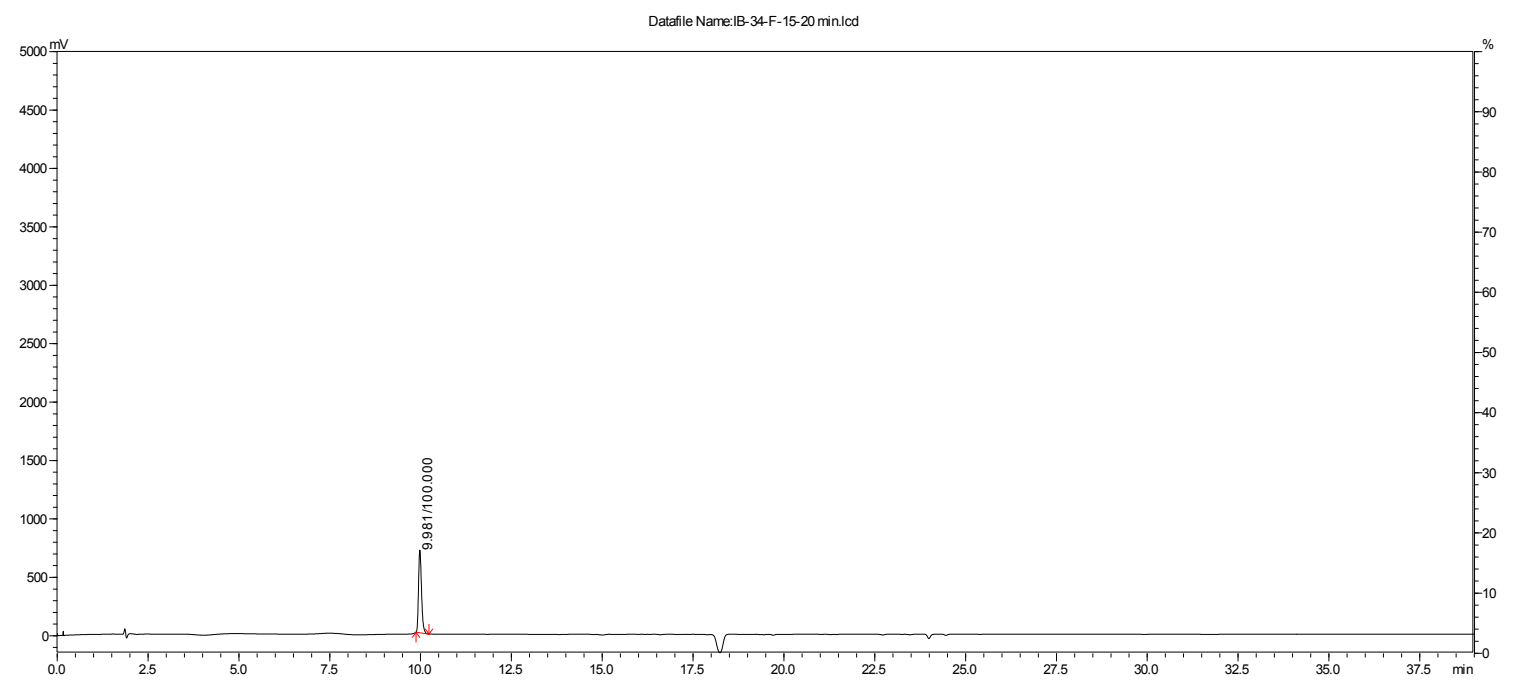

HPLC of 12, 20 minute gradient zoom

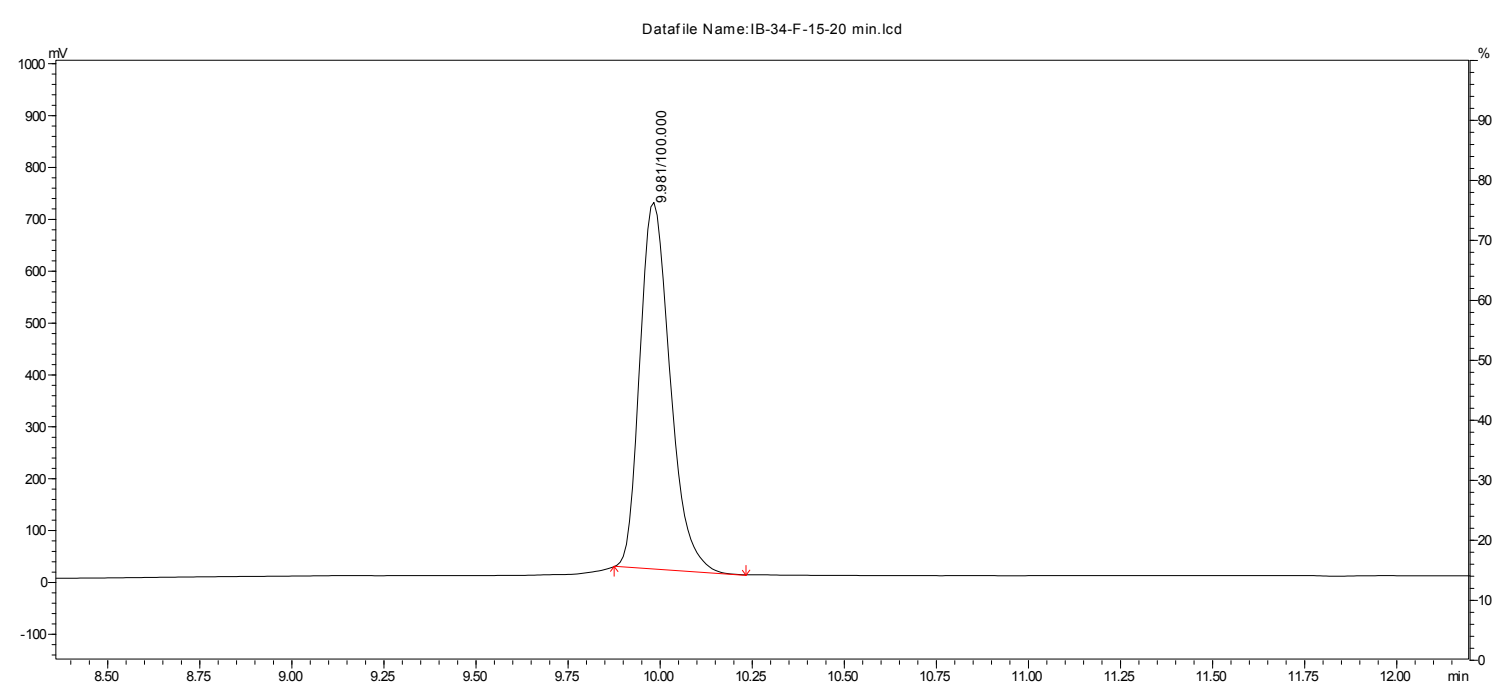

HPLC of 12, 50 minute gradient

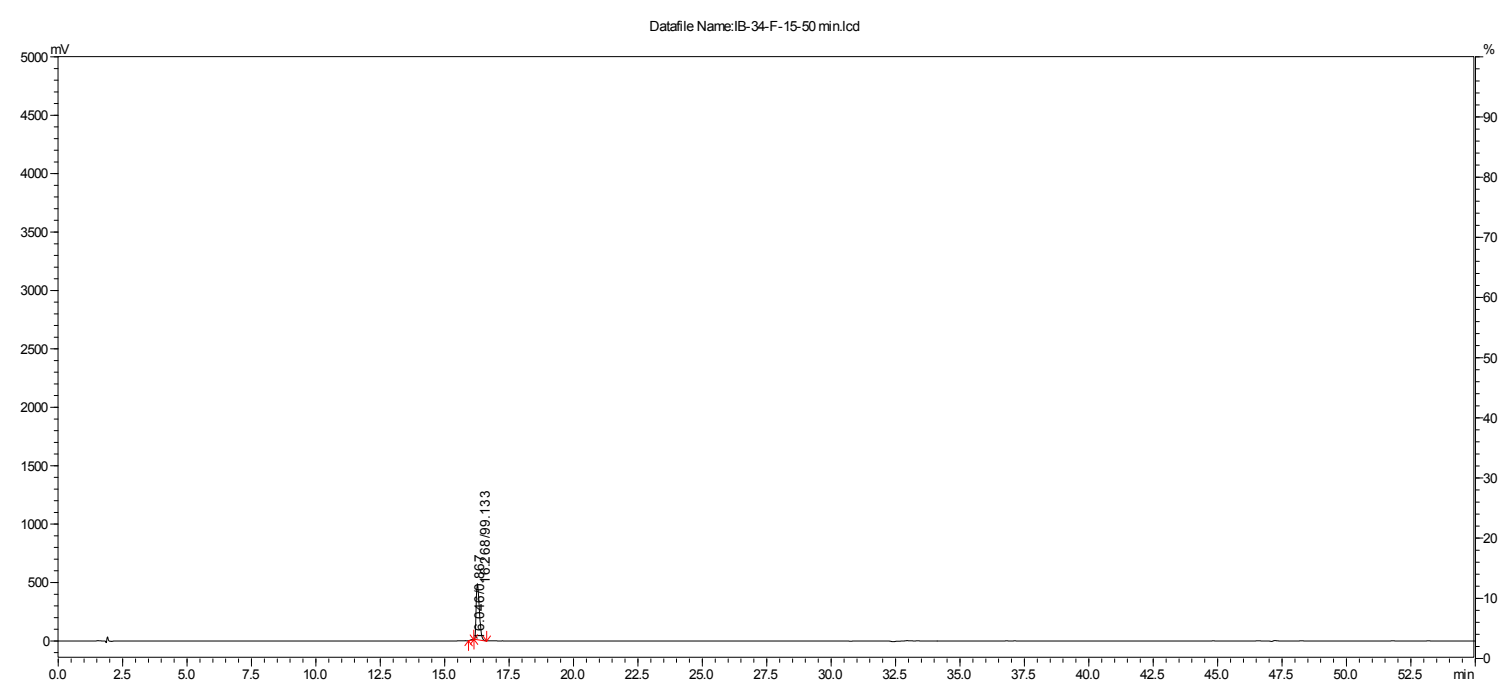

HPLC of 12, 50 minute gradient zoom 


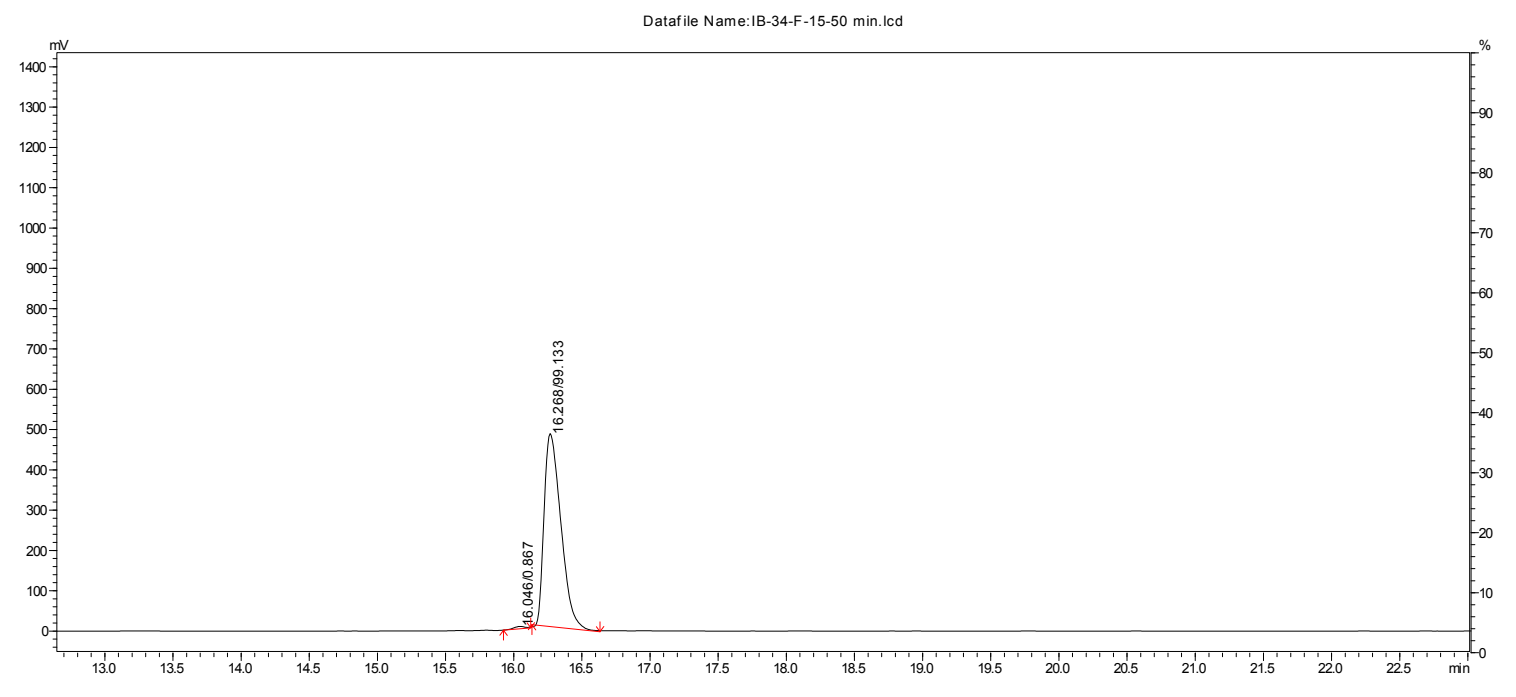

\section{HPLC of 13}

HPLC of 13, 20 minute gradient

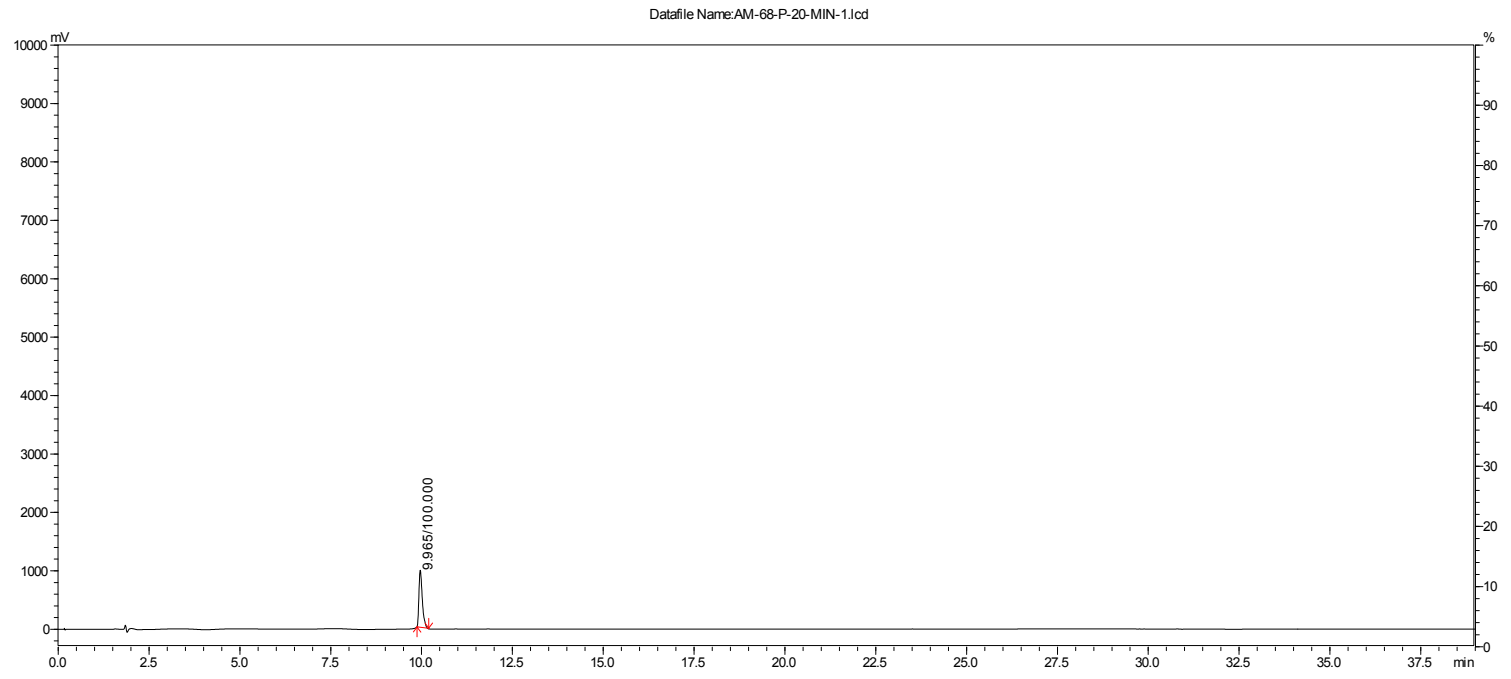

HPLC of 13, 20 minute gradient zoom

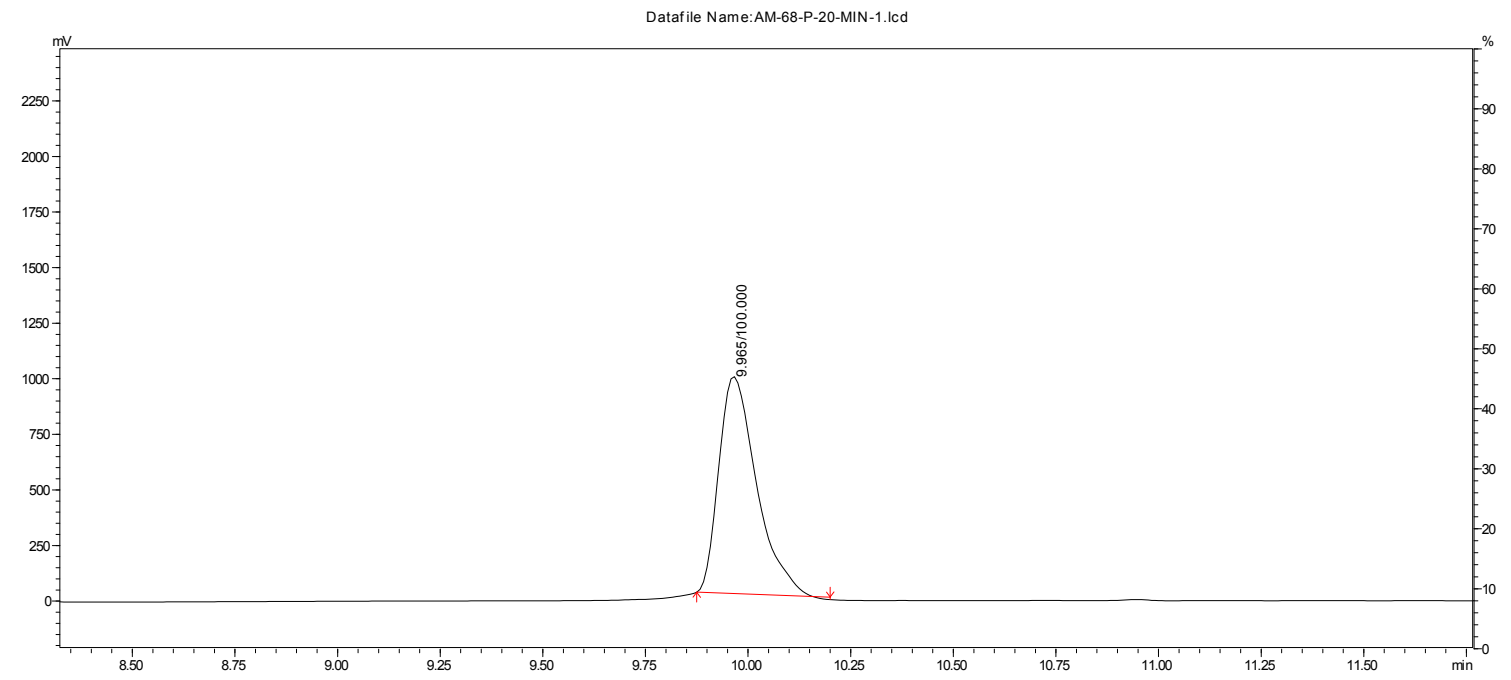


HPLC of 13, 50 minute gradient

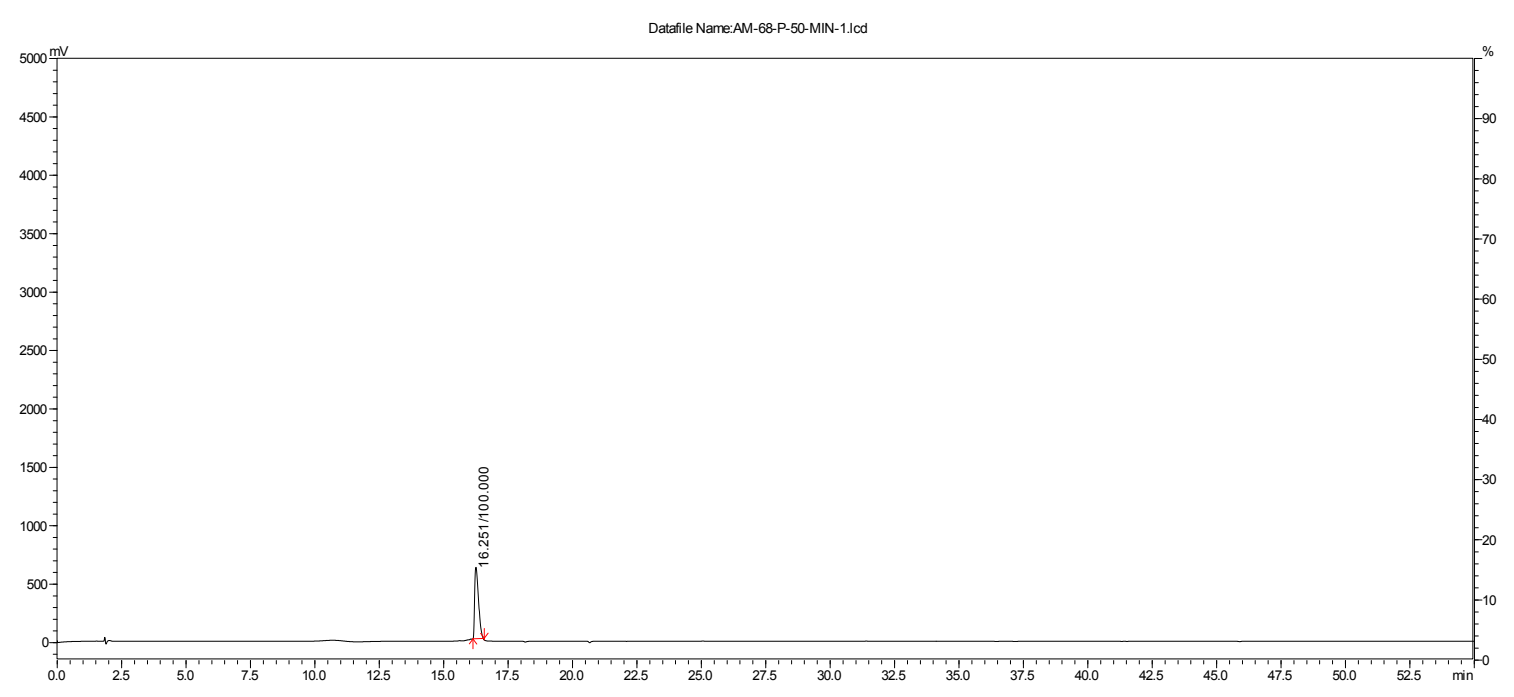

HPLC of 13, 50 minute gradient zoom

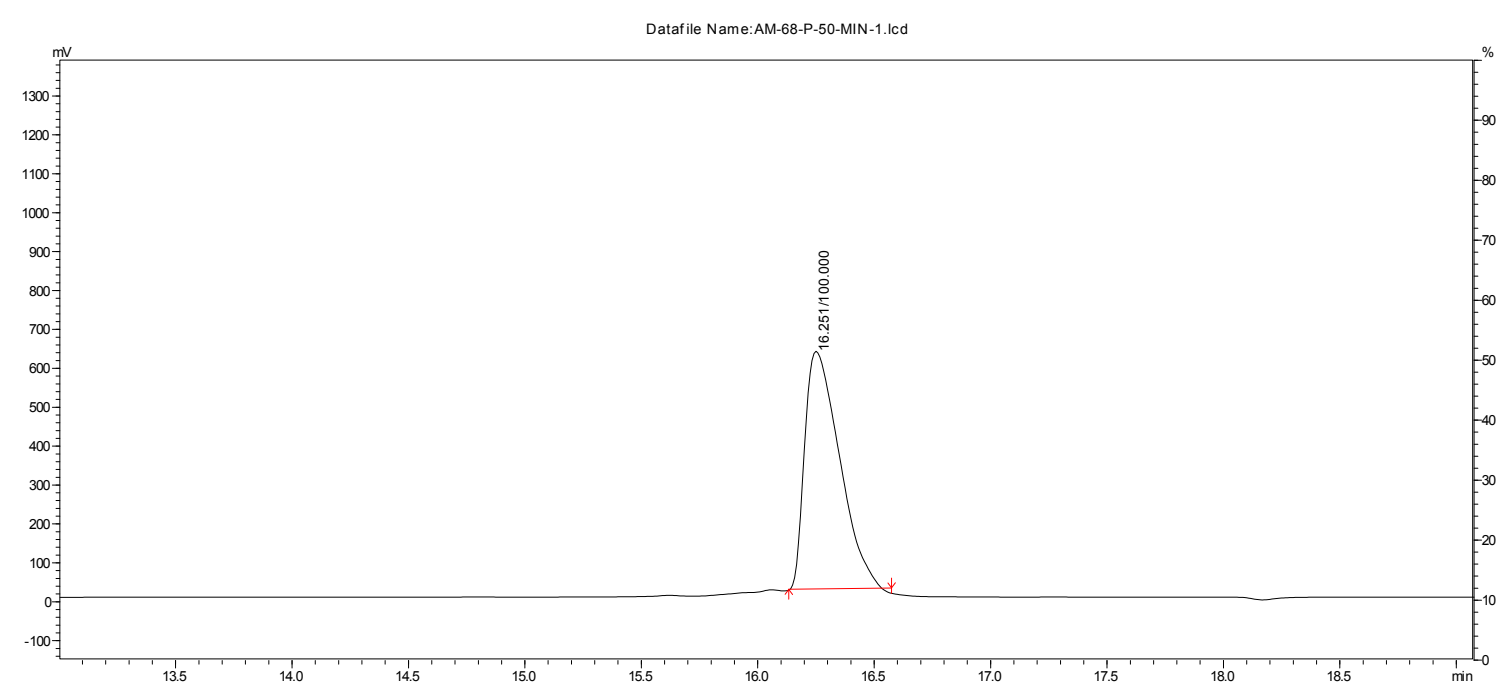

HPLC of 14

HPLC of 14, 20 minute gradient 


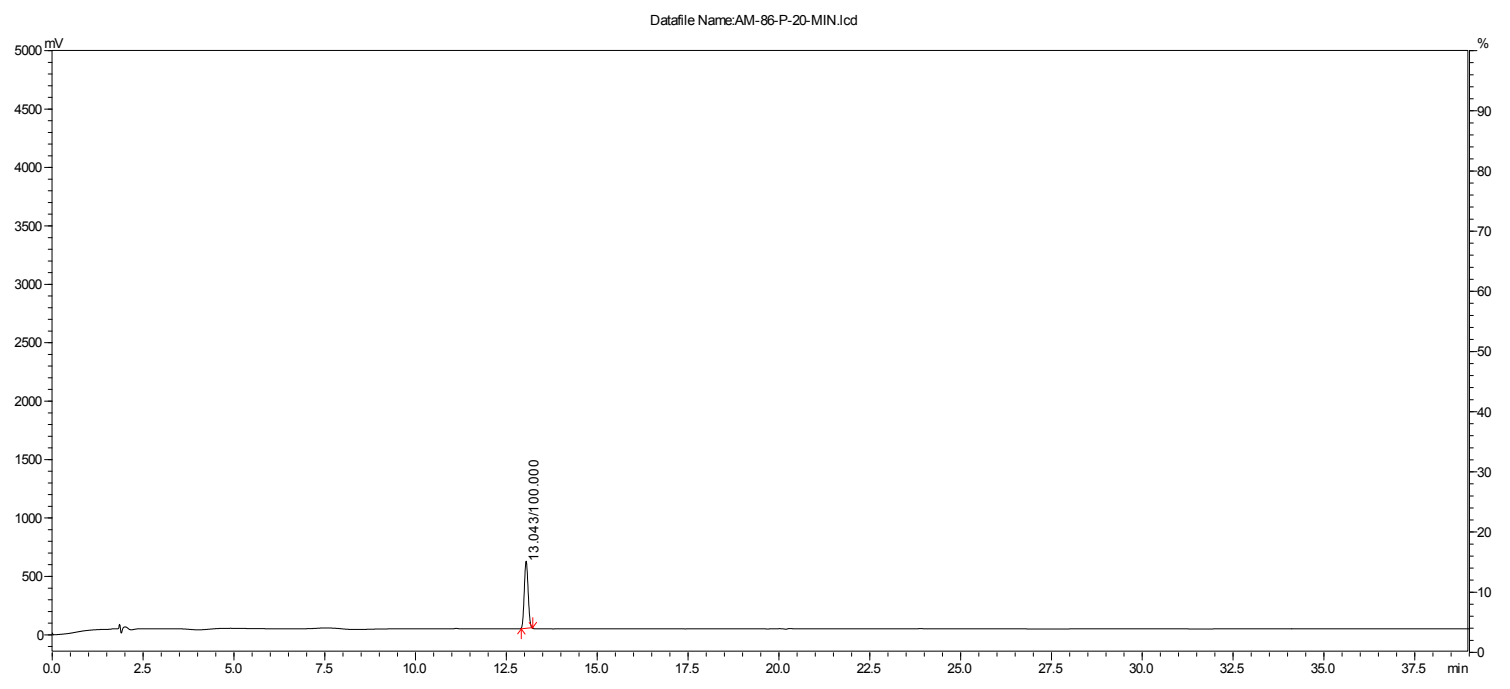

HPLC of 14, 20 minute gradient zoom

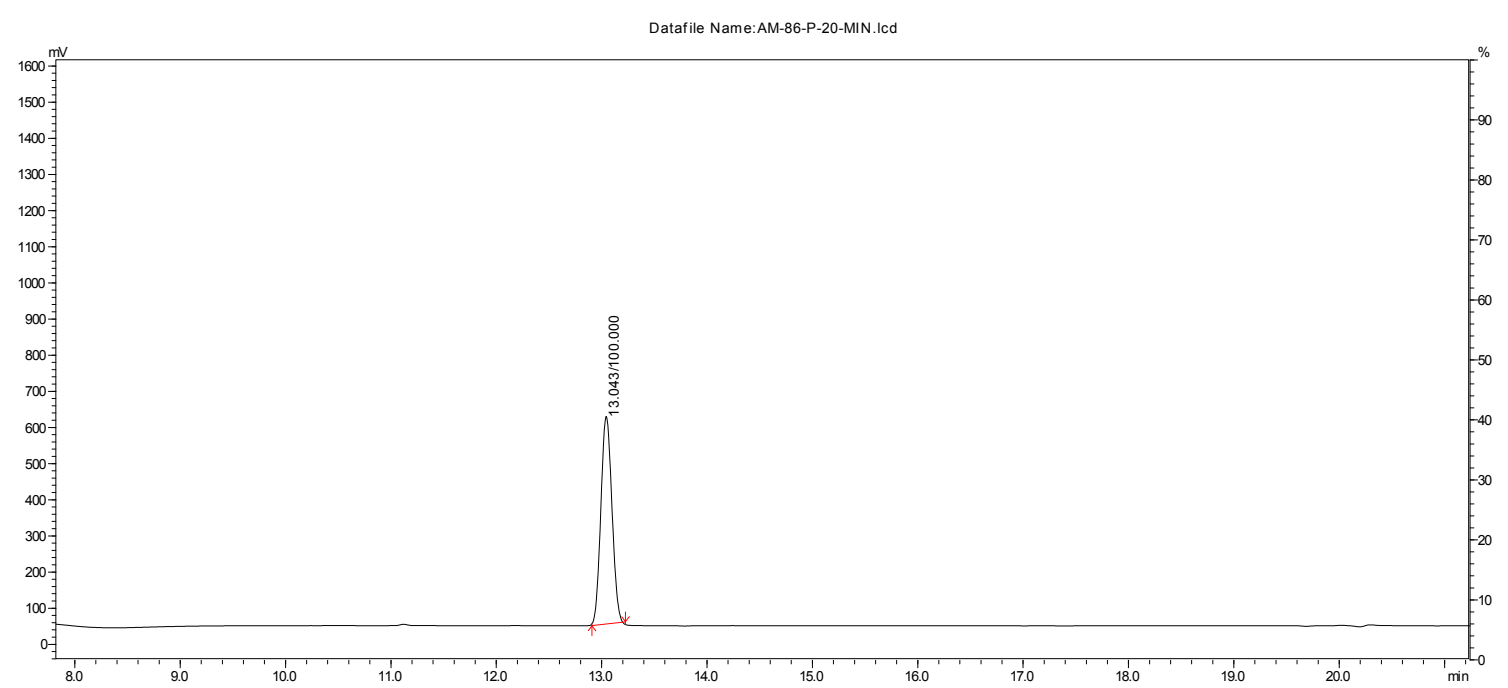

HPLC of 14, 50 minute gradient

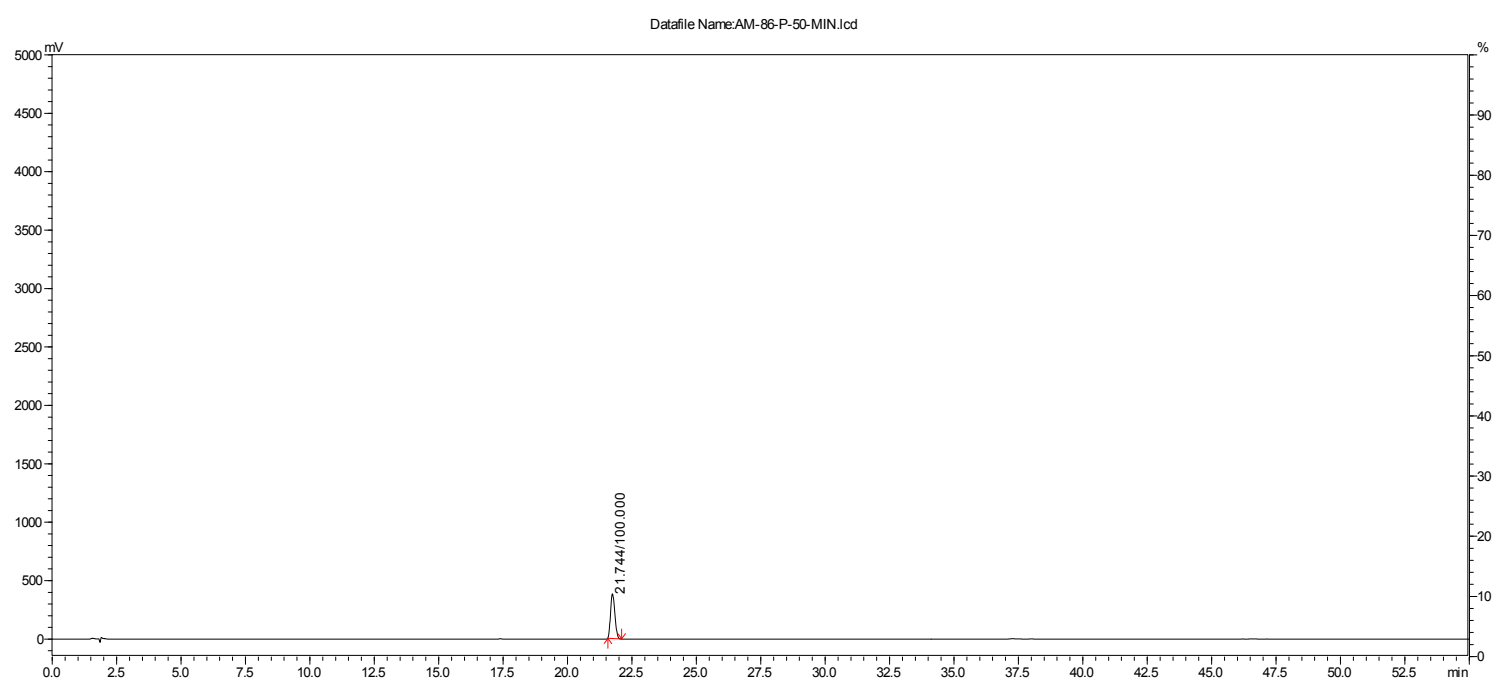

HPLC of 14, 50 minute gradient zoom 


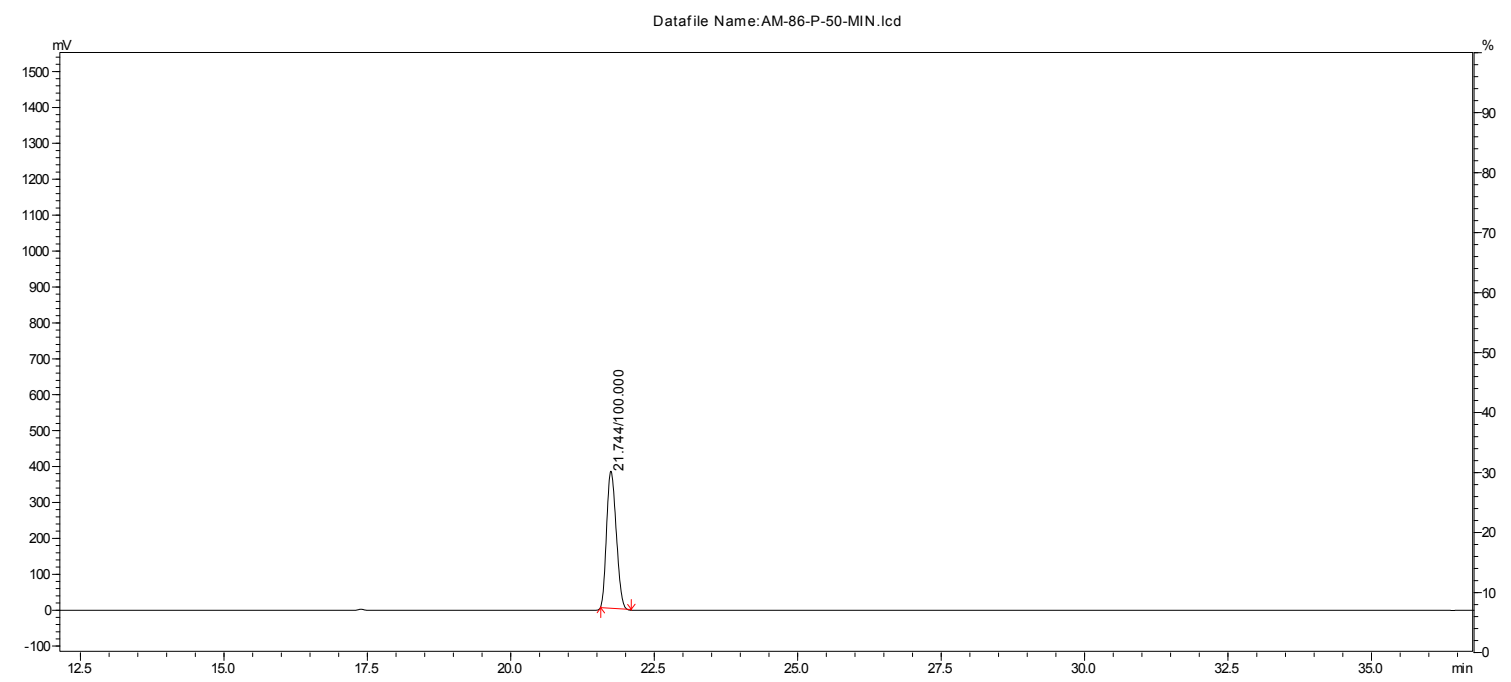

